\title{
Establishment and application of real-time PCR-based methods to study the epidemiology of Fusarium Head Blight
}

Etablierung und Anwendung der Real-time PCR

für epidemiologische Untersuchungen zu Ährenfusariosen

\author{
Dissertation \\ zur Erlangung des Doktorgrades \\ der Fakultät für Agrarwissenschaften \\ der Georg-August-Universität Göttingen
}

Göttingen, im Juli 2006 
D 7

1. Referent: Prof. Dr. Petr Karlovsky

2. Korreferent: Prof. Dr. Andreas von Tiedemann

Tag der mündlichen Prüfung: 13. Juli 2006 


\section{Contents}

Chapter 1: General introduction ............................................................. 1

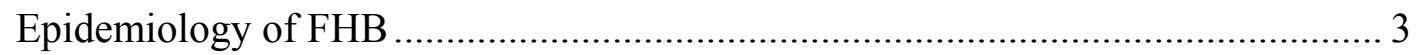

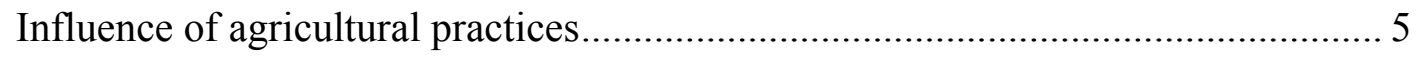

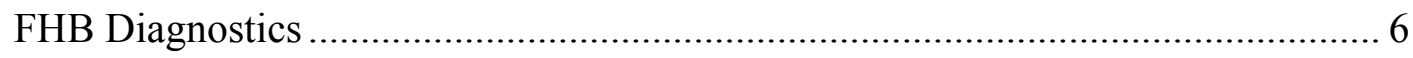

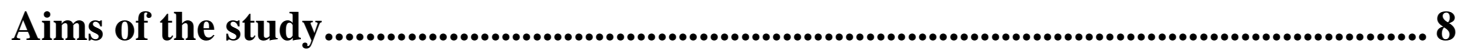

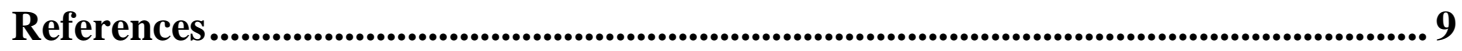

\section{Chapter 2: Simultaneous detection of Fusarium culmorum and} F. graminearum in plant material by duplex PCR with melting curve analysis......................................................................................... 15

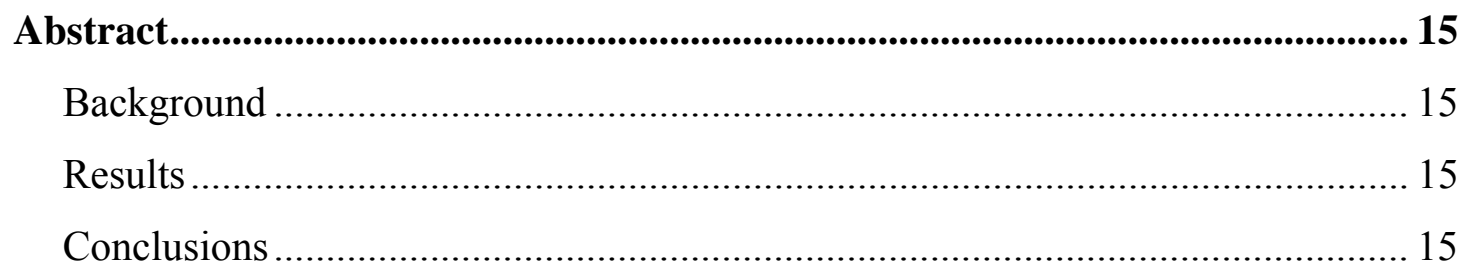

Background .................................................................................................................................... 15

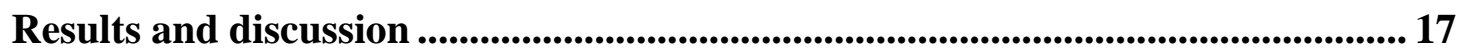

Optimization of DNA extraction and PCR conditions....................................... 17

Duplex PCR with SYBR Green I and melting curve analysis ............................ 18

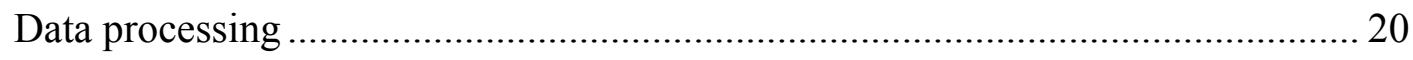

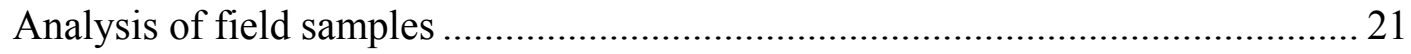

Conclusions................................................................................................................................. 21

Methods........................................................................................................................................... 21

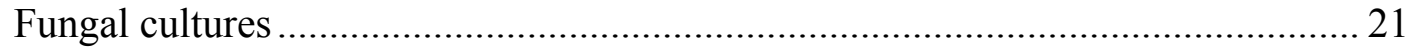

DNA isolation from pure fungal cultures grown in liquid media .......................... 22

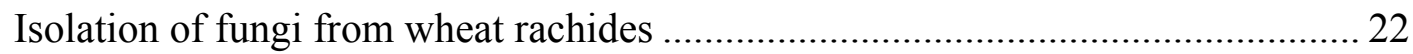

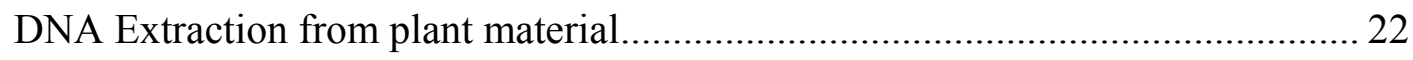


DNA extraction from the mycelia grown on agar plates .................................... 22

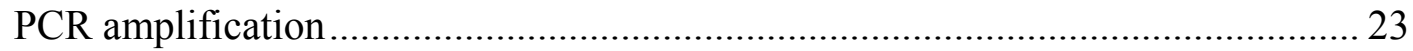

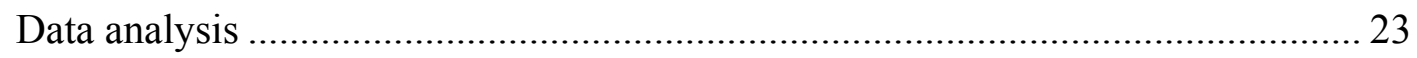

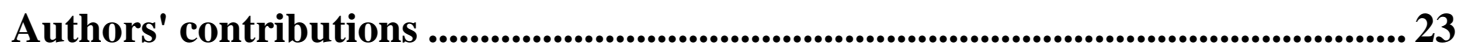

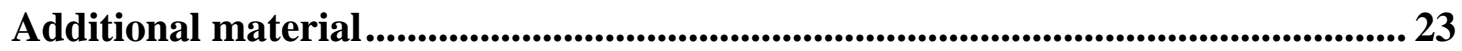

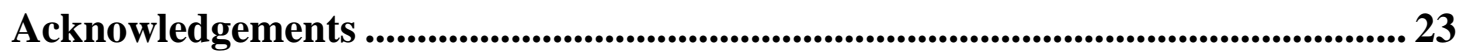

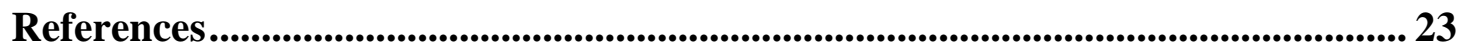

\section{Chapter 3: Cost-effective quantification of Fusarium culmorum and}

F. graminearum in plant material by real-time PCR ........................... 25

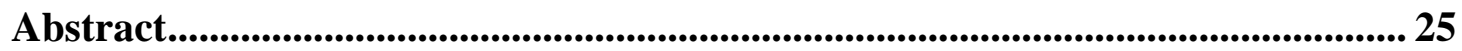

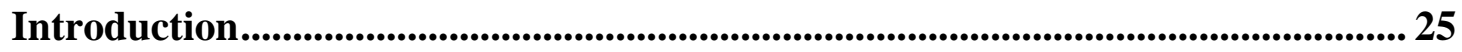

Materials and Methods........................................................................................... 28

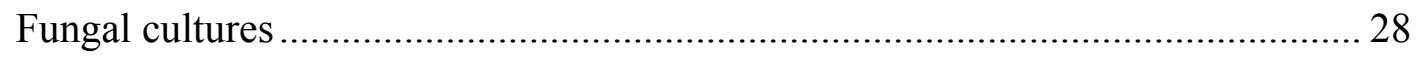

DNA isolation from pure fungal cultures grown in liquid media ......................... 29

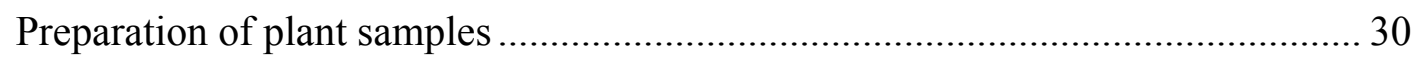

Quantitative DNA extraction from plant material ............................................. 30

Preparation of standards for quantitative real-time PCR .................................... 30

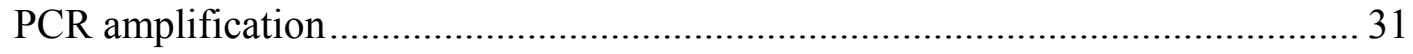

PCR product and Fusarium spp. quantification............................................ 32

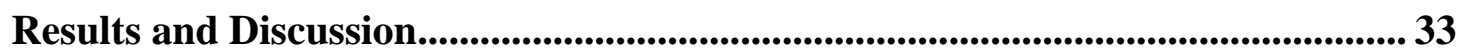

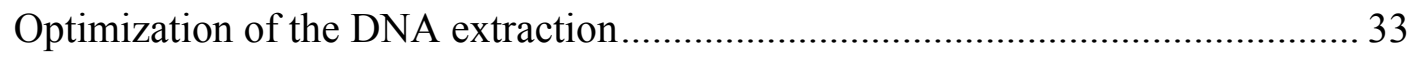

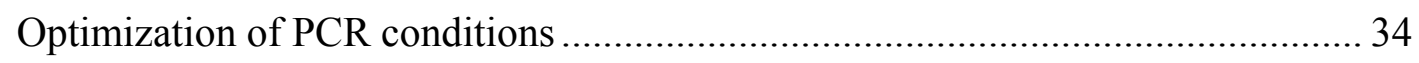

Standards for quantitative real-time PCR ….................................................. 36

Comparison with other PCR-based methods ................................................... 37

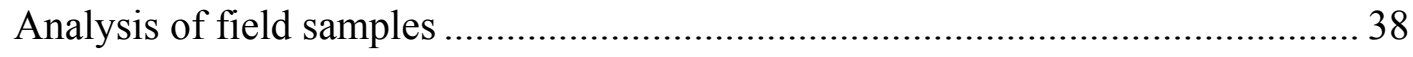

Conclusions ............................................................................................................................. 38

Acknowledgements ........................................................................................................ 39 


\section{Chapter 4: Detection of Fusarium graminearum and F. culmorum in} rachides from wheat ears afflicted with Fusarium head blight and in grain identifies $F$. graminearum as the major cause of FHB and DON contamination

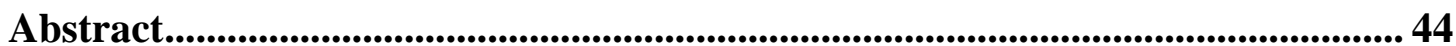

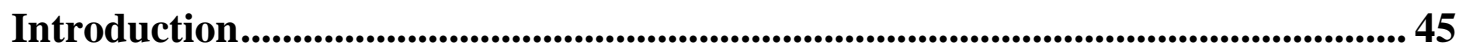

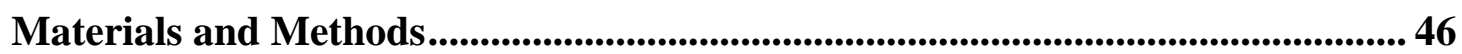

Qualitative detection of F. graminearum and F. culmorum in wheat rachides ...... 46

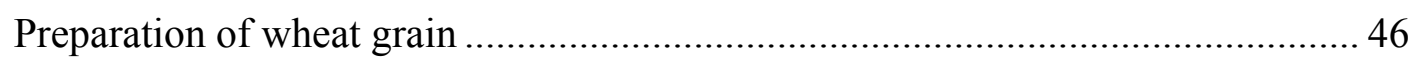

Quantitative DNA extraction from plant material .............................................. 47

Preparation of standards for quantitative real-time PCR ..................................... 48

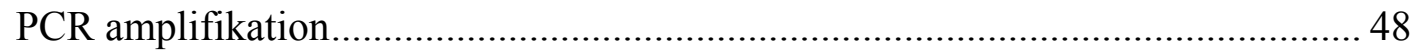

PCR product and Fusarium spp. quantification................................................... 49

Quantitative analysis of deoxynivalenol (DON) ................................................ 49

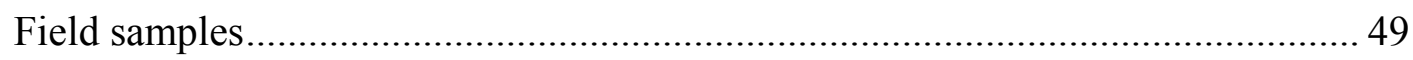

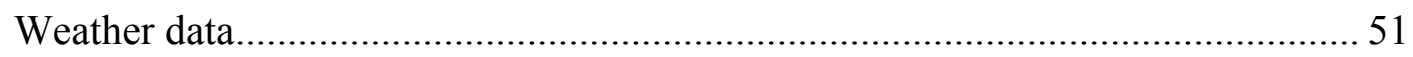

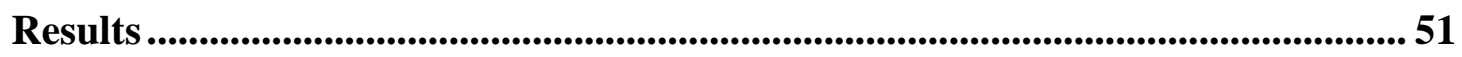

Analysis of wheat rachides for Fusarium colonization...................................... 51

Relationship between rachis colonization and the contamination of grain with

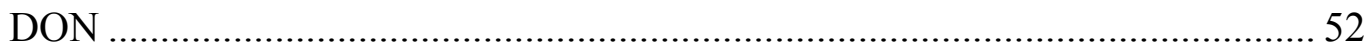

Relationship between DON contamination and DNA content of grain ................. 54

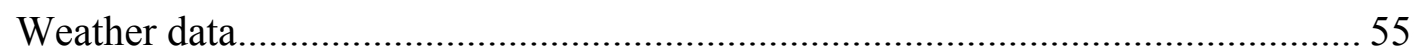

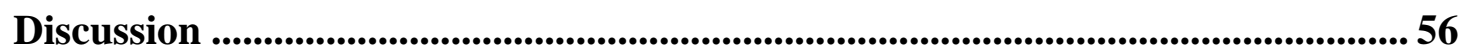

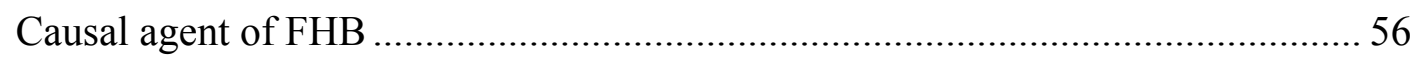

Relative contribution of F. graminearum and F. culmorum to DON

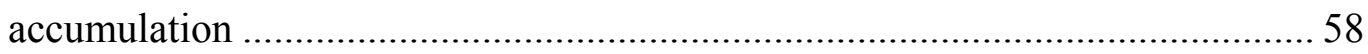

DON accumulation, FHB rating and virulence: a common lapse in the interpretation of their relationship 


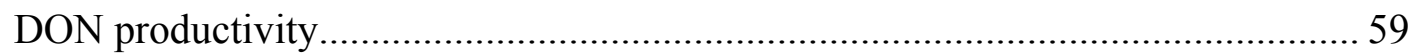

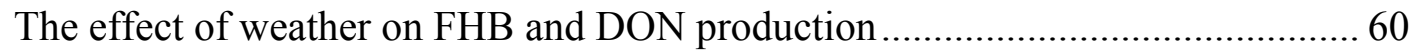

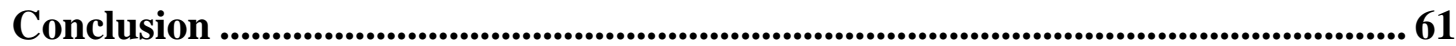

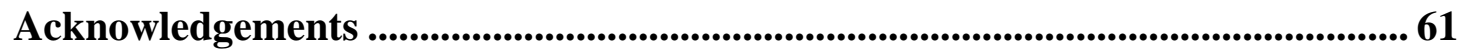

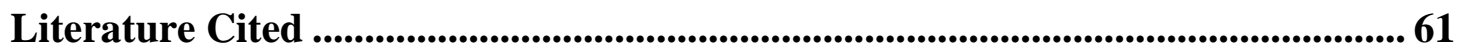

Chapter 5: General discussion ...................................................................... 67

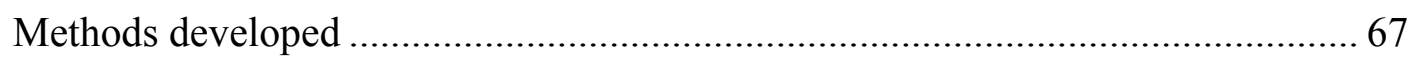

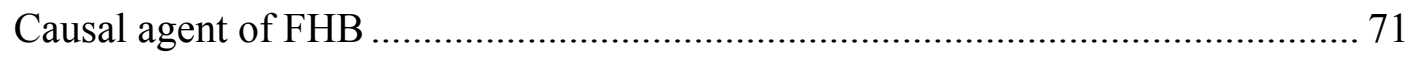

Relationship of toxin contamination and Fusarium spp. DNA............................. 73

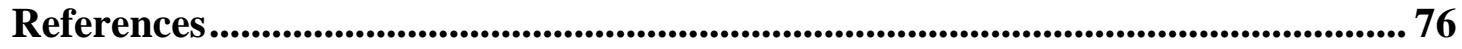

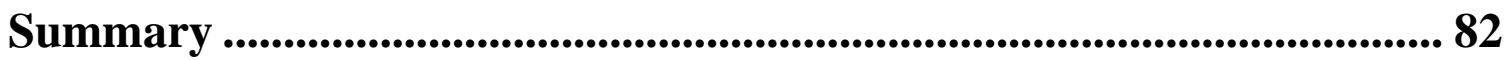

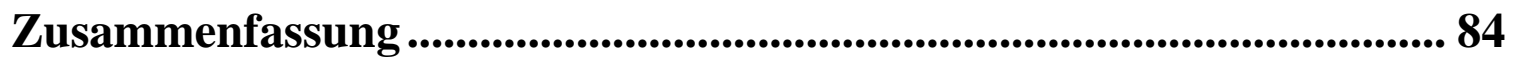

Danksagung................................................................................................. 86

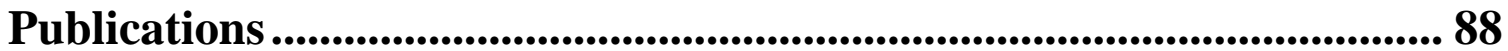

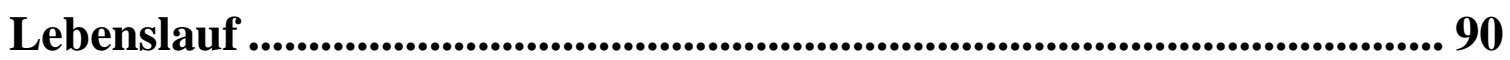




\section{Chapter 1: General introduction}

Fusarium head blight (FHB) is one of the most destructive diseases of wheat and barley worldwide. High economic losses caused by epidemics of FHB were reported especially from the United States, Canada and China (Shaner, 2003).

The infection of heads of small grain cereals and maize plants with Fusarium spp. impairs both grain yield and quality (Parry et al., 1995) by adversely effecting grain size, weight, germination rate, protein content, baking quality of the flour, and other technological parameters through fungal colonization of the ear and cutting off the supply of nutrients to the upper spikelets. Irrespective of those impairments, the most serious consequence of FHB is the contamination of grain and cereal products with Fusarium mycotoxins (Pieters et al., 2002; Peraica et al., 1999). Mycotoxins are secondary metabolites produced by fungi that are capable of causing disease and death in humans and animals (Bennett and Klich, 2003).

Because grains of low quality are used in feedstuff production rather than in human foods, livestock health, welfare and productivity may be severely compromised by consumption of Fusarium mycotoxins. Safety of some animal products may also be at risk (D'Mello et al., 1999). The effects of low doses of Fusarium mycotoxins consumed over prolonged time periods on humans are not fully understood (Pestka and Smolinski, 2005; Rocha et al., 2005). Therefore, fungal contamination has become a key concern in food and feed safety assessments, and many countries have set legal limits for Fusarium toxin concentrations in food and feed (Anonymous, 2004; Anonymous, 1999; D'Mello et al., 1999).

The most frequently encountered Fusarium mycotoxins in FHB in Europe has proved to be deoxynivalenol (DON) and zearalenone produced by $F$. graminearum and F. culmorum (Bottalico and Perrone, 2002). DON is reported to be virulence factor of F. graminearum in wheat (Langevin et al., 2004; Bai et al., 2002; Proctor et al., 1995), emphasizing the importance of DON for the fungus. Although DON is one of the least acutely toxic trichothecenes, it rises an important food safety issue because it is a very common contaminant of grain (Rotter et al., 1996). The gross toxic effects of DON on animals include growth retardation, reproductive disorders, immunodeficiency, feed refusal and vomiting. The phytotoxic effects of deoxynivalenol on plants can be 
summarized as growth retardation and inhibition of seedling and green plant regeneration (Rocha et al., 2005).

A particular problematic fact is that trichothecenes survive processes employed in the production of food of cereal origin. The fate of trichothecenes during processing is particularly affected by their relatively high heat stability and water solubility. For drymilled products, the most highly contaminated fractions are those that contain the outer portions of the grain. For wet milling, the trichothecenes are primarily transferred to the aqueous fractions. The most contaminated streams enter the animal food chain, although there is no evidence of a significant trichothecenes transmission into animal products. However, the effects of major steps in grain processing used in European food production, e.g. baking and brewing, are not fully understood (Hazel and Patel, 2004). The Scientific Committee for Food have set Tolerable Daily Intakes (TDIs) for DON (1 $\mu \mathrm{g}$ per kg bodyweight per day) and nivalenol (NIV, $0.7 \mu \mathrm{g}$ per $\mathrm{kg}$ bodyweight per day), trichothecenes of the type B produced by F. graminearum and F. culmorum. Wheat and wheat containing products (like bread and pasta) represent the major source of intake for these trichothecenes by the population of EU member states. The mean intake for DON is below the TDI, however for the young children groups the mean intakes are sometimes close to the TDI. For NIV, the intake is far below the TDI (Schothorst and van Egmond, 2004).

Several PCR assays were developed for genes involved in the toxin biosynthesis that would permit the early detection of Fusarium species producing toxins within a food or feed product (Mule et al., 2005). A common feature of these assays is the incapacity to identify the causal agent, which is important for epidemiological questions. The level of DON and the amount of F. culmorum and F. graminearum DNA in grain correlate well, indicating that these two species, which are major DON producing Fusarium spp., produce quite constant amounts of DON in relation to their biomass. The correlation coefficient for DON and DNA content were reported to be 0.68 (Nicholson et al., 2003) and 0.82 (Waalwijk et al., 2004) for the sum of F. culmorum and F. graminearum DNA, and 0.96 in artificially inoculated wheat samples for Fusarium species containing biosynthetic genes for DON (Schnerr et al., 2002). Additionally, a strong correlation of disease severity of FHB with DON levels after artificial inoculation with Fusarium spp. was found (Haidukowski et al., 2005; Mesterhazy et al., 2005). However, these data do not answer the question which of these two fungi is the causing agent of DON contamination. 


\section{Epidemiology of FHB}

F. graminearum and F. culmorum attack a wide range of plant species including members of families Fabaceae, Cucurbitaceae and a wide range of Poaceae (Shaner, 2003), including all cereals produced under moderate climate conditions. A key prerequisite for FHB reduction through crop management is to understand the epidemiology of the disease.

Many toxigenic Fusarium species have been associated with FHB infected grains (Nicholson et al., 2003; Bottalico and Perrone, 2002; Parry et al., 1995), but the predominant pathogens found worldwide are F. graminearum and F. culmorum. These fungi cause FHB in small grains and Gibberella ear rot in maize (Edwards et al., 2002), whereas F. graminearum is supposed to be the dominant species in hotter central Europe, and F. culmorum tends to predominate in cooler maritime regions of northwest Europe (Bottalico and Perrone, 2002; Parry et al., 1995). The taxonomical status of F. graminearum has recently been challenged. O'Donnell et al. proposed the existence of nine phylogenetically distinct species within the F. graminearum clade (O'Donnell et al., 2004). In Europe and America only lineage 7 has so far been reported (Ward et al., 2002; O'Donnell et al., 2000). Therefore, epidemiological studies in those regions may be focused on this lineage.

Possible sources of inoculum for FHB were reported to be crop debris, alternative hosts and Fusarium seedling blight and foot rot of cereals (Parry et al., 1995). For Fusarium graminearum, propagules from crop debris are the main source of initial inoculum (Xu, 2003). The spore dispersal of the two Fusarium spp. differs. The sexual stage of F. graminearum, Gibberella zeae, is capable of producing ascospores formed in asci on plant residues on the soil surface at temperatures between 15 and $25^{\circ} \mathrm{C}$, but not below $15^{\circ} \mathrm{C}$ or above $30^{\circ} \mathrm{C}$ (Gilbert and Fernando, 2004). These perithecia-derived ascospores are forcibly discharged during the evening in response to rising relative humidity and can be transported by wind (Fernando et al., 1997), but also by rain splashes (Paul et al., 2004). The disease foci deriving of infected plots inoculated with G. zeae-colonized corn kernels were limited to several meters (Fernando et al., 1997), making FHB mainly a field-specific problem. In addition to this quite limited transport, a long-distance transport of ascospores via the planetary boundary layer (50 $\mathrm{m}$ to nearly $1 \mathrm{~km}$ above soil surface) also occurs (Maldonado-Ramirez et al., 2005). This enables G. zeae to cause an infection without primary inoculum being present on a field (Schmale et al., 2005). 
Weather conditions favorable for ascospore production are closely related to rainfall events, although the precise relationship is not clear (Xu, 2003).

F. culmorum does not possess a sexual cycle. Conidia of F. culmorum presumably reach the ears by traversing from one leave to the next in rain splashes. This is also valid for the vegetative conidia of $F$. graminearum. Both conidia and ascospores have been shown to be important for causing FHB (Xu, 2003), dependent on the weather conditions. Infection of wheat ears was shown to occur mainly during anthesis. Warm and moist conditions during anthesis are the key factors for FHB development (Xu, 2003).

Jansen et al. described the infection pathway of $F$. graminearum on wheat spikes in detail. After germination of the fungal spore on the spike surface, the hyphae travel along the epicarp and infect the developing kernel through the epicarp. Successively, the layers of the fruit coat and finally the starch and protein accumulating endosperm are destroyed. Hyphae reaching the rachis proceed to apically located developing kernels. In the absence of trichothecenes, the fungus is blocked by the development of heavy cell wall thickenings in the rachis node of wheat, a defense inhibited by the mycotoxin (Jansen et al., 2005). This observation shows that trichothecenes are virulence factors affecting the spread and the disease in Triticeae. This is not necessarily the case in other host species (Langevin et al., 2004). The disruption of the nutrient supply to the upper spike in combination with the effect of mycotoxins causes shriveled kernels (tombstones) or total degeneration of the seeds. The upper part of the spike becomes bleached resulting in the typical head blight symptoms. The kernels downward the infection site are developed in full size, but contain variable amounts of mycotoxins.

Several empirical models were derived from the field data and proposed for use in disease forecasting (De Wolf et al., 2003; Rossi et al., 2003; Hooker et al., 2002). However, these models may not be applicable to a broader range of areas because of the nature of the field data used $(\mathrm{Xu}, 2003)$. The model of De Wolf et al. (2003) is based on within-season weather data in the United States and mainly describes the risk of infection, but not the development of the disease after flowering. Hooker et al. (2002) try to predict deoxynivalenol content in winter wheat using weather variables pre- and postheading. This model is only based on data from southern and eastern Ontario limiting the applicability of the results. A third model developed by Rossi et al. (2003) assumes that, in a wheat-growing area, inoculum is always present for all included Fusarium spp. in equal doses. This is in contradiction to the effect of pre-crop and tillage system to the extent of FHB reviewed repeatedly (Champeil et al., 2004). Therefore, Xu (2003) called 
for future research focusing on the development of more generally applicable forecasting models and on understanding the relationships between disease severity, fungal biomass and the production of associated mycotoxins.

\section{Influence of agricultural practices}

The influence of agricultural practices on Fusarium infection of cereals and subsequent contamination of grain by trichothecene mycotoxins have been reviewed repeatedly (Champeil et al., 2004; Edwards, 2004; Gilbert and Fernando, 2004; Pirgozliev et al., 2003). The effectiveness of cultural, biological and chemical control strategies have been investigated for the control of FHB. The qualitative effects of these practices on the severity of the disease and the production of toxins are in the process of being elucidated but, in many cases, detailed studies have not yet been carried out or conflicting results have been obtained. Most importantly, these effects have seldom been evaluated quantitatively in relation to the biomass of those Fusarium spp., which are the cause of FHB symptoms and mycotoxins. Three different cultural practices are considered to be of prime importance for combating this disease and the production of mycotoxins: deep tillage, the choice of the preceding crop in the rotation and the choice of appropriate cultivar, as varietal effects exist (Champeil et al., 2004).

The effects of previous crop residues and tillage practices on FHB of wheat were examined by Dill-Macky and Jones (2000). Fusarium head blight incidence and severity were greatest when wheat followed corn and least when wheat followed soybeans, emphasizing the critical role of the pre-crop maize for the occurrence of FHB. Incidence and severity were lower in moldboard-plowed plots than in either chisel-plowed or no-till plots, although differences among chisel-plow and no-till treatments were not apparent. The higher FHB severity was combined with lower yield and higher DON content of the harvested grain. Hence, the move toward soil conservation and reduced-till systems contributes to an increased risk of FHB. On the other hand, these tillage systems are highly desirable in the context of erosion prevention. Dill-Macky and Jones also found that differences in the type and quantity of crop residues in small plots affected disease development. Therefore, it is likely that local sources of inoculum, such as those within a grower's field, contribute directly to the inoculum load and disease potential (Dill-Macky and Jones, 2000). Thereby, it should be taken in consideration that F. graminearum is capable of producing ascospores on wheat residues even after 23 months, especially on residues remaining on the soil surface, although the biomass of the residues decreased 
significantly (Pereyra et al., 2004). In contrast to these effective control strategies, the adaptation of nitrogen fertilization represents no relevant tool in managing FHB in practical wheat cultivation (Lemmens et al., 2004).

Concerning the choice of appropriate cultivar, much effort has gone into breeding resistant wheat varieties and into improving our understanding of the possible mechanisms and genetic basis of resistance (Parry et al., 1995). Head blight resistance in wheat is not specific for either F. graminearum or F. culmorum. Resistance components include resistance to penetration, resistance to colonization and mechanisms that influence kernel DON content. The resistance to Fusarium in wheat is a quantitative trait with relative high heritability, controlled by a few genes with major effects. A major quantitative trait locus (QTL) for head blight resistance from the Chinese variety Sumai 3 has been identified. Research is now directed at identifying additional QTLs to make accumulation of resistance genes in elite wheat lines possible. This breeding progress addresses the urgent need for head blight resistance in future wheat varieties (Snijders, 2004). However, resistant cultivars available are reducing FHB severity, but they do not prevent mycotoxin contamination.

A range of fungicides has been identified with good activity against FHB pathogens. Unfortunately, the efficacy of these fungicides is significantly influenced by the time of application and the dose rate used (Pirgozliev et al., 2003). In the context of a good agricultural practice, the use of fungicides to combat FHB is a critical point, as the necessity of a treatment is not foreseeable at the time of application due to the lack of symptoms. In addition, the effect of fungicide treatment is variable and can even cause an increase in mycotoxin contamination (Edwards, 2004).

\section{FHB Diagnostics}

The relative contribution of each Fusarium species to the disease in a particular situation depends upon a range of variables, which might also affect the amount of mycotoxins produced. It is desirable to know the identity and amount of each pathogen within the host tissues (Nicholson et al., 2003). For example, quantitative analysis of a large number of samples in a species-specific manner is required for the evaluation of the relationship between disease severity, fungal biomass and DON contamination. To elucidate the influence of different agricultural practices and weather conditions on the FHB incidence and severity, it is necessary to track the life cycle of the relevant Fusarium spp. in the field, including the plant residues. Plating surface-sterilized plant material or grain on 
agar media does not allow the quantification of the growing fungi, and ELISA methods are not capable of the differentiation between different Fusarium species, which is important because of significant epidemiological and toxicological differences within this genus.

PCR is the method of choice for species-specific detection of fungi in plant material (Martin and Rygiewicz, 2005). Amplification products are traditionally separated by electrophoresis, which also does not allow for the quantitative analysis of template DNA (McCartney et al., 2003). Quantification of DNA template can be achieved by competitive PCR based on internal standards, which are amplified with the same primer pair as the investigated DNA. The ratio of the intensities of the two products serves as a measure of the amount of the template (Nicholson et al., 1998). However, competitive PCR was never established as a routine method in epidemiology because it is laborintensive and has a limited throughput.

PCR-based assays to determine the type of toxin produced, especially trichothecenes, have also been developed to be applied for example at the quality control of cereals (Mule et al., 2005; Bluhm et al., 2004; Schnerr et al., 2001). As the toxin producing capacity is not species specific, these assays are not suitable to answer questions related to the involvement of different species.

During the last decade, species specific PCR primers for all FHB-relevant pathogens were developed by several groups, as reviewed by Nicholson et al. (2003). These assays have a common feature of being based on electrophoretic detection in agarose gels, which limits their throughput. Therefore, the applicability for epidemiological studies, which typically include a high number of samples, is limited. The drawbacks of the traditional PCR are reduced by the development of real-time PCR-based methods (Wilhelm and Pingoud, 2003), which allow fast, accurate detection and quantification and provide new tools to monitor the exposure of a crop to pathogen inoculum that are more reliable and faster than conventional methods (McCartney et al., 2003). Real-time PCR combines the sensitivity of conventional PCR with the generation of a specific fluorescent signal, providing real-time analysis of the reaction kinetics and allowing quantification of specific DNA targets (Gachon et al., 2004; Schena et al., 2004). The fluorescent signal eliminates the requirement for post-amplification processing steps, such as gel electrophoresis and ethidium bromide staining. This significantly reduces time and labor required for the analysis and greatly increases the throughput of PCR, making it suitable for large-scale analyses (Schena et al., 2004). Known primers specific 
for F. graminearum and F. culmorum (Nicholson et al., 1998; Schilling et al., 1996) served us as a basis for the development of real-time PCR assays to detect and quantify these pathogens in complex matrices like plant debris or wheat flour.

\section{Aims of the study}

The relative contribution of each Fusarium species to the disease in a particular situation depends upon a range of variables, which might also affect the amount of mycotoxins produced. Real-time PCR methods should serve to determine the identity and amount of F. graminearum and F. culmorum within host tissues.

Firstly, the qualitative detection should be established to be able to identify the two pathogens within rachides of infected wheat spikes, enabling the determination of the causing agent of FHB symptoms. A suitable high-throughput DNA extraction method for wheat rachides is required for a fast, inexpensive, qualitative PCR assay for F. culmorum and F. graminearum.

The second aim was the quantitative determination of both fungi in complex plant material like wheat flour and plant debris. Therefore, a DNA extraction protocol suitable to analyze inhomogeneously colonized plant material in order to reduce the sampling error had to be combined with inexpensive real-time PCR assays for F. culmorum and F. graminearum. For quantification purpose, a suitable standard curve had to be established to relate the PCR results to the fungal DNA amount per sample. A prerequisite for both assays, besides their performance in a high-throughput environment, was the specificity for F. graminearum and F. culmorum, which had also to be confirmed.

The third aim of the study was the identification of the causing agent of FHB in wheat rachides and the determination of the relative importance of F. graminearum and F. culmorum in relation to the DON content of wheat. The collected data should serve to adjust quantitative parameters of a risk assessment model for FHB, which should be the final result of the cooperative project funded by the Federal Ministry of Food, Agriculture and Consumer Protection (BMELV). The construction of the model is not a part of this study.

The goal of the BMELV-project is the development of a computer based decision support system minimizing the fusaria infection risk and toxin contamination in wheat. The project partners are the Central Institution for Decision Support Systems in Crop Protection (ZEPP) and the Dienstleistungszentrum Ländlicher Raum, Rheinhessen-Nahe- 
Hunsrück in Bad Kreuznach, the Federal Plant Protection Extension Services, and the Federal Agriculture Research Centre (FAL) in Braunschweig.

The main aim of the model called FUSOPT is the reduction of toxin contamination. The model rates and combines agronomical risk factors and simulates biological processes of spore production, dispersal and infection of wheat dependent of weather conditions before and during the flowering of wheat. FUSOPT shall calculate field-specific threshold for plant protection and identify fields and regions with high risk of a FHB infection. The use of fungicides against FHB also shall be directed, while the priority is given to the other agronomical factors to reduce FHB in the context of the good agricultural practice. The forecasting function of the model will show the effect of agronomical risk constellations and demonstrate options to reduce FHB by adapting agronomical practices. Thus, the model FUSOPT shall become an essential part of good agricultural practice to reduce FHB and toxin contamination in wheat.

\section{References}

Anonymous. 1999. Verordnung über Höchstmengen an Mykotoxinen in Lebensmitteln (Mykotoxin-Höchstmengenverordnung - MHmV), p. 1248-1251 Bundesgesetzblatt, Vol. 1. Bundesanzeiger Verlagsges.m.b.H., Bonn.

Anonymous. 2004. Verordnung zur Änderung der Mykotoxin-Höchstmengenverordnung und der Diätverordnung, p. 151-152 Bundesgesetzblatt, Vol. 1. Bundesanzeiger Verlagsges.m.b.H., Bonn.

Bai, G.H., A.E. Desjardins, and R.D. Plattner. 2002. Deoxynivalenol-nonproducing Fusarium graminearum causes initial infection, but does not cause disease spread in wheat spikes. Mycopathologia 153: 91-98.

Bennett, J.W., and M. Klich. 2003. Mycotoxins. Clinical Microbiology Reviews 16: $497-$ 516.

Bluhm, B.H., M.A. Cousin, and C.P. Woloshuk. 2004. Multiplex real-time PCR detection of fumonisin-producing and trichothecene-producing groups of Fusarium species. Journal of Food Protection 67: 536-543.

Bottalico, A., and G. Perrone. 2002. Toxigenic Fusarium species and mycotoxins associated with head blight in small-grain cereals in Europe. European Journal of Plant Pathology 108: 611-624. 
Champeil, A., T. Dore, and J.F. Fourbet. 2004. Fusarium head blight: epidemiological origin of the effects of cultural practices on head blight attacks and the production of mycotoxins by Fusarium in wheat grains. Plant Science 166: 1389-1415.

De Wolf, E.D., L.V. Madden, and P.E. Lipps. 2003. Risk assessment models for wheat Fusarium head blight epidemics based on within-season weather data. Phytopathology 93: 428-435.

Dill-Macky, R., and R.K. Jones. 2000. The effect of previous crop residues and tillage on Fusarium head blight of wheat. Plant Disease 84: 71-76.

D'Mello, J.P.F., C.M. Placinta, and A.M.C. Macdonald. 1999. Fusarium mycotoxins: a review of global implications for animal health, welfare and productivity. Animal Feed Science \& Technology 80: 183-205.

Edwards, S.G. 2004. Influence of agricultural practices on fusarium infection of cereals and subsequent contamination of grain by trichothecene mycotoxins. Toxicology Letters 153: 29-35.

Edwards, S.G., J. O'Callaghan, and A.D.W. Dobson. 2002. PCR-based detection and quantification of mycotoxigenic fungi. Mycological Research 106: 1005-1025.

Fernando, W.G.D., T.C. Paulitz, W.L. Seaman, P. Dutilleul, and J.D. Miller. 1997. Head blight gradients caused by Gibberella zeae from area sources of inoculum in wheat field plots. Phytopathology 87: 414-421.

Gachon, C., A. Mingam, and B. Charrier. 2004. Real-time PCR: what relevance to plant studies? Journal of Experimental Botany 55: 1445-1454.

Gilbert, J., and W.G.D. Fernando. 2004. Epidemiology and biological control of Gibberella zeae Fusarium graminearum. Canadian Journal of Plant PathologyRevue Canadienne De Phytopathologie 26: 464-472.

Haidukowski, M., M. Pascale, G. Perrone, D. Pancaldi, C. Campagna, and A. Visconti. 2005. Effect of fungicides on the development of Fusarium head blight, yield and deoxynivalenol accumulation in wheat inoculated under field conditions with Fusarium graminearum and Fusarium culmorum. Journal of the Science of Food and Agriculture 85: 191-198.

Hazel, C.M., and S. Patel. 2004. Influence of processing on trichothecene levels. Toxicology Letters 153: 51-59.

Hooker, D.C., A.W. Schaafsma, and L. Tamburic-Ilincic. 2002. Using weather variables pre- and post-heading to predict deoxynivalenol content in winter wheat. Plant Disease 86: 611-619. 
Jansen, C., D. von Wettstein, W. Schafer, K.H. Kogel, A. Felk, and F.J. Maier. 2005. Infection patterns in barley and wheat spikes inoculated with wild-type and trichodiene synthase gene disrupted Fusarium graminearum. Proceedings of the National Academy of Sciences of the United States of America 102: 16892-16897.

Langevin, F., F. Eudes, and A. Comeau. 2004. Effect of trichothecenes produced by Fusarium graminearum during Fusarium head blight development in six cereal species. European Journal of Plant Pathology 110: 735-746.

Lemmens, M., K. Haim, H. Lew, and P. Ruckenbauer. 2004. The effect of nitrogen fertilization on Fusarium head blight development and deoxynivalenol contamination in wheat. Journal of Phytopathology 152: 1-8.

Maldonado-Ramirez, S.L., D.G. Schmale, E.J. Shields, and G.C. Bergstrom. 2005. The relative abundance of viable spores of Gibberella zeae in the planetary boundary layer suggests the role of long-distance transport in regional epidemics of Fusarium head blight. Agricultural and Forest Meteorology 132: 20-27.

Martin, K.J., and P.T. Rygiewicz. 2005. Fungal-specific PCR primers developed for analysis of the ITS region of environmental DNA extracts. BMC Microbiology 5: 28.

McCartney, H.A., S.J. Foster, B.A. Fraaije, and E. Ward. 2003. Molecular diagnostics for fungal plant pathogens. Pest Management Science 59: 129-142.

Mesterhazy, A., T. Bartok, G. Kaszonyi, M. Varga, B. Toth, and J. Varga. 2005. Common resistance to different Fusarium spp. causing Fusarium head blight in wheat. European Journal of Plant Pathology 112: 267-281.

Mule, G., M.T. Gonzalez-Jaen, L. Hornok, P. Nicholson, and C. Waalwijk. 2005. Advances in molecular diagnosis of toxigenic Fusarium species: A review. Food Additives and Contaminants 22: 316-323.

Nicholson, P., D.R. Simpson, G. Weston, H.N. Rezanoor, A.K. Lees, D.W. Parry, and D. Joyce. 1998. Detection and quantification of Fusarium culmorum and Fusarium graminearum in cereals using PCR assays. Physiological and Molecular Plant Pathology 53: 17-37.

Nicholson, P., E. Chandler, R.C. Draeger, N.E. Gosman, D.R. Simpson, M. Thomsett, and A.H. Wilson. 2003. Molecular tools to study epidemiology and toxicology of Fusarium head blight of cereals. European Journal of Plant Pathology 109: 691703. 
O'Donnell, K., H.C. Kistler, B.K. Tacke, and H.H. Casper. 2000. Gene genealogies reveal global phylogeographic structure and reproductive isolation among lineages of Fusarium graminearum, the fungus causing wheat scab. Proceedings of the National Academy of Sciences of the United States of America 97: 7905-7910.

O'Donnell, K., T.J. Ward, D.M. Geiser, H.C. Kistler, and T. Aoki. 2004. Genealogical concordance between the mating type locus and seven other nuclear genes supports formal recognition of nine phylogenetically distinct species within the Fusarium graminearum clade. Fungal Genetics and Biology 41: 600-623.

Parry, D.W., P. Jenkinson, and L. McLeod. 1995. Fusarium ear blight (scab) in small grain cereals -- A review. Plant Pathology 44: 207-238.

Paul, P.A., S.M. El-Allaf, P.E. Lipps, and L.V. Madden. 2004. Rain splash dispersal of Gibberella zeae within wheat canopies in Ohio. Phytopathology 94: 1342-1349.

Peraica, M., B. Radic, A. Lucic, and M. Pavlovic. 1999. Toxic effects of mycotoxins in humans. Bulletin of the World Health Organization 77: 754-766.

Pereyra, S.A., R. Dill-Macky, and A.L. Sims. 2004. Survival and inoculum production of Gibberella zeae in wheat residue. Plant Disease 88: 724-730.

Pestka, J.J., and A.T. Smolinski. 2005. Deoxynivalenol: Toxicology and potential effects on humans. Journal of Toxicology and Environmental Health-Part B-Critical Reviews 8: 39-69.

Pieters, M.N., J. Freijer, B.J. Baars, D.C.M. Fiolet, J. van Klaveren, and W. Slob. 2002. Risk assessment of deoxynivalenol in food: Concentration limits, exposure and effects, p. 235-248 Mycotoxins and Food Safety, Vol. 504. KLUWER ACADEMIC/PLENUM PUBL, New York.

Pirgozliev, S.R., S.G. Edwards, M.C. Hare, and P. Jenkinson. 2003. Strategies for the control of Fusarium head blight in cereals. European Journal of Plant Pathology 109: 731-742.

Proctor, R.H., T.M. Hohn, and S.P. McCormick. 1995. Reduced Virulence of Gibberella zeae Caused by Disruption of a Trichothecene Toxin Biosynthetic Gene. Molecular Plant-Microbe Interactions 8: 593-601.

Rocha, O., K. Ansari, and F.M. Doohan. 2005. Effects of trichothecene mycotoxins on eukaryotic cells: A review. Food Additives and Contaminants 22: 369-378.

Rossi, V., S.G. , E.P. , F.S. , and A.D. Vecchio. 2003. A model estimating the risk of Fusarium head blight on wheat. OEPP/EPPO Bulletin 33: 431-435. 
Rotter, B.A., D.B. Prelusky, and J.J. Pestka. 1996. TOXICOLOGY OF DEOXYNIVALENOL (VOMITOXIN) [Review]. Journal of Toxicology \& Environmental Health 48: 1-34.

Schena, L., F. Nigro, A. Ippolito, and D. Gallitelli. 2004. Real-time quantitative PCR: a new technology to detect and study phytopathogenic and antagonistic fungi. European Journal of Plant Pathology 110: 893-908.

Schilling, A.G., E.M. Moller, and H.H. Geiger. 1996. Polymerase chain reaction-based assays for species-specific detection of Fusarium culmorum, F. graminearum, and F. avenaceum. Phytopathology 86: 515-522.

Schmale, D.G., D.A. Shah, and G.C. Bergstrom. 2005. Spatial patterns of viable spore deposition of Gibberella zeae in wheat fields. Phytopathology 95: 472-479.

Schnerr, H., L. Niessen, and R.F. Vogel. 2001. Real time detection of the tri5 gene in Fusarium species by LightCycler (TM)-PCR using SYBR((R))Green I for continuous fluorescence monitoring. International Journal of Food Microbiology 71: 53-61.

Schnerr, H., R.F. Vogel, and L. Niessen. 2002. Correlation between DNA of trichothecene-producing Fusarium species and deoxynivalenol concentrations in wheat-samples. Letters in Applied Microbiology 35: 121-125.

Schothorst, R.C., and H.P. van Egmond. 2004. Report from SCOOP task 3.2.10 "collection of occurrence data of Fusarium toxins in food and assessment of dietary intake by the population of EU member states" - Subtask: trichothecenes. Toxicology Letters 153: 133-143.

Shaner, G. 2003. Epidemiology of Fusarium Head Blight of Small Grain Cereals in North America, p. 512, In K. J. Leonard and W. R. Bushnell, eds. Fusarium Head Blight of Wheat and Barley. The American Phytopathological Society, St. Paul, Minnesota, USA.

Snijders, C.H.A. 2004. Resistance in wheat to Fusarium infection and trichothecene formation. Toxicology Letters 153: 37-46.

Waalwijk, C., R. van der Heide, I. de Vries, T. van der Lee, C. Schoen, G. Costrel-de Corainville, I. Hauser-Hahn, P. Kastelein, J. Kohl, P. Lonnet, T. Demarquet, and G.H.J. Kema. 2004. Quantitative detection of Fusarium species in wheat using TaqMan. European Journal of Plant Pathology 110: 481-494.

Ward, T.J., J.P. Bielawski, H.C. Kistler, E. Sullivan, and K. O'Donnell. 2002. Ancestral polymorphism and adaptive evolution in the trichothecene mycotoxin gene cluster 
of phytopathogenic Fusarium. Proceedings of the National Academy of Sciences of the United States of America 99: 9278-9283.

Wilhelm, J., and A. Pingoud. 2003. Real-time polymerase chain reaction. Chembiochem 4: 1120-1128.

Xu, X.M. 2003. Effects of environmental conditions on the development of Fusarium ear blight. European Journal of Plant Pathology 109: 683-689. 


\title{
Simultaneous detection of Fusarium culmorum and F. graminearum in plant material by duplex PCR with melting curve analysis Christoph Brandfass and Petr Karlovsky*
}

Address: University of Göttingen, Institute of Plant Pathology, Grisebachstraße 6, 37077 Göttingen, Germany

Email: Christoph Brandfass - cbrandf@gwdg.de; Petr Karlovsky* - Karlovsky@web.de

* Corresponding author

Published: 23 January 2006

BMC Microbiology 2006, 6:4 doi:|0.1 |86/|47|-2|80-6-4
Received: I I May 2005

Accepted: 23 January 2006

This article is available from: http://www.biomedcentral.com/|47|-2/80/6/4

(C) 2006 Brandfass and Karlovsky; licensee BioMed Central Ltd.

This is an Open Access article distributed under the terms of the Creative Commons Attribution License (http://creativecommons.org/licenses/by/2.0), which permits unrestricted use, distribution, and reproduction in any medium, provided the original work is properly cited.

\begin{abstract}
Background: Fusarium head blight (FHB) is a disease of cereal crops, which has a severe impact on wheat and barley production worldwide. Apart from reducing the yield and impairing grain quality, FHB leads to contamination of grain with toxic secondary metabolites (mycotoxins), which pose a health risk to humans and livestock. The Fusarium species primarily involved in FHB are $F$. graminearum and $F$. culmorum. A key prerequisite for a reduction in the incidence of $F H B$ is an understanding of its epidemiology.
\end{abstract}

Results: We describe a duplex-PCR-based method for the simultaneous detection of $F$. culmorum and F. graminearum in plant material. Species-specific PCR products are identified by melting curve analysis performed in a real-time thermocycler in the presence of the fluorescent dye SYBR Green I. In contrast to multiplex real-time PCR assays, the method does not use doubly labeled hybridization probes.

Conclusion: PCR with product differentiation by melting curve analysis offers a cost-effective means of qualitative analysis for the presence of $F$. culmorum and $F$. graminearum in plant material. This method is particularly suitable for epidemiological studies involving a large number of samples.

\section{Background}

Fusarium head blight (FHB) is a disease of cereal crops, which has a severe impact on wheat and barley production worldwide. The infection of heads of small grain cereals and maize plants with Fusarium spp. impairs grain yield and quality [1]. Apart from adversely effecting grain size, weight, protein content, baking quality of the flour, and other technological parameters, the contamination of grain and cereal products with Fusarium mycotoxins is the most serious consequence of FHB $[2,3]$. The consumption of commodities contaminated with mycotoxins poses a health risk to both humans and farm animals, making fungal contamination a key concern in food and feed safety assessments. Because grains of low quality are used in feedstuff production rather than in human foods, health and productivity impairment in farm animals caused by mycotoxin contamination of feeds have regularly been reported in the last decades from Europe [4]. Our understanding of the effects of low doses of Fusarium mycotoxins consumed over prolonged time periods (possibly the whole life span) on humans is poor because of technical difficulties in addressing these issues by doing epidemiological studies. While the EU is still in the process of developing legal limits for Fusarium mycotoxins in grains, food and feeds, some European countries have already established national limits $[5,6]$. 
Table I: Fungal strains used in the present study. Source code: I: Centraalbureau voor Schimmelcultures, Utrecht, The Netherlands; 2: Deutsche Sammlung von Mikroorganismen und Zellkulturen, Braunschweig, Germany; 3: E. Möller, University of Hohenheim, Germany; 4: H. Nirenberg (BBA Berlin, Germany) via E. Möller, University of Hohenheim, Germany; 5: Institute of Plant Pathology, University of Göttingen, Germany; 6: International Center for Agricultural Research in the Dry Areas, Aleppo, Syria; 7: J.F. Leslie (Kansas State University, Manhattan) via E. Möller, University of Hohenheim, Germany; 8: National Institute for Agricultural Research, Paris, France; 9: Th. Miedaner (State Plant Breeding Institute) via E. Möller, University of Hohenheim, Germany

\begin{tabular}{|c|c|c|c|}
\hline Species & Strain & Source & Origin \\
\hline Alternaria alternata & A 4.I.I & 5 & Triticum aestivum, leaf, 1983 \\
\hline Cladosporium herbarum & $\mathrm{CH} 3$ & 3 & unknown \\
\hline Cladosporium herbarum & $\mathrm{CH} 4$ & 3 & unknown \\
\hline Drechslera sorokiniana & D 3.1 & 5 & Triticum aestivum, leaf \\
\hline Fusarium acuminatum & ICARDA 92090 & 6 & Hordeum vulgare, root, Bouider station \\
\hline Fusarium acuminatum & ICARDA 92099 & 6 & Hordeum vulgare, Bouider station \\
\hline Fusarium acuminatum & ICARDA 93682 & 6 & Hordeum vulgare, root \\
\hline Fusarium acuminatum & ICARDA 93803 & 6 & Hordeum vulgare, root, Viransehir \\
\hline Fusarium acuminatum & ICARDA 9383I & 6 & Hordeum vulgare, root, Viransehir \\
\hline Fusarium avenaceum & DSM 6216I & 2 & Dianthus caryophyllus, rotten stem base, Germany \\
\hline Fusarium avenaceum & FA 95 & 3 & unknown \\
\hline Fusarium compactum & ICARDA 93823 & 6 & unknown \\
\hline Fusarium crookwellense & BBA 63558, DSM 8704 & 4 & unknown \\
\hline Fusarium crookwellense & BBA 64483 & 4 & unknown \\
\hline Fusarium crookwellense & BBA 64545 & 4 & unknown \\
\hline Fusarium culmorum & CBS 122.73 & 1 & Triticum sp., Great Britain, 1973 \\
\hline Fusarium culmorum & CBS 250.52 (Fc3.3) & I & Secale cereale, grain, 1952 \\
\hline Fusarium culmorum & DSM 62184 & 2 & Zea mays, grain, 1952 \\
\hline Fusarium culmorum & DSM 62191 & 2 & Triticum aestivum, head, Mainz, Germany \\
\hline Fusarium culmorum & Fcl5 & 9 & Triticum aestivum, seed, Söllingen, Germany, 1987 \\
\hline Fusarium culmorum & $\mathrm{Fc2}$ & 4 & Hordeum vulgare, head, Finland, 1982 \\
\hline Fusarium culmorum & $\mathrm{Fc} 22$ & 9 & Secale cereale, stem, Bad Schönborn, Germany, 1989 \\
\hline Fusarium culmorum & $\mathrm{Fc} 36$ & 9 & Secale cereale, stem, Bergen (Celle), Germany \\
\hline Fusarium culmorum & Fc65 & 9 & Secale cereale, Svalöf, Sweden, 1992 \\
\hline Fusarium culmorum & Fc66 & 3 & Triticum aestivum, head, Italy, 1992 \\
\hline Fusarium culmorum & Fc67 & 3 & Triticum aestivum, head, Italy, 1992 \\
\hline Fusarium culmorum & Fc73 & 3 & soil, Tasmania, Australia \\
\hline Fusarium equiseti & ICARDA 93002 & 6 & unknown \\
\hline Fusarium equiseti & ICARDA 93532 & 6 & unknown \\
\hline Fusarium equiseti & ICARDA 93574 & 6 & unknown \\
\hline Fusarium equiseti & ICARDA 93715 & 6 & unknown \\
\hline Fusarium equiseti & ICARDA 93788 & 6 & unknown \\
\hline Fusarium graminearum & BBA 62048 & 4 & Triticum aestivum, Germany, 1973 \\
\hline Fusarium graminearum & CBS 389.62 & 1 & Triticum aestivum, East-Flevoland, The Netherlands, 196I \\
\hline Fusarium graminearum & DSM 1095 & 2 & Zea mays, Indiana, USA, 1973 \\
\hline Fusarium graminearum & DSM 4527 & 2 & Zea mays, Bavaria, Germany, 1982 \\
\hline Fusarium graminearum & DSM 4528 & 2 & Zea mays, Germany, 1982 \\
\hline Fusarium graminearum & DSM 62217 & 2 & Zea mays, Ireland, 1968 \\
\hline Fusarium graminearum & DSM 62722 & 2 & Lolium perenne, rotting base, Germany \\
\hline Fusarium graminearum & DSM 62722 & 2 & Lolium sp., Kiel, Germany, 1968 \\
\hline Fusarium graminearum & DSM 64848 & 2 & Triticum durum, Rottenburg, Germany, 1987 \\
\hline Fusarium graminearum & DSM 67638 & 2 & Triticum aestivum, Bavaria, Germany, 1992 \\
\hline Fusarium graminearum & $\mathrm{Fg} 3$ & 4 & Triticum durum, head, 1985 \\
\hline Fusarium graminearum & $\mathrm{Fg} 5$ & 4 & unknown \\
\hline Fusarium oxysporum & SAGW I24 & 5 & Aalsmeer, The Netherlands, 1987 \\
\hline Fusarium poae & DSM 62376 & 2 & Avena sativa, kernel, Germany \\
\hline Fusarium poae & FP 2 & 9 & unknown \\
\hline Gibberella fujikuroi & B-0028I & 7 & Saccharum officinarum, Taiwan \\
\hline Gibberella fujikuroi & B-01722 & 7 & unknown \\
\hline Gibberella fujikuroi & B-0382I & 7 & unknown \\
\hline Gibberella fujikuroi & B-03828 & 7 & unknown \\
\hline Gibberella fujikuroi & B-03853 & 7 & unknown \\
\hline Microdochium nivale var. majus & GN 7 & 9 & Hordeum vulgare, head, Switzerland \\
\hline Microdochium nivale var. nivale & GN 25 & 9 & Hordeum vulgare \\
\hline Microdochium nivale var. nivale & GN 35 & 9 & Secale cereale, base, Georgen \\
\hline
\end{tabular}


Table I: Fungal strains used in the present study. Source code: I: Centraalbureau voor Schimmelcultures, Utrecht, The Netherlands; 2: Deutsche Sammlung von Mikroorganismen und Zellkulturen, Braunschweig, Germany; 3: E. Möller, University of Hohenheim, Germany; 4: H. Nirenberg (BBA Berlin, Germany) via E. Möller, University of Hohenheim, Germany; 5: Institute of Plant Pathology, University of Göttingen, Germany; 6: International Center for Agricultural Research in the Dry Areas, Aleppo, Syria; 7: J.F. Leslie (Kansas State University, Manhattan) via E. Möller, University of Hohenheim, Germany; 8: National Institute for Agricultural Research, Paris, France; 9: Th. Miedaner (State Plant Breeding Institute) via E. Möller, University of Hohenheim, Germany (Continued)

\begin{tabular}{llll}
\hline Microdochium nivale var. nivale & GN 36 & 9 & Secale cereale, base, Oli/Schwäbische Alb, Germany \\
Pseudocercosporella herpotrichoides & INRA I64 & 8 & Ille et Vilaine, France, I986 \\
Pseudocercosporella herpotrichoides var. acuformis & C39A & 5 & 1988 \\
Pseudocercosporella herpotrichoides var. acuformis & PHA 20/3 & 3 & Secale cereale, I99I \\
Rhizoctonia cerealis & INRA I6I & 8 & Marne, France, I98I \\
Rhizoctonia cerealis & SAGW I05 & 5 & Triticum aestivum, Loxstedt-Dünenfähr, Germany, I984 \\
Rhizoctonia cerealis & SAGW I07 & 5 & Oldenburg, Germany, I985 \\
Septoria nodorum & 7n/II/2 & 5 & Triticum aestivum, leaf, Göttingen, I993
\end{tabular}

In spite of breeding efforts aiming at FHB-resistant cultivars, and despite a recent shift of the priority of chemical protection development towards fungicides targeting $\mathrm{FHB}$, the disease continues to pose a major challenge to grain growers all over the world [7]. A key prerequisite for a reduction in the incidence of FHB through crop management is an understanding of its epidemiology. The Fusarium species primarily involved in FHB are F. graminearum and F. culmorum [8]. The biology and infection mode of these two species are very different from each other: $F$. graminearum reaches cereal heads via ascospores forcibly discharged from asci formed on plant residues on the soil surface. In comparison, F. culmorum does not possess a sexual cycle. It is assumed that $F$. culmorum reaches the ears by traversing from one leave to the next in rain splashes [9], but some researchers find this hypothesis unsatisfactory. A speculation that F. culmorum and possibly also $F$. graminearum can infect cereal plants systemically and grow in the stem upwards from the root to the ear has been revived repeatedly in recent years, but it has not been proven so far [10].

Another important question in FHB epidemiology is whether species other than from $F$. graminearum and $F$. culmorum also contribute significantly to the symptoms and mycotoxin contamination. A number of fungal species have been isolated from infected or even healthylooking ears collected in the field, including a plethora of Fusarium spp. $[11,12]$, but it is not known whether these isolates actively contribute to the FHB or whether they just grow saprophytically in the dead surface tissues, which are normally removed during grain cleaning and processing.

Current epidemiological studies on FHB are expected to provide answers to these and other questions crucial to disease management. These studies require the analysis of a large number of samples in a species-specific manner. Although the quantitative determination of fungal biomass is required for certain tasks (e.g., virulence assessment for species or isolates), qualitative data are often sufficient in studies in epidemiology. PCR is the method of choice for both purposes, because reliable species-specific primers are known for all FHB-relevant species [1217]. However, classical PCR is not suitable for epidemiological studies because agarose electrophoresis limits the throughput $[18,19]$. Here we describe a fast, inexpensive, qualitative duplex PCR assay for F. culmorum and F. graminearum, which are the key species causing FHB in wheat and barley. The method is based on the melting curve analysis of amplification products generated in a real-time PCR thermocycler.

\section{Results and discussion Optimization of DNA extraction and PCR conditions}

The processing of the wheat rachides posed a challenge, because the small sample size (2-3 segments of the spike axis per sample) and firm texture of the material put high demands on the homogenization of the samples. The high number of samples precluded manual grinding in a mortar; we therefore used a reciprocal mill. Pulverizing wheat rachides in polypropylene tubes with stainless steel or wolfram carbide balls was found to be inefficient, but a large stainless steel ball ( $32 \mathrm{~g}, 20 \mathrm{~mm}$ ) in a stainless steel container crushed the rachides into a fine powder. We optimized the factors affecting the DNA yield and quality in a CTAB-based DNA extraction method (details to be published), the optimized protocol is described in the Methods section.

Our initial PCR experiments, undertaken under the conditions described in the literature for classical PCR with primers Fg16N and OPT18, did not result in the amplification and detection of the expected products by fluorescence $[13,14]$. Therefore, we optimized the PCR conditions concerning primer concentration, polymerase activity, $\mathrm{MgCl}_{2}$, SYBR Green I concentration and cycling parameters. For this optimization fungal DNA of the strains Fg3, Fg5, Fc2 and CBS 250.52 (Table 1) was used. The improved protocol is described in the Methods section. 

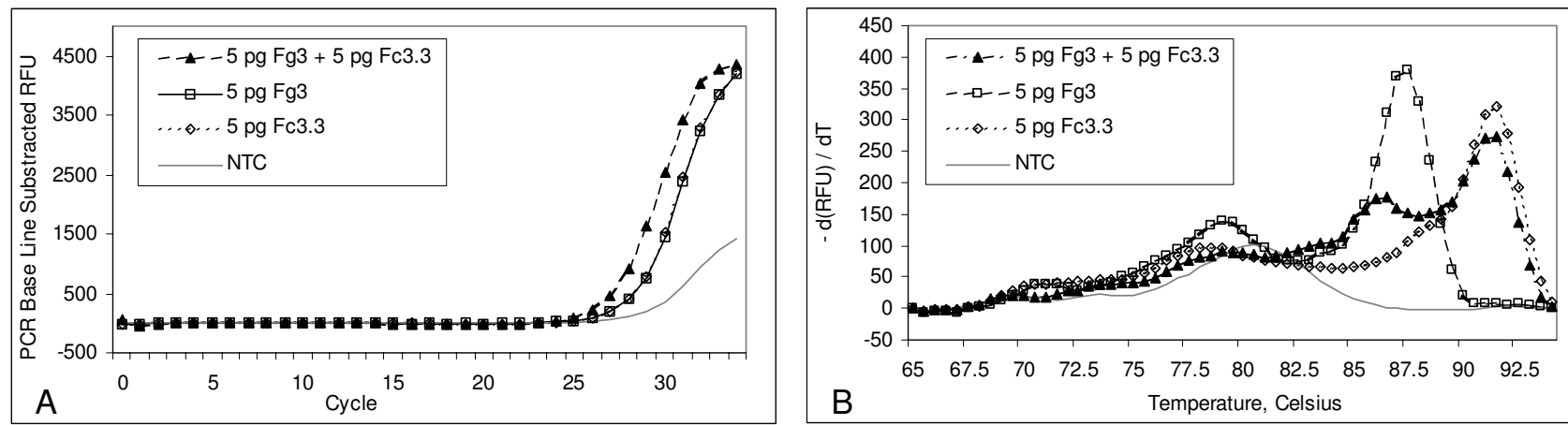

\section{Figure I}

Progress and melting curves of PCR products used for the detection of $F$. culmorum and $F$. graminearum. PCR and melting curve analysis was performed in a real-time thermocycler with primer pairs specific for $F$. culmorum and $F$. graminearum and SYBR Green I fluorescence detection as described in the Methods. The SYBR Green I was diluted to $0.4 \times$ the recommended concentration. Genomic DNA from F. graminearum (continuous curves with squares), F. culmorum (dotted curves with diamonds), a mixture containing DNA from both species (dashed curves with triangles) and no DNA (no-template control, "NTC ", gray curve without symbols) were used as templates. A: Progress curves, showing the fluorescence signal during the annealing phase in each reaction cycle. B: Melting curves recorded on PCR products after 35 cycles. The rise of fluorescence in the no-template control produces a melting point maximum at about $80^{\circ} \mathrm{C}$, far lower than where Fusarium target are detected. Because melting curves presented in Figure IB were recorded with low template amounts, the unspecific products are also visible, but they do not prevent the detection of Fusarium DNA in amounts equal to or higher than the limit of detection.

The specificity of primers we selected for our assay was evaluated in the literature as follows: $\mathrm{Fg} 16 \mathrm{~N}$ was tested with $21 \mathrm{~F}$. culmorum isolates, $24 \mathrm{~F}$. graminearum isolates, 20 isolates of other Fusarium species and 5 isolates of other fungal species associated with cereals [14]. OPT18 was tested with 69 F. culmorum isolates, 34 F. graminearum isolates, 25 isolates of other Fusarium species and 27 isolates of other fungal species associated with cereals [13]. All tests confirmed the specificity of Fg16N for F. graminearum and OPT18 for F. culmorum. Because PCR conditions used in these tests were different from the conditions of our assay, we re-evaluated the primer specificity in our duplex assay. We tested a range of fungal species regularly encountered on cereals, especially Fusarium spp. (Table 1). All isolates of F. culmorum and F. graminearum tested positively, giving signals in the expected range of melting temperature. There was no cross-reaction between $F$. culmorum and F. graminearum. All other fungal isolates listed in Tab. 1 tested negatively. The amplification of $F$. culmorum and F. graminearum was not inhibited by the presence of a large excess of wheat DNA (10 ng wheat DNA in a reaction containing $10 \mathrm{pg}$ of Fusarium spp. DNA) nor did pure wheat DNA generate any signal under these conditions.

Duplex PCR with SYBR Green I and melting curve analysis The fluorescent dye SYBR Green I, which intercalates unspecifically to all double-stranded DNA products, is commonly used in real-time PCR when just one specific amplicon is produced. In our protocol, the dye serves to identify two different products after amplification with the help of a melting curve analysis. In contrast to the realtime PCR mode, this method does not allow for quantification because the fluorescence measured during amplification is the sum of the signals generated by two specific PCR products and possibly unspecific products, too. Particularly, the primer pair Fg16N F/R tends to generate a fluorescent signal even in no-template controls at the end of the amplification (Figure 1).

A melting curve analysis was set up to characterize the amplification products after PCR. Melting points, represented by maxima of the first derivative of the melting curves, were different for the two PCR products in our system. A low heating rate $\left(0.5^{\circ} \mathrm{C} 30 \mathrm{~s}^{-1}\right)$ during melting curve acquisition was essential because the resolution of the melting curves drops with increasing heating rate.

To reduce the fraction of false positives, absolute and relative limits were set for the magnitude of signals represented by peak areas on the first derivative of the melting curves. The absolute peak area and the fraction of the peak area in relation to the total area under the melting curve were used as the absolute and relative thresholds. Their limits were respectively set to 100 and 0.1 .

The melting temperature of a PCR product depends mainly on its length and GC content. It is also affected by the nucleotide sequence because of the stacking interactions among adjacent nucleotides. The species-specific 
Table 2: Limits of detection for F. culmorum and F. graminearum in duplex PCR with melting curve analysis.

\begin{tabular}{|c|c|c|c|}
\hline \multicolumn{2}{|c|}{ DNA used as template } & \multicolumn{2}{|c|}{ Species detected } \\
\hline F. graminearum & F. culmorum & F. graminearum & F. culmorum \\
\hline $5 \mathrm{pg}$ & $5 \mathrm{pg}$ & + & + \\
\hline $100 \mathrm{pg}$ & $100 \mathrm{pg}$ & - & + \\
\hline $100 \mathrm{pg}$ & $10 \mathrm{pg}$ & + & + \\
\hline $10 \mathrm{pg}$ & $100 \mathrm{pg}$ & - & + \\
\hline $5 \mathrm{pg}$ to $5 \mathrm{ng}$ & - & + & - \\
\hline- & $5 \mathrm{pg}$ to $5 \mathrm{ng}$ & - & + \\
\hline
\end{tabular}

Positive detection $(+)$ was defined as the presence of a peak in the melting profile which fulfills these conditions:

(i) its melting point identified by thermocycler software lies within $91.0 \pm 1.0^{\circ} \mathrm{C}$ for $F$. culmorum and $86.5 \pm 1.0^{\circ} \mathrm{C}$ for $F$. graminearum

(ii) absolute peak area amounts to at least 100 densitometry units

(iii) the relative peak area in relation to the total area under the melting curve amounts to at least $10 \%$.

Identical results were obtained in the presence of an excess $(10 \mathrm{ng})$ of wheat DNA.

PCR product for F. culmorum generated with primers OPT18 F/R was 472 bp long and had a melting temperature of $91.0^{\circ} \mathrm{C} \pm 1^{\circ} \mathrm{C}$ in the PCR buffer, whereas the product for F. graminearum was 280 bp long and had a melting point of $86.5^{\circ} \mathrm{C} \pm 1{ }^{\circ} \mathrm{C}$ (Figure 1 ). A third, wide-shaped peak occasionally occurred between 76 and $82^{\circ} \mathrm{C}$. This originated from "primer dimers" and other unspecific amplification products. These latter products were found particularly in samples with a low concentration of Fusarium DNA. As the result presented in the Figure 1 shows, unspecific products do not prevent the detection of Fusarium DNA in amounts equal to or higher than the limit of detection (Table 2). The nonspecific products in the notemplate control possess a melting point of about $80^{\circ} \mathrm{C}$, which is much lower than the melting temperatures at which Fusarium targets are detected.

Experiments with primer pairs used separately revealed that the unspecific products were produced by primers Fg16N F/R, while primers OPT18 F/R did not generate any unspecific products even in controls with no template DNA.

In contrast to the commonly held view that SYBR Green I binds equally well to all double-stranded DNA sequences, we observed that the F. culmorum product binds the dye more efficiently than the F. graminearum product. Similar differences in the binding affinity of SYBR Green I to different PCR products have been reported by Giglio et al. [20]. Because of this preferential binding of the dye to the F. culmorum product, F. graminearum could not be detected by melting curve analysis in the presence of 100 pg or more of F. culmorum DNA, irrespective of the amount of F. graminearum DNA. Attempts to counteract this effect by increasing the SYBR Green I concentration in the PCR reaction mixture were hampered by the inhibition of the PCR by the dye. Since even the addition of more SYBR Green I after the completion of the PCR did not prevent the suppression of the F. graminearum signal by the F. culmorum DNA (data not shown), we consequently re-optimized the PCR conditions for F. graminearum detection in the presence of 5 and $100 \mathrm{pg} F$. culmorum DNA (see Table 2).

During the re-optimization of the PCR conditions we noticed that increasing the SYBR Green I concentration caused an increase in the melting temperature of the PCR products. Table 3 shows the results of a systematic investigation of this phenomenon for the F. graminearum product. A shift caused by increasing the SYBR Green I concentration from $0.1 \times$ to $0.7 \times$ dilution amounted to as much as $2^{\circ} \mathrm{C}$.

The detection limits of the melting curve analysis are summarized in Table 2. The assay is used for samples with a low amount of total DNA (e.g., DNA extracted from rachides of cereal ears) or when merely one product was expected (e.g. identification of pure cultures or Fusarium spp. isolates). Therefore, we recommend keeping the total amount of Fusarium spp. DNA in the assay under $50 \mathrm{pg}$ when the presence of both species is expected. This can be achieved by employing amounts smaller than 1 ng plant DNA in the reaction or by monitoring the $\mathrm{C}_{\mathrm{T}}$ value which has to be bigger than 20 .

Because the suppression of the F. graminearum signal by $F$. culmorum only occurs when the PCR products are characterized by the melting curve analysis, agarose gels can be used to confirm the interpretation of the melting curves when large amounts of $F$. culmorum DNA are detected. This is characterized by a signal (melting curve maximum) specific for $F$. culmorum and a $\mathrm{C}_{\mathrm{T}}$-values of the whole amplicon smaller than 25 . In our study of 500 wheat sam- 
Table 3: Influence of SYBR Green I concentration on the melting temperature of the PCR product specific for F. graminearum. 50 pg of Fg3 DNA were used as a template for PCR with the primer pair FgI6N F/R in addition to different SYBR Green I concentrations and 3 $\mathrm{mM} \mathrm{MgCl}$. The other parameters were set as described in the Methods.

SYBR Green I concentration in the amplification mix

Melting temperature of the $280 \mathrm{bp}$ PCR product

\begin{tabular}{lll}
\hline $0.1 \times$ & $84.5^{\circ} \mathrm{C}$ \\
$0.2 \times$ & $85.0^{\circ} \mathrm{C}$ \\
$0.3 \times$ & $85.5^{\circ} \mathrm{C}$ \\
$0.4 \times$ & $86.0^{\circ} \mathrm{C}$ \\
$0.7 \times$ & $86.5^{\circ} \mathrm{C}$ \\
\hline
\end{tabular}

ples, no F. graminearum signal was inhibited by F. culmorum DNA (see below).

\section{Data processing}

The form in which the results of the melting curve analysis are provided by real-time thermocyclers has not been designed for automated evaluation or a high-throughput environment. To facilitate the interpretation of the results of a multiplex melting-curve-based PCR analysis, we designed a spreadsheet which transformed the output from the thermocycler into a user-friendly, colorenhanced tabular report. In addition to the presentation of the results, the spreadsheet integrates a convenient plate setup (arrangement of samples in the PCR plate) with a pipetting scheme for the reaction mixtures. The data processing and reporting tool consists of eight spreadsheets in Microsoft Excel 2000 (see Additional file 1).

The first sheet "Plate Setup" can be customized according to the user's needs. The content of the plate setup sheet, including identifiers, is used by the interpretation sheet "Data Analysis". The second sheet "Pipetting Scheme" just helps to calculate pipetting, it does not contain any link to the remaining parts of the file. Raw data from the iCycler are copied into the third and fourth sheets: the $\mathrm{C}_{\mathrm{T}}$ table
("PCR Quantification" menu) is copied into the third Excel sheet called "CT Table" and the Peak table ("Melt curve" menu) is transferred into the fourth Excel sheet designated "Peak Table". These two sheets, together with the identifiers taken from the plate setup, are the basis for the "Data Analysis" sheet which presents the final results. The auxiliary sheet "Adaptation" contains merely some formatting schemes used by the "Data Analysis" sheet, it does not need to be dealt with by the user. The sixth sheet "Print Sheet" is an empty sheet which can be used for print format adjustments by the user after data from the "Data Analysis" sheet has been copied on to it, because editing options are limited within the "Data Analysis" sheet. The final sheet "Manual" consists of a manual describing the use of the spreadsheet. The spreadsheet file can be downloaded from [21].

The information given for each well in the PCR plate consists of a well identifier, $\mathrm{C}_{\mathrm{T}}$ value, melting temperatures, areas under the peaks in the first derivative of the melting curve, and the fraction of the peak area in relation to the total area under the curve (Figure 2). Only these two peaks, corresponding to the products with the highest melting temperatures, are processed. The calculation of the areas under the peaks in the first derivative melting curves is an undocumented feature of the iCycler software:

\begin{tabular}{|c|c|c|c|c|c|c|c|c|c|c|c|c|}
\hline & A1 & \multicolumn{2}{|c|}{$\begin{array}{l}5 \mathrm{pg} \mathrm{Fg} 3+ \\
5 \mathrm{pg} \mathrm{Fc} 3.3\end{array}$} & 2 & \multicolumn{2}{|c|}{$5 \mathrm{pg} \mathrm{Fg} 3$} & 3 & \multicolumn{2}{|c|}{5 pg Fc3.3 } & A4 & \multicolumn{2}{|c|}{$\begin{array}{c}\text { negative } \\
\text { control }\end{array}$} \\
\hline$C_{T}$ & 23.8 & Area & Fraction & 24.3 & Area & Fraction & 24.6 & Area & Fraction & 26.3 & Area & Fraction \\
\hline 1st Peak & 91.5 & 877 & 0.38 & 87.5 & 1326 & 0.58 & 91.5 & 1354 & 0.57 & 80.5 & 623 & 0.85 \\
\hline 2nd Peak & 86.5 & 856 & 0.37 & 79 & 847 & 0.37 & 78 & 1002 & 0.43 & 73.5 & 52 & 0.07 \\
\hline
\end{tabular}

\section{Figure 2}

Section of the interpretation sheet corresponding to 4 wells. Each result consists of a well position, sample identifier, $\mathrm{C}_{\mathrm{T}}$ value, melting temperatures, areas under the melting curve peaks, and fractions of these areas in relation to the total area under the melting curve. The melting data are calculated for the two products with the highest melting temperatures only. Fields are automatically highlighted in a species-specific manner (green: F. culmorum, yellow: F. graminearum) and a warning is issued by a red coloring of the fields when the peak size does not reach the preset absolute and relative minimal values. In addition, if there is an unexpected third melting-curve maximum at temperatures higher than $80^{\circ} \mathrm{C}$ (indicating the presence of additional PCR products from F. culmorum or F. graminearum), the corresponding well will be highlighted in orange to indicate that the user should check the raw data. 
these values are not available within iCycler interface, but they are transferred together with other melting curve data when the table is copied to a spreadsheet via the clipboard. To work with other thermocyclers, the spreadsheet presumably will need to be modified according to the format used to export the melting curves.

The interpretation of the results is facilitated by an automatic highlighting of the important fields: the presence of F. culmorum (melting temperature between 90.0 and $92.0^{\circ} \mathrm{C}$ ) is indicated by green and $F$. graminearum (melting temperature between 85.5 and $87.5^{\circ} \mathrm{C}$ ) is colored yellow. If the peak area or the fraction of the peak area in relation to the total area under the melting curve does not reach the set quality limits (see previous section), the fields will be colored red to warn of potential false positives. These limits can be adjusted centrally in the head of the interpretation sheet, based on the intensity of the signals produced by the DNA standards.

In some cases, there are more than two melting curve maxima at temperatures higher than $80^{\circ} \mathrm{C}$ where the PCR products of $F$. culmorum and F. graminearum are to be expected. In such a rare case, the corresponding well will be marked orange in the interpretation sheet. This is an indication that the raw data should be checked.

\section{Analysis of field samples}

The method was tested by analyzing 500 DNA samples extracted from the rachides of wheat heads with symptoms of FHB sampled throughout Germany in 2003. At least one of the two fungi was identified in all but 21 samples. Both pathogens were detected in 14 rachides. In 398 rachides, only $F$. graminearum could be detected and 67 samples showed only a F. culmorum signal. The latter samples were additionally analyzed for the presence of $F$. graminearum by PCR, in which the F. culmorum-specific primers were omitted to see whether the F. graminearum signals would be suppressed by F. culmorum DNA. This single-target analysis confirmed the results of duplex PCR for all 67 samples, demonstrating that the suppression of the F. graminearum signals by F. culmorum DNA did not occur in any of the 500 samples analyzed.

Therefore, we suggest that a confirmatory analysis (by a single-target PCR or by gel electrophoresis of products of duplex PCR analysis) for samples positive for F. culmorum but not F. graminearum is unnecessary when working with wheat rachides. However, an extra effort for a confirmatory analysis is rather low (13\% of samples in our case). The application of a duplex assay leads to a significant reduction of the sample number as compared to using two separate assays, even when samples positive for F. culmorum and negative for $F$. graminearum are analyzed a second time for confirmation.
A standard method for the taxonomic characterization of field samples regarding their colonization with Fusarium spp. consists of the isolation of pure cultures on PDA plates, growing the isolates for 7 days on SNA plates or carnation leaf agar and the examination of spores in a microscope. An additional taxonomically relevant marker is the color of fungal colonies on PDA plates. We performed this analysis on 10 rachis samples from ears with FHB symptoms. All samples contained F. graminearum, which was confirmed by melting curve analysis-based PCR. In order to verify the PCR method for F. culmorum, we selected from a larger set 10 field samples previously identified as containing F. culmorum by morphological characters and subjected these samples to melting curve analysis-based PCR. All ten samples tested positive for $F$. culmorum.

To compare both methods, morphological taxonomy requires cultivation for at least 12 days followed by timeconsuming microscopic examination. In contrast, the PCR method delivers the results within two days and facilitates parallel processing.

\section{Conclusion}

The method developed in this study allows the simultaneous identification of F. graminearum and F. culmorum in one PCR without the use of doubly labeled hybridization probes or electrophoresis. Species-specific PCR products are differentiated by melting curve analysis. The detection limit for each single species was 5 pg of genomic DNA. An excess of one species impairs the detection limit for the other species due to the competition of the PCR products for binding of the fluorescent dye used for detection. Because F. culmorum products bind SYBR Green I better than F. graminearum products, large amount of F. culmorum DNA impairs the detection of $F$. graminearum. This effect was partially compensated for by increasing the dye concentration. This competition for dye binding does not play a significant role as long as the amount of F. culmorum DNA is low. The assay described in this study is suitable for fast and cost-effective analysis of a large number of samples for the presence of F. culmorum and F. graminearum. It will be particularly useful in epidemiological studies, as exemplified by the investigation of a large collection of rachides isolated from wheat ears exhibiting symptoms of FHB.

\section{Methods \\ Fungal cultures}

The fungal strains used are listed in Table 1. The fungal cultures were maintained at $10^{\circ} \mathrm{C}$ on SNA medium $(0.5 \mathrm{~g}$ $\mathrm{l}^{-1} \mathrm{MgSO}_{4} \times 7 \mathrm{H}_{2} \mathrm{O}, 1 \mathrm{~g} \mathrm{l}^{-1} \mathrm{KNO}_{3}$ (Roth, Karlsruhe, Germany), $0.2 \mathrm{~g} \mathrm{l}^{-1}$ sucrose, $0.2 \mathrm{~g} \mathrm{l}^{-1}$ glucose, $0.5 \mathrm{~g} \mathrm{l}^{-1} \mathrm{KCl}, 1 \mathrm{~g}$ $\mathrm{l}^{-1} \mathrm{KH}_{2} \mathrm{PO}_{4}$ and $15 \mathrm{~g} \mathrm{l}^{-1}$ agar (Merck, Darmstadt, Germany)). The Fusarium spp. cultures for DNA extraction 
were grown for 10 days in $100 \mathrm{ml}$ Potato Dextrose Broth (PDB, $24 \mathrm{~g} \mathrm{l}^{-1}$; Scharlau, Barcelona, Spain). The fungal mycelium was harvested by filtration and freeze-dried.

\section{DNA isolation from pure fungal cultures grown in liquid media}

We used a variant of the CTAB method [22], simplified by others [e.g. [23]], and modified in our laboratory as follows. The lyophilized mycelium (200 mg) was pulverized in a mortar with a small amount of sand (Riedel-de Haen, Hanover, Germany). The ground mycelium was transferred into a 50-ml centrifugation tube containing $10 \mathrm{ml}$ of TES buffer (100 mM Tris (Roth, Karlsruhe, Germany), 20 mM EDTA (Merck, Darmstadt, Germany), 1\% (w/v) SDS (Biomol, Hamburg, Germany), pH set to 8.0 with HCL) and $4 \mathrm{mg}$ proteinase K (Merck, Darmstadt, Germany). The lysis mixture was incubated at $45^{\circ} \mathrm{C}$ for 45 min and the content of the tubes was mixed thoroughly by turning the tubes every $10 \mathrm{~min}$. Subsequently, $3.9 \mathrm{ml}$ of $5 \mathrm{M} \mathrm{NaCl}$ (Fluka, Buchs, Switzerland) were added and the sample was mixed before adding $1.4 \mathrm{ml}$ of $10 \%(\mathrm{w} / \mathrm{v})$ cetyltrimethylammonium bromide (CTAB, Merck, Darmstadt, Germany). The samples were incubated for $10 \mathrm{~min}$ at $65^{\circ} \mathrm{C}$, cooled in an ice/water bath, and then $10 \mathrm{ml}$ chloroform-isoamyl alcohol (24:1, Roth, Karlsruhe, Germany) were added. After mixing the emulsion thoroughly, the tubes were kept over night in an ice/water-bath. The upper phase (including a small part of the lower phase) was transferred into another centrifugation tube by pipetting and spun for $20 \mathrm{~min}$ at $4,000 \mathrm{~g}\left(5^{\circ} \mathrm{C}\right)$. The watery phase was transferred to a new tube containing $10 \mathrm{ml}$ isopropanol (Roth, Karlsruhe, Germany) at room temperature, mixed thoroughly and centrifuged for $10 \mathrm{~min}$ at $4,000 \mathrm{~g}$ and room temperature. The supernatant was decanted and the pellet was rinsed with 70\% (v/v) ethanol (Roth, Karlsruhe, Germany), dried and dissolved in $4.5 \mathrm{ml} \mathrm{TE}$ (10 mM Tris, $1 \mathrm{mM}$ EDTA, pH set to 8.0 with $\mathrm{HCl}$ ). In spite of the large volume of buffer used to dissolve the DNA, the process took $6 \mathrm{~h}$ or longer in some extractions. Dissolving the pellet can be speeded up by heating the tubes to $40^{\circ} \mathrm{C}$ and then mechanically destroying the pellet. Undissolved material was removed by centrifugation; the DNA was concentrated by ethanol precipitation (1/10 vol. of $5 \mathrm{M}$ ammonium acetate (Merck, Darmstadt, Germany) and 2.5 vol. of $96 \%$ (v/v) ethanol) and dissolved in $0.5 \mathrm{ml}$ TE. The quality and quantity of DNA were assessed by electrophoresis in $0.8 \%(\mathrm{w} / \mathrm{v})$ agarose gels (Cambrex, Rockland, ME, USA) prepared in TAE buffer (40 mM Tris, $1 \mathrm{mM}$ EDTA, pH set to 8.5 with acetic acid, Riedel-de Haen, Hanover, Germany). The electrophoresis was carried out at $4 \mathrm{~V} \mathrm{~cm}^{-1}$ for $60 \mathrm{~min}$. Double-stranded DNA was stained with ethidium (ethidium bromide, $2 \mathrm{mg}$ $\mathrm{l}^{-1}$ ), (Applichem, Darmstadt, Germany). The gels were documented with the help of a digital imaging system (Vilber Lourmat, Marne la Vallee, France). Densitometry values were compared with those of Lambda Phage DNA (methylated, from Escherichia coli host strain W3110, Sigma, Taufkirchen, Germany). The densitometry was performed using Multi Analyst-Software (BioRad, Hercules, CA, USA).

\section{Isolation of fungi from wheat rachides}

To identify the infectious agent causing the FHB, rachides of symptomatic heads were isolated and dissected into pieces spanning 2-3 segments of the spike axis. The rachis samples were rinsed with tap water and surface-sterilized by incubating for $3 \mathrm{~min}$ in $3 \%(\mathrm{v} / \mathrm{v})$ sodium hypochlorite solution (Roth, Karlsruhe, Germany). They were then dried, inserted into agar in PDA-plates (PDB $+1.5 \%(\mathrm{w} / \mathrm{v})$ agar) and incubated at $20^{\circ} \mathrm{C}$ for 3-5 days. The mycelia growing out of the rachides were preserved by freezing in $15 \%$ (v/v) glycerol (Roth, Karlsruhe, Germany) at $-80^{\circ} \mathrm{C}$.

\section{DNA extraction from plant material}

The rachides were dried at $60^{\circ} \mathrm{C}$ over night and a single section (2-3 segments) was ground in a ball mill (Mixer Mill MM 200, Retsch, Haan, Germany) in a stainless steel container with a 20-mm, 32-g steel sphere (Retsch, Haan, Germany) for $30 \mathrm{~s}$ at maximum speed. The milling container was rinsed with $1.4 \mathrm{ml}$ CTAB-buffer ( $10 \mathrm{mM}$ Tris, 20 mM EDTA, 0.02 M CTAB, 0.8 M NaCl, 0.03 M N-laurylsarcosine (Fluka, Buchs, Switzerland), $0.13 \mathrm{M}$ sorbitol, $1 \%(\mathrm{w} / \mathrm{v})$ polyvinylpolypyrolidone, $\mathrm{pH}$ set to 8.0 with $\mathrm{NaOH}$ (Merck, Darmstadt, Germany). Two $\mu$ l mercaptoethanol (Fluka, Buchs, Switzerland) and $20 \mu \mathrm{g}$ proteinase $\mathrm{K}$ (from a stock solution $20 \mathrm{mg} / \mathrm{ml}$ ) were added shortly before use and the mixture was transferred to a 2$\mathrm{ml}$ tube. After an initial incubation period of $10 \mathrm{~min}$ at $42^{\circ} \mathrm{C}$ and a second incubation for $10 \mathrm{~min}$ at $65^{\circ} \mathrm{C}$, during which the content of the tubes was mixed each $3 \mathrm{~min}, 0.8$ $\mathrm{ml}$ of chloroform-isoamyl alcohol (24:1) were added. The samples were then thoroughly emulsified and centrifuged for $10 \mathrm{~min}$ at $5,000 \mathrm{~g}$ at room temperature. $750 \mu \mathrm{l}$ of the upper phase were transferred to a $1.5-\mathrm{ml}$ tube containing $500 \mu \mathrm{l}$ isopropanol, mixed, incubated for $20 \mathrm{~min}$ at room temperature and centrifuged for $15 \mathrm{~min}$ at $15,000 \mathrm{~g}$ at room temperature. The pellet was washed with $70 \%(\mathrm{v} / \mathrm{v})$ ethanol, dried and dissolved in $200 \mu \mathrm{l} \mathrm{TE}$. To ensure that the DNA was dissolved completely, the sediment covered by the TE buffer was incubated over night at $4{ }^{\circ} \mathrm{C}$. The quality and concentration of DNA were assessed by agarose electrophoresis as described above.

\section{DNA extraction from the mycelia grown on agar plates}

To extract the DNA from a mycelium growing on the surface of a small agar plaque, the protocol for plant material (see above) was slightly modified. At the beginning of the procedure, the agar plaque was homogenized with $1 \mathrm{ml}$ CTAB-buffer in a reciprocal mill in a $2-\mathrm{ml}$ tube with 9 wolfram carbide spheres (diameter $3 \mathrm{~mm}$, Retsch, Haan, 
Germany). At the end of the procedure, the DNA was dissolved in $100 \mu \mathrm{l}$ TE-buffer. A 1:100-dilution was used in the PCR.

\section{PCR amplification}

The iCycler System (BioRad, Hercules, CA, USA) was used for amplification and melting curve analysis. Primers Fg16N F (ACAGATGACAAGATTCAGGCACA) and Fg16N $\mathrm{R}$ (TTCTTTGACATCTGTTCAACCCA) were used to amplify a $280 \mathrm{bp}$ fragment specific for $F$. graminearum [14]. Primers OPT18 F (GATGCCAGACCAAGACGAAG) and OPT18 R (GATGCCAGACGCACTAAGAT) served to multiply a 472 bp fragment specific for F. culmorum [13]. All the primers were synthesized by Operon Biotechnologies (Cologne, Germany). Both primer pairs Fg16N F/R and OPT18 F/R were derived from randomly amplified genomic fragments, the function of target sequences is unknown.

The amplification mix consisted of $1 \times \mathrm{NH}_{4}$-reaction buffer (diluted from $10 \times \mathrm{NH}_{4}$-reaction buffer: $160 \mathrm{mM}$ $\left(\mathrm{NH}_{4}\right)_{2} \mathrm{SO}_{4}, 670 \mathrm{mM}$ Tris-HCl, 0.1\% (v/v) Tween-20, pH 8.8 at $25^{\circ} \mathrm{C}$, Bioline, Luckenwalde, Germany), $5 \mathrm{mM}$ $\mathrm{MgCl}_{2}$ (Bioline, Luckenwalde, Germany), $0.2 \mathrm{mM}$ of each dATP, dTTP, dCTP and dGTP (Bioline, Luckenwalde, Germany), $0.3 \mu \mathrm{M}$ of each primer, $0.7 \mathrm{u}$ BIOTaq DNA polymerase (Bioline, Luckenwalde, Germany), $10 \mathrm{nM}$ Fluorescein (BioRad, Hercules, CA, USA, diluted from 1 $\mu \mathrm{M}$ in $1 \times \mathrm{NH}_{4}$-reaction buffer, to collect well factors, specific for the iCycler), $0.4 \times$ SYBR Green I solution (Invitrogen, Karlsruhe, Germany), $1 \mu$ of template DNA and $\mathrm{ddH}_{2} \mathrm{O}$ up to $25 \mu \mathrm{l}$. The detection of amplification products, based on the fluorescence of SYBR Green I, was performed with filters set at $490 \pm 10 \mathrm{~nm}$ for excitation and $530 \pm 15 \mathrm{~nm}$ for emission.

The PCR was performed with the following cycling protocol. Initial denaturation for $1.5 \mathrm{~min}$ at $95^{\circ} \mathrm{C}$ (the denaturation time is used by the thermocycler to collect data for the calculation of the well correction factors, which is needed to compensate for differences among wells of the microtitre plate) was followed by 35 cycles with $30 \mathrm{~s}$ at $94^{\circ} \mathrm{C}, 45 \mathrm{~s}$ at $64^{\circ} \mathrm{C}$, and $45 \mathrm{~s}$ at $72^{\circ} \mathrm{C}$. The final elongation was performed for $5 \mathrm{~min}$ at $72^{\circ} \mathrm{C}$. During the PCR, the detection of fluorescence was carried out in the annealing step of each cycle. Following amplification, the melting curves were acquired by heating the samples to $95^{\circ} \mathrm{C}$ for $1 \mathrm{~min}$, cooling to $55^{\circ} \mathrm{C}$ for one min and then slowly increasing the temperature from $65^{\circ} \mathrm{C}$ to $95^{\circ} \mathrm{C}$ at the rate

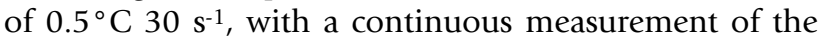
fluorescence.

When an electrophoretic analysis of PCR products was necessary, $4 \mu \mathrm{l}$ of the reaction mixture were combined with $2 \mu \mathrm{l}$ of loading buffer (100 mM EDTA, 50\% (v/v)
Glycerol, 0.025\% (w/v) bromphenol-blue, Merck, Darmstadt, Germany) and loaded on a $1.7 \%(\mathrm{w} / \mathrm{v})$ agarose gel prepared in TAE buffer. The electrophoresis and the documentation were carried out as described above.

\section{Data analysis}

Sample identifiers, $\mathrm{C}_{\mathrm{T}}$ values (threshold cycles) and the results of the melting curve analysis were exported from the thermocycler into the pre-formatted Excel spreadsheets, which facilitated the automatic data processing and reporting (see Additional file 1). The Excel file can be downloaded from [21], its structure and function is described in detail in the Data Processing paragraph of the Results section.

\section{Authors' contributions}

$\mathrm{CB}$ carried out the experiments, designed the spreadsheets and drafted parts of the manuscript. PK conceived and guided the study, and wrote parts of the manuscript. Both authors read and approved the final version of the manuscript.

\section{Additional material}

\section{Additional File 1}

DuplexPCRFusarium. The pre-formatted Excel spreadsheet facilitates automatic data processing and reporting. In short, data concerning the two largest maxima identified on the first derivative of each melting curve are processed as follows: the size of the peaks are checked against pre-set minimal values, the melting temperatures are compared with values expected for both species-specific PCR products, and the final results are presented in a tabular report.

Click here for file

[http://www.biomedcentral.com/content/supplementary/14712180-6-4-S1.xls]

\section{Acknowledgements}

We thank Joachim Weinert for providing us with the plant material and for his continuing support and discussions. The authors acknowledge the International PhD Program for the Agricultural Sciences in Göttingen for supporting the first correction of the manuscript and Margaret Nemec-Groth for proofreading the revised manuscript. The work was funded by a grant from the German Federal Ministry of Consumer Protection, Food and Agriculture (Grant No. 02 HS 023).

\section{References}

I. Parry DW, Jenkinson P, McLeod L: Fusarium ear blight (scab) in small grain cereals - A review. Plant Pathology 1995, 44:207-238.

2. Pieters MN, Freijer J, Baars BJ, Fiolet DCM, van Klaveren J, Slob W: Risk assessment of deoxynivalenol in food: Concentration limits, exposure and effects. In Mycotoxins and Food Safety Volume 504. New York: Kluwer Academic/Plenum Publ; 2002:235-248.

3. Peraica M, Radic B, Lucic A, Pavlovic M: Toxic effects of mycotoxins in humans. Bulletin of the World Health Organization 1999 , 77:754-766.

4. D'Mello JPF, Placinta CM, Macdonald AMC: Fusarium mycotoxins: a review of global implications for animal health, welfare and productivity. Animal Feed Science and Technology 1999, 80: I83-205. 
5. Anonymous: Verordnung über Höchstmengen an Mykotoxinen in Lebensmitteln (Mykotoxin-Höchstmengenverordnung - MHmV). In Bundesgesetzblatt Volume I. Bonn: Bundesanzeiger Verlagsges.m.b.H; 1999: I248-I25I.

6. Anonymous: Verordnung zur Änderung der Mykotoxin-Höchstmengenverordnung und der Diätverordnung. In Bundesgesetzblatt Volume I. Bonn: Bundesanzeiger Verlagsges.m.b.H; 2004:15I-152.

7. Pirgozliev SR, Edwards SG, Hare MC, Jenkinson P: Strategies for the control of Fusarium head blight in cereals. European Journal of Plant Pathology 2003, 109:731-742.

8. Waalwijk C, Kastelein P, de Vries I, Kerenyi Z, van der Lee T, Hesselink T, Kohl J, Kema G: Major changes in Fusarium spp. in wheat in the Netherlands. European Journal of Plant Pathology 2003, 109:743-754

9. Xu XM: Effects of environmental conditions on the development of Fusarium ear blight. European Journal of Plant Pathology 2003, 109:683-689.

10. Snijders CHA: Systemic fungal growth of Fusarium culmorum in stems of winter wheat. Journal of Phytopathology - Phytopathologische Zeitschrift 1990, 129: I33-140

11. Bottalico A, Perrone G: Toxigenic Fusarium species and mycotoxins associated with head blight in small-grain cereals in Europe. European Journal of Plant Pathology 2002, 108:6 I I-624.

12. Nicholson P, Chandler E, Draeger RC, Gosman NE, Simpson DR, Thomsett M, Wilson AH: Molecular tools to study epidemiology and toxicology of Fusarium head blight of cereals. European Journal of Plant Pathology 2003, 109:691-703.

13. Schilling AG, Moller EM, Geiger HH: Polymerase chain reactionbased assays for species-specific detection of Fusarium culmorum, F. graminearum, and F. avenaceum. Phytopathology 1996, 86:515-522.

14. Nicholson P, Simpson DR, Weston G, Rezanoor HN, Lees AK, Parry DW, Joyce D: Detection and quantification of Fusarium culmorum and Fusarium graminearum in cereals using PCR assays. Physiological and Molecular Plant Pathology 1998, 53:17-37.

15. Edwards SG, O'Callaghan J, Dobson ADW: PCR-based detection and quantification of mycotoxigenic fungi. Mycological Research 2002, 106: 1005-1025.

16. Reischer GH, Lemmens M, Farnleitner A, Adler A, Mach RL: Quantification of Fusarium graminearum in infected wheat by species specific real-time PCR applying a TaqMan Probe. Journal of Microbiological Methods 2004, 59: I4I- 146.

17. Reischer GH, Lemmens M, Farnleitner A, Adler A, Mach RL: Erratum to "Quantification of Fusarium graminearum in infected wheat by species specific real-time PCR applying a TaqMan probe" [J. Microbiol. Methods 59 (2004) I4I-146]. Journal of Microbiological Methods 2004, 59:437-437.

18. Schena L, Nigro F, Ippolito A, Gallitelli D: Real-time quantitative PCR: a new technology to detect and study phytopathogenic and antagonistic fungi. European Journal of Plant Pathology 2004, I 1 0:893-908

19. McCartney HA, Foster SJ, Fraaije BA, Ward E: Molecular diagnostics for fungal plant pathogens. Pest Management Science 2003, 59:129-142.

20. Giglio S, Monis PT, Saint CP: Demonstration of preferential binding of SYBR Green I to specific DNA fragments in realtime multiplex PCR. Nucleic Acids Research 2003, 31:

21. Downloads Petr Karlovsky group [http://www.gwdg.de/ inst phyt/karlovsky/downloads/DuplexPCRFusarium.xls]

22. Murray MG, Thompson WF: Rapid isolation of high molecularweight plant DNA. Nucleic Acids Research 1980, 8:4321-4325.

23. Stewart CN, Via LE: A rapid CTAB DNA isolation technique useful for rapid fingerprinting and other PCR applications. Biotechniques 1993, 14:748.

Publish with Biomed Central and every scientist can read your work free of charge

"BioMed Central will be the most significant development for disseminating the results of biomedical research in our lifetime. "

Sir Paul Nurse, Cancer Research UK

Your research papers will be:

- available free of charge to the entire biomedical community

- peer reviewed and published immediately upon acceptance

- cited in PubMed and archived on PubMed Central

- yours - you keep the copyright
BioMedcentral 


\title{
Chapter 3: Cost-effective quantification of Fusarium culmorum and F. graminearum in plant material by real-time PCR
}

Christoph Brandfass, Petr Karlovsky

\begin{abstract}
Brandfass, C., Karlovsky, P. 2006. Cost-effective quantification of Fusarium culmorum and F. graminearum in plant material by real-time PCR.
\end{abstract}

We describe a real-time PCR-based method for the quantification of F. culmorum and F. graminearum in plant material. After a CTAB-based DNA-extraction, species-specific DNA fragments are amplified by PCR. The kinetics of the amplification is monitored with the help of the fluorescent dye SYBR Green I which intercalates into doublestranded DNA. We demonstrate that real-time PCR with product quantification by SYBR Green fluorescence offers a cost-effective alternative to the use of doubly labeled hybridization probes for the quantitative analysis of F. culmorum and F. graminearum biomass in plant material. This method is particularly suitable for epidemiological studies involving a large number of samples.

Additional keywords: assay, corn, Gibberella zeae, ear blight, epidemiology, head blight, maize debris, small-grain cereals, wheat scab.

\section{Introduction}

Fusarium head blight (FHB) is a disease of cereal crops with a severe impact on wheat and barley production worldwide. The infection of heads of small grain cereals and maize plants with Fusarium spp. impairs both grain yield and quality (Leonard and Bushnell, 2003; Parry et al., 1995). Apart from adversely effecting the grain size, weight, protein content, baking quality of the flour, and other technological parameters, the most serious consequence of FHB is the contamination of grain and cereal products with Fusarium mycotoxins (Pieters et al., 2002; Peraica et al., 1999). Because grains of low quality are used in feedstuff production rather than for human foods, health damage in 
farm animals and losses in meat production caused by mycotoxin contamination of feeds have regularly been reported in the last decades (D'Mello et al., 1999). Concerning the impact of mycotoxins on human health, our understanding of the effects of low doses consumed over prolonged time periods or the whole life span is poor because of technical difficulties in addressing these issues in epidemiological studies (Pestka and Smolinski, 2005). Two trichothecene mycotoxins produced by Fusarium spp. are listed among small-molecular toxins regarded as global bioterrorist threat agents (Ecker et al., 2005). While the EU is still in the process of developing legal limits for Fusarium mycotoxins in grains, food and feeds, many countries have already established national limits (Anonymous, 2004; Anonymous, 1999; D'Mello et al., 1999).

In spite of breeding efforts aiming at FHB-resistant cultivars (Bai and Shaner, 2004; Snijders, 2004) and prioritization of fungicide development towards FHB, the disease continues to pose a major challenge to grain growers all over the world (Pirgozliev et al., 2003). A key prerequisite for FHB reduction through crop management is to understand the epidemiology of the disease. Fusarium species primarily involved in FHB are F. graminearum and F. culmorum (Waalwijk et al., 2003). The biology and the infection mode of these two species differ: F. graminearum reaches cereal heads via ascospores forcibly discharged from asci formed on plant residues on the soil surface, while F. culmorum does not possess a sexual cycle. F. culmorum presumably reaches the ears by traversing from one leave to the next in rain splashes $(\mathrm{Xu}, 2003)$, but some researchers find this hypothesis unsatisfactory. A speculation that F. culmorum and possibly also $F$. graminearum can infect cereal plants systemically and grow within the stem from the root up to the ear has been revived repeatedly in recent years, but it has not been proven so far (Snijders, 1990).

Another important question in FHB epidemiology is whether species other than F. graminearum and F. culmorum contribute significantly to the symptoms of FHB and mycotoxin contamination. A number of fungal species have been isolated from infected or even healthy-looking ears collected in the field, including a plethora of Fusarium spp. (Nicholson et al., 2003; Bottalico and Perrone, 2002; Parry et al., 1995), but it is not known whether all these species actively contribute to the FHB or whether they just grow saprophytically in dead tissues on the ear surface. These are normally removed during grain cleaning and processing.

Deoxynivalenol (DON) and nivalenol (NIV) are the major representatives of trichothecene mycotoxins in grain. The level of trichothecenes and the amount of 
F. culmorum and F. graminearum DNA correlate well, indicating that these two species are largely responsible for the presence of the trichothecenes. The correlation coefficient for DON and DNA content were reported to be 0.68 (Nicholson et al., 2003) and 0.82 (Waalwijk et al., 2004) for the sum of F. culmorum and F. graminearum DNA, and 0.96 or 0.75 (depending on the concentration range) for Fusarium species containing biosynthetic genes for DON (Schnerr et al., 2002).

The relative contribution of each Fusarium species to the disease in a particular situation depends upon a range of variables, which might also affect the amount of mycotoxins produced. It is desirable to know the identity and amount of each pathogen within the host tissues (Nicholson et al., 2003). For example, quantitative analysis of a large number of samples in a species-specific manner is required for the evaluation of the relationship between fungal biomass and DON contamination, and for the assessment of the virulence of fungal species and isolates.

PCR is the method of choice for species-specific detection of fungi in plant material (Martin and Rygiewicz, 2005). Amplification products are traditionally separated by electrophoresis, which does not allow for the quantitative analysis of template DNA (Schena et al., 2004; McCartney et al., 2003). Quantification of DNA template can be achieved by competitive PCR, based on internal standards, which are amplified with the same primer pair as the investigated DNA. The ratio of the intensities of the two products serves as a measure of the amount of the template. Paul Nicholson's group developed competitive PCR assays for several Fusarium species (Nicholson et al., 1998) and used them successfully in a series of projects, among others to address the effects of fungicides on DON production. However, competitive PCR never took off as a routine method in epidemiology because it is labor-intensive and has a limited throughput.

Real-time PCR allows species-specific quantification within a range of several orders of magnitude and is capable of processing several hundred samples per instrument per day. Reliable species-specific PCR primers are known for all FHB-relevant species (Reischer et al., 2004a; Reischer et al., 2004b; Nicholson et al., 2003; Edwards et al., 2002; Nicholson et al., 1998; Schilling et al., 1996).

Existing real-time PCR methods for Fusarium spp. are based on the TaqMan technology and commercial DNA extraction kits. Here we describe a combination of an upscaled DNA extraction protocol reducing the sampling error with inexpensive real-time PCR assays for F. culmorum and F. graminearum based on SYBR Green I fluorescence detection. The protocol is particularly useful in epidemiological studies, as we 
demonstrated in an investigation of the colonization of a large number of wheat samples by F. culmorum and F. graminearum.

\section{Materials and Methods}

\section{Fungal cultures}

The fungal strains we used are listed in Table 1 . Cultures were maintained at $10^{\circ} \mathrm{C}$ on SNA medium $\left(0.5 \mathrm{~g} \mathrm{l}^{-1} \mathrm{MgSO}_{4} \times 7 \mathrm{H}_{2} \mathrm{O}, 1 \mathrm{~g} \mathrm{l}^{-1} \mathrm{KNO}_{3}, 0.2 \mathrm{~g} \mathrm{l}^{-1}\right.$ sucrose, $0.2 \mathrm{~g} \mathrm{l}^{-1}$ glucose, $0.5 \mathrm{~g} \mathrm{l}^{-1} \mathrm{KCl}, 1 \mathrm{~g} \mathrm{l}^{-1} \mathrm{KH}_{2} \mathrm{PO}_{4}$ and $15 \mathrm{~g} \mathrm{l}^{-1}$ agar). The Fusarium spp. cultures for DNA extraction were grown for 10 days in $100 \mathrm{ml}$ potato dextrose broth (PDB, $24 \mathrm{~g} \mathrm{l}^{-1}$ ); mycelium was harvested by filtration and freeze-dried.

Table 1: Fungal strains used in the present study. Sources and origins of isolates are listed in Brandfass and Karlovsky (2006).

\begin{tabular}{|l|c|}
\hline Species & Number of Isolates \\
\hline Alternaria alternata & 2 \\
\hline Cladosporium herbarum & 1 \\
\hline Drechslera sorokiniana & 5 \\
\hline Fusarium acuminatum & 2 \\
\hline Fusarium avenaceum & 1 \\
\hline Fusarium compactum & 3 \\
\hline Fusarium crookwellense & 12 \\
\hline Fusarium culmorum & 5 \\
\hline Fusarium equiseti & 12 \\
\hline Fusarium graminearum & 1 \\
\hline Fusarium oxysporum & 2 \\
\hline Fusarium poae & 5 \\
\hline Gibberella fujikuroi & 1 \\
\hline Microdochium nivale var. majus & 3 \\
\hline Microdochium nivale var. nivale & 1 \\
\hline Pseudocercosporella herpotrichoides & 2 \\
\hline Pseudocercosporella herpotrichoides var. acuformis & 3 \\
\hline Rhizoctonia cerealis & 1 \\
\hline Stagonospora nodorum & \\
\hline
\end{tabular}




\section{DNA isolation from pure fungal cultures grown in liquid media}

We used a variant of the CTAB method (Murray and Thompson, 1980), simplified by others (e.g. Stewart and Via, 1993), and modified in our laboratory as follows. The lyophilized mycelium (200 mg) was pulverized in a mortar with a small amount of silica sand. The ground mycelium was transferred into a 50-ml centrifugation tube containing $10 \mathrm{ml}$ of TES buffer (100 mM Tris, $20 \mathrm{mM}$ EDTA, 1\% (w/v) SDS, pH set to 8.0 with $\mathrm{HCL}$ ) and $4 \mathrm{mg}$ proteinase $\mathrm{K}$. The lysis mixture was incubated at $45^{\circ} \mathrm{C}$ for $45 \mathrm{~min}$ and the content of the tubes was mixed by turning the tubes every $10 \mathrm{~min}$. Subsequently, 3.9 $\mathrm{ml}$ of $5 \mathrm{M} \mathrm{NaCl}$ were added and the sample was mixed before adding $1.4 \mathrm{ml}$ of $10 \%$ (w/v) cetyltrimethylammonium bromide (CTAB, Merck, Darmstadt, Germany). The samples were incubated for $10 \mathrm{~min}$ at $65^{\circ} \mathrm{C}$, cooled in an ice/water bath, and then $10 \mathrm{ml}$ chloroform-isoamyl alcohol (24:1) were added. After mixing the emulsion thoroughly, the tubes were kept over night in an ice/water-bath. The upper phase (including a small part of the lower phase) was transferred into another centrifugation tube by pipetting and spun for $20 \mathrm{~min}$ at $4,000 \mathrm{~g}\left(5^{\circ} \mathrm{C}\right)$. The aqueous phase was transferred to a new tube containing $10 \mathrm{ml}$ isopropanol at room temperature, mixed thoroughly and centrifuged for $10 \mathrm{~min}$ at 4,000 $\mathrm{g}$ and room temperature. The supernatant was decanted and the pellet was rinsed with 70\% (v/v) ethanol, dried and dissolved in $4.5 \mathrm{ml} \mathrm{TE} \mathrm{(10} \mathrm{mM} \mathrm{Tris,} 1 \mathrm{mM}$ EDTA, $\mathrm{pH}$ set to 8.0 with $\mathrm{HCl}$ ). In spite of the large volume of buffer used to dissolve the DNA, the process took $6 \mathrm{~h}$ or longer in some extractions. Dissolving the pellet can be speeded up by heating the tubes to $40^{\circ} \mathrm{C}$ and then mechanically destroying the pellet. Undissolved material was removed by centrifugation; the DNA was concentrated by ethanol precipitation (1/10 vol. of $5 \mathrm{M}$ ammonium acetate and 2.5 vol. of $96 \%(\mathrm{v} / \mathrm{v})$ ethanol) and dissolved in $0.5 \mathrm{ml} \mathrm{TE}$. Quality and quantity of DNA were assessed by electrophoresis in $0.8 \%(\mathrm{w} / \mathrm{v})$ agarose gels (Cambrex, Rockland, ME, USA) prepared in TAE buffer (40 mM Tris, $1 \mathrm{mM}$ EDTA, $\mathrm{pH}$ set to 8.5 with acetic acid). The electrophoresis was carried out at $4 \mathrm{~V} \mathrm{~cm}^{-1}$ for $60 \mathrm{~min}$. Double-stranded DNA was stained with ethidium (ethidium bromide, $2 \mathrm{mg}^{-1}$ ). Gels were documented with the help of a digital imaging system (Vilber Lourmat, Marne la Vallee, France). Densitometry values were compared with those of lambda phage DNA (methylated, from Escherichia coli host strain W3110). The densitometry was performed using Multi Analyst-Software (BioRad, Hercules, CA, USA). 


\section{Preparation of plant samples}

Wheat grain samples (88-92\% dry matter) were separated from the chaff by airflow and sieve cleaning with a stationary threshing machine, especially to remove rachides and glumes. Subsequently 500 g-portions of grain were ground in a cross hammer mill (Cross Beater Mill SK 1, bottom sieve $2 \mathrm{~mm}$, Retsch, Haan, Germany), the flour was mixed and a $40 \mathrm{~g}$ sub-sample was frozen at $-20^{\circ} \mathrm{C}$.

Maize debris meal was prepared by drying basal stems without leaves (pieces spanning 20 to $30 \mathrm{~cm}$ upwards the onset of the adventitious roots) to $88-92 \%$ dry matter. Then the samples were chaffed and ground with the cross hammer mill, bottom sieve $2 \mathrm{~mm}$, before sub-samples were frozen at $-20^{\circ} \mathrm{C}$.

\section{Quantitative DNA extraction from plant material}

To extract DNA from ground plant samples, $1 \mathrm{~g}$ of wheat flour or $500 \mathrm{mg}$ of maize debris flour were blended in a $50 \mathrm{ml}$-tube with $10 \mathrm{ml} \mathrm{CTAB-buffer}(10 \mathrm{mM}$ Tris, $20 \mathrm{mM}$ EDTA, $0.02 \mathrm{M} \mathrm{CTAB,} 0.8 \mathrm{M} \mathrm{NaCl}, 0.03 \mathrm{M}$ N-laurylsarcosine, $0.13 \mathrm{M}$ sorbitol, 1\% (w/v) polyvinylpolypyrolidone (Merck, Darmstadt, Germany), $\mathrm{pH}$ set to 8.0 with $\mathrm{NaOH}$. Twenty microliters mercaptoethanol and $0.2 \mathrm{mg}$ proteinase $\mathrm{K}$ (from a stock solution 20 $\mathrm{mg} \mathrm{ml}^{-1}$ ) were added shortly before use. The mixture was treated for $5 \mathrm{sec}$ in an ultrasonic bath (Sonorex RK 100, Bandelin, Berlin, Germany). After an initial incubation period of $10 \mathrm{~min}$ at $42^{\circ} \mathrm{C}$ and a second incubation for $10 \mathrm{~min}$ at $65^{\circ} \mathrm{C}$, during which the content of the tubes was mixed every $3 \mathrm{~min}, 8 \mathrm{ml}$ of chloroform-isoamyl alcohol (24:1) were added. The samples were then thoroughly emulsified, incubated for $10 \mathrm{~min}$ on ice and centrifuged for $10 \mathrm{~min}$ at 5,000 $\mathrm{g}$ at room temperature. Six hundred microliters of the upper phase were transferred to a 1.5-ml tube containing $194 \mu \mathrm{l}$ of a $30 \%$ (w/v) PEG (Serva, Heidelberg, Germany) solution and $100 \mu 15 \mathrm{M} \mathrm{NaCl}$, mixed, and centrifuged for $15 \mathrm{~min}$ at $15,000 \mathrm{~g}$ at room temperature. The pellet was washed with $70 \%(\mathrm{v} / \mathrm{v})$ ethanol, dried and dissolved in $200 \mu 1$ TE. To ensure that the DNA was dissolved completely, the sediment covered by the TE buffer was incubated over night at $4{ }^{\circ} \mathrm{C}$. The quality and concentration of DNA were assessed by agarose electrophoresis as described above. A 1:10-dilution was used in the PCR.

\section{Preparation of standards for quantitative real-time PCR}

DNA standards and DNA from unknown samples have to be amplified under identical conditions. Therefore, quantified standard-DNA of Fusarium spp. was mixed with DNA extracted from uncontaminated wheat flour to imitate matrix effects. A dilution series 
from $0.5 \mathrm{pg}$ to $0.5 \mathrm{ng}$ of Fusarium spp. DNA with a dilution factor of 10 was produced separately for F. culmorum and F. graminearum DNA in the matrix of plant DNA. For each pathogen two standard curves were set up, one for wheat flour and one for maize debris. In addition to the standard curve, two negative controls were processed in each PCR set, one containing no template (water) and one containing $50 \mathrm{pg}$ of the other Fusarium species (e.g. F. graminearum for F. culmorum analysis) mixed with DNA of a healthy plant. In Table 2 the standards for the quantification of F. culmorum in wheat flour are shown as an example.

Table 2: Standards for the quantification of F. culmorum DNA in wheat flour samples. Fungal DNA of the strains Fusarium graminearum CBS 389.62 (Fg7.1) and Fusarium culmorum DSM 62191 (Fc1) was used as standards.

\begin{tabular}{|c|c|c|c|c|c|c|}
\hline $\begin{array}{c}\text { Sample } \\
\text { type }\end{array}$ & \multicolumn{2}{|c|}{ Negative controls } & \multicolumn{4}{|c|}{ Standards } \\
\hline $\begin{array}{c}\text { Sample } \\
\text { No. }\end{array}$ & 1 & 2 & $3-4$ & $5-6$ & $7-8$ & $9-10$ \\
\hline $\begin{array}{c}\text { DNA } \\
\text { content }\end{array}$ & $\begin{array}{c}\text { No } \\
\text { template }\end{array}$ & $\begin{array}{c}50 \mathrm{pg} \mathrm{Fg} 7.1 \mathrm{in} \\
\text { healthy wheat } \\
\text { flour DNA 1:10 }\end{array}$ & $\begin{array}{c}0.5 \mathrm{pg} \mathrm{Fc1} \mathrm{in} \\
\text { healthy wheat } \\
\text { flour DNA 1:10 }\end{array}$ & $\begin{array}{c}5 \mathrm{pg} \mathrm{Fc1} \mathrm{in} \\
\text { healthy wheat } \\
\text { flour DNA 1:10 }\end{array}$ & $\begin{array}{c}50 \mathrm{pg} \mathrm{Fc1} \mathrm{in} \\
\text { healthy wheat }\end{array}$ & $\begin{array}{c}0.5 \mathrm{ng} \text { Fc1 in } \\
\text { healthy wheat } \\
\text { flour } 1: 10\end{array}$ \\
flour DNA 1:10
\end{tabular}

\section{PCR amplification}

The iCycler System (BioRad, Hercules, CA, USA) was used for the amplification and quantification of Fusarium spp. DNA in plant samples. Primers Fg16N F (ACAGAT GACAAGATTCAGGCACA) and Fg16N R (TTCTTTGACATCTGTTCAACCCA) were used to amplify a $280 \mathrm{bp}$ fragment specific for F. graminearum (Nicholson et al., 1998). Primers OPT18 F (GATGCCAGACCAAGACGAAG) and OPT18 R (GATGCC AGACGCACTAAGAT) served to multiply a 472 bp fragment specific for F. culmorum (Schilling et al., 1996). Both primer pairs were derived from randomly amplified genomic fragments, the function of the target sequences is unknown.

The amplification mix for F. culmorum-specific PCR consisted of $\mathrm{NH}_{4}$-reaction buffer (16 mM ( $\left.\mathrm{NH}_{4}\right)_{2} \mathrm{SO}_{4}, 67 \mathrm{mM}$ Tris- $\mathrm{HCl}, 0.01 \%$ (v/v) Tween-20, $\mathrm{pH} 8.8$ at $25^{\circ} \mathrm{C}$; Bioline, Luckenwalde, Germany), $4 \mathrm{mM} \mathrm{MgCl}_{2}, 0.2 \mathrm{mM}$ of each dATP, dTTP, dCTP and dGTP (Bioline, Luckenwalde, Germany), $0.3 \mu \mathrm{M}$ of primer OPT18 F and OPT18 R, $0.25 \mathrm{u}$ BIOTaq DNA polymerase (Bioline, Luckenwalde, Germany), $10 \mathrm{nM}$ Fluorescein (BioRad, Hercules, CA, USA, diluted from $1 \mu \mathrm{M}$ in $1 \mathrm{x} \mathrm{NH}_{4}$-reaction buffer, to collect 
well factors, which is specific for the iCycler), 0.1x SYBR Green I solution (Invitrogen, Karlsruhe, Germany), $1 \mu$ of template DNA and doubly distilled water $\left(\mathrm{ddH}_{2} \mathrm{O}\right)$ filled to a total volume of $25 \mu$. The amplification mix for the F. graminearum-specific PCR consisted of 1x SYBR Premix Ex Taq (containing TaKaRa Ex Taq HS, dNTP Mixture, $\mathrm{Mg}^{2+}$, and SYBR Green I, Takara Bio, Otsu, Japan), $0.3 \mu \mathrm{M}$ of primer Fg16N F and Fg16N R, $10 \mathrm{nM}$ Fluorescein, $1 \mu \mathrm{l}$ of template DNA and $\mathrm{ddH}_{2} \mathrm{O}$ filled to $25 \mu 1$. The detection of amplification products, based on the fluorescence of SYBR Green I, was performed with filters set at $490 \pm 10 \mathrm{~nm}$ for excitation and $530 \pm 15 \mathrm{~nm}$ for emission.

The PCR was performed with the following cycling protocol. Initial denaturation for 1.5 min at $95^{\circ} \mathrm{C}$ (the denaturation time is used by the thermocycler to collect data for the calculation of the well correction factors, which is needed to compensate for differences among wells of the microtiter plate) was followed by 35 cycles with $30 \mathrm{~s}$ at $94^{\circ} \mathrm{C}, 45 \mathrm{~s}$ at $64^{\circ} \mathrm{C}$, and $45 \mathrm{~s}$ at $72^{\circ} \mathrm{C}$. The final elongation was performed for $5 \mathrm{~min}$ at $72^{\circ} \mathrm{C}$. During the PCR, the detection of fluorescence was carried out in the annealing step of each cycle. Following amplification, the melting curves were acquired by heating the samples to $95^{\circ} \mathrm{C}$ for $1 \mathrm{~min}$, cooling to $55^{\circ} \mathrm{C}$ for one min and then slowly increasing the

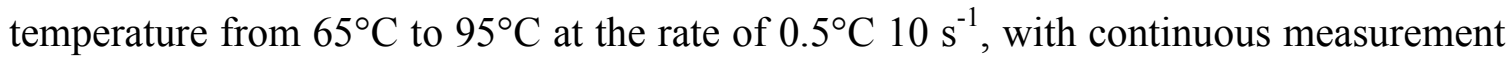
of the fluorescence.

When an electrophoretic analysis of PCR products was necessary (only during the optimization process), $4 \mu \mathrm{l}$ of the reaction mixture were combined with $2 \mu \mathrm{l}$ of loading buffer (100 mM EDTA, 50\% (v/v) Glycerol, 0.025\% (w/v) bromphenol-blue) and loaded on a $1.7 \%(\mathrm{w} / \mathrm{v})$ agarose gel prepared in TAE buffer. The electrophoresis and the documentation were carried out as described above.

\section{PCR product and Fusarium spp. quantification}

The quantitative data were exported from the iCycler software using the "Reports" function within the "PCR Standard Curve" sheet of the iCycler program. To relate the DNA quantities per PCR tube to the plant samples, the data had to be multiplied with a factor specific for the DNA extraction method used. These factors are 33.333 for the conversion of pg Fusarium spp. DNA per PCR sample to $\mu \mathrm{g}$ Fusarium spp. DNA per kg wheat flour and 66.667 to convert the pg Fusarium spp. DNA per PCR sample to $\mu \mathrm{g}$ Fusarium spp. DNA per kg maize debris flour. Different factors for wheat flour and maize debris are needed because the weights of these kinds of samples as used in the 
optimized extraction protocol differ (see Material and Methods, Quantitative DNA extraction from plant material).

\section{Results and Discussion}

\section{Optimization of the DNA extraction}

Our goal was to optimize DNA extraction for invariable yield and constant PCR efficiency. We started with samples of $100 \mathrm{mg}$ wheat flour in $1 \mathrm{ml}$ CTAB buffer using a protocol developed for agar plaques (Brandfass and Karlovsky, 2006) and experienced a large variation among PCR signal among sample replicas. The same was true for maize stem flour, prepared from maize residues collected in the field after harvest in autumn or in spring of the following year. Furthermore, the high starch and protein content of wheat flour samples interfered with DNA precipitation, resulting in large pellets that were difficult to dissolve.

Mulfinger et al. (2000) reported that sampling technique has a major influence on the analytical results in Fusarium contamination studies. The sample size is a critical factor for the quantification of fungal biomass in plant samples, as fungal growth is inhomogeneous within a kernel and variable among kernels. To reduce the effect of this variability on the DNA yield, we upscaled the DNA extraction procedure as follows. For each sample, $500 \mathrm{~g}$ of wheat was ground in a hammer mill and one gram of the resulting flour was used for DNA extraction with $10 \mathrm{ml}$ of CTAB buffer. The homogenization in a reciprocal mill used in the original protocol with agar plaques was replaced with a short treatment in an ultrasonic bath. Because wheat flour contains large amounts of starch and protein, which co-precipitate with DNA and hamper the dissolution of the DNA pellet, we prolonged the chloroform-isoamyl extraction to 10 minutes on ice. Furthermore, we found that shortening the PEG precipitation step improved reproducibility of PCR amplification; therefore the centrifugation was started immediately after the DNA extract was vigorously mixed with $\mathrm{PEG} / \mathrm{NaCl}$ solution. In order to prevent PCR inhibition by substances co-extracted with DNA (Wilson, 1997), DNA dissolved in $200 \mu 1$ TE still needed to be diluted 10-fold with water for PCR. One microliter of 10-times diluted DNA was used as a template per $25 \mu 1$ reaction mixture. Increasing the amount of DNA has not improved the detection limit with DNA prepared according to our CTAB protocol nor with DNA extracted with DNeasy Plant Mini Kit (Qiagen, Hilden, Germany). Presumably, PCR inhibitors extracted from plant material were not 
completely eliminated by the DNA purification protocols used, or the large amount of target DNA inhibited PCR per se. The increase of sample size and the modifications of the DNA purification protocol significantly improved the reproducibility of both DNA yield and PCR efficiency. The reproducibility of the yield in the optimized DNA extraction protocol is demonstrated in Fig. 1, the protocol is described in detail in Materials and Methods. We suppose that other protocols designed for DNA extraction from plant material would also work well with our assay (for example, see Manen et al., 2005).

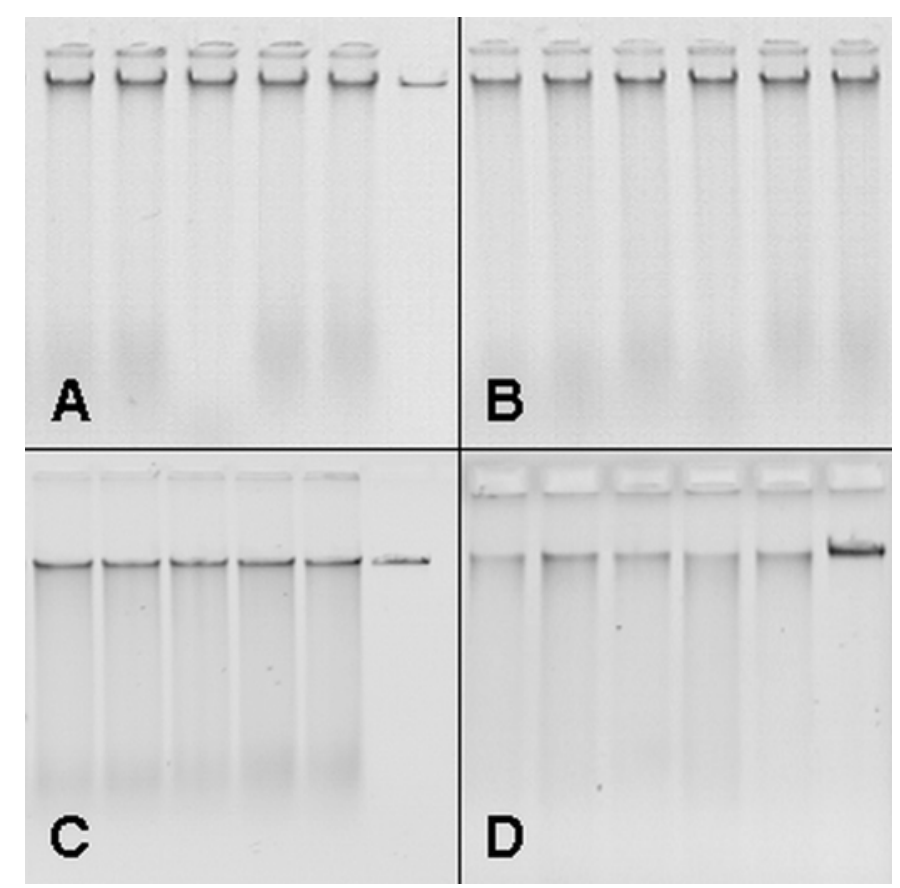

Figure 1: Yield and quality of DNA extracted from wheat flour and maize stem residues. Four microliters (of $200 \mu \mathrm{l}$ total) of DNA extracted from $1 \mathrm{~g}$ of wheat flour or $500 \mathrm{mg}$ of maize debris flour by a modified CTAB protocol (see Material and Methods for details) were loaded on a $0.8 \%$ agarose gel and separated at $4 \mathrm{~V} \mathrm{~cm}^{-1}$ for $60 \mathrm{~min}$.

A) Lane 1-5: healthy wheat kernels (five identical samples), lane 6: $25 \mathrm{ng} \lambda$-DNA

B) Lane 1-6: infected wheat kernels (six different samples)

C) Lane 1-5: healthy maize stem residues (five identical samples), lane 6: $25 \mathrm{ng} \lambda$-DNA

D) Lane 1-5: infected maize stem residues (five different samples), lane 6: $25 \mathrm{ng} \lambda$-DNA

\section{Optimization of PCR conditions}

Our initial PCR experiments were done under the conditions described in the literature for classical PCR with primers Fg16N and OPT18 (Nicholson et al., 1998; Schilling et al., 1996). Because these conditions led to poor performance in the real-time mode, we re-optimized the primer concentration, polymerase activity, $\mathrm{MgCl}_{2}, \mathrm{SYBR}$ Green I concentration and cycling parameters, using a native Taq polymerase (BioTaq, Bioline, 
Luckenwalde, Germany). The performance of the optimized assay for F. culmorum was satisfactory, but the sensitivity of the F. graminearum-assay was not sufficient for wheat flour samples. Furthermore, unspecific products were formed in samples with a low concentration of F. graminearum DNA. After comparing different commercial kits and ready-made polymerase cocktails, we found that "SYBR Premix Ex Taq" (Takara Bio, Otsu, Japan) secured the best performance for the F. graminearum-assay, lowering the detection limit tenfold as compared with our reaction mix based on native Taq polymerase.

The specificity of the primers we selected for our assay was evaluated in the literature as follows: Fg16N was tested with $21 \mathrm{~F}$. culmorum isolates, $24 \mathrm{~F}$. graminearum isolates, 20 isolates of other Fusarium species and 5 isolates of other fungal species associated with cereals (Nicholson et al., 1998). O’Donnell et al. (2004) proposed the existence of nine phylogenetically distinct species within the F. graminearum clade. In Europe and America only lineage 7 has so far been reported (Ward et al., 2002; O'Donnell et al., 2000). It is not sure that all the lineages proposed by O'Donnell et al. can be detected with the help of Fg16N F/R primers. These primers amplify a section of the sequence amplified with the Fg16 F/R primer set (Nicholson et al., 1998). According to Waalwijk et al. (2003), F. graminearum lineages 1, 2, 6 and 7 were amplified using the Fg16 F/R primer set, whereas no PCR products were detected for lineages 3, 4 and 5.

F. culmorum-specific primers OPT18 were tested in the original publication with 69 F. culmorum isolates, 34 F. graminearum isolates, 25 isolates of other Fusarium species and 27 isolates of other fungal species associated with cereals (Schilling et al., 1996). All tests confirmed the specificity of OPT18 for F. culmorum.

Because PCR conditions used in specificity tests reported in the literature were different from the conditions of our assay, we re-evaluated the primer specificity in the real-time PCR. A range of fungal species regularly encountered on cereals was tested (Table 1). All F. culmorum and F. graminearum (12 isolates of each species) tested positively in the corresponding assays generating PCR products with the expected melting temperatures. There was no cross-reaction between F. culmorum and F. graminearum. All other fungal isolates listed in Table 1 tested negatively in both assays. The amplification of F. culmorum and F. graminearum was not inhibited by the presence of a large excess of wheat DNA (10 ng wheat DNA in a reaction containing $10 \mathrm{pg}$ of Fusarium spp. DNA) nor did pure wheat DNA generate any signal under these conditions. 


\section{Standards for quantitative real-time PCR}

As in any indirect analytical method, the quality of the standard curve is crucial for quantitative real-time PCR. Coamplification of specific plant DNA sequences (Winton et al., 2002) cannot serve as an internal standard because plant DNA in maize debris is degraded by saprophytes to a variable degree. Mixing defined amounts of fungal mycelium with uncontaminated plant material is probably the best way of preparing standard curves in Fusarium biomass determination (Lüders et al., in preparation). Fungal biomass in our plant samples was very low, however, making the preparation of defined mycelium/plant mixtures difficult. A naturally infected maize debris sample from heavily infected material contained about $1 \mu \mathrm{g}$ F. graminearum DNA per gram, the least colonized wheat and maize samples contained F. graminearum DNA under the detection limit of the method. Therefore, the calibration curve was constructed with pure F. graminearum DNA dissolved in the matrix (DNA extracted from healthy maize or wheat flour, Fig. 2).

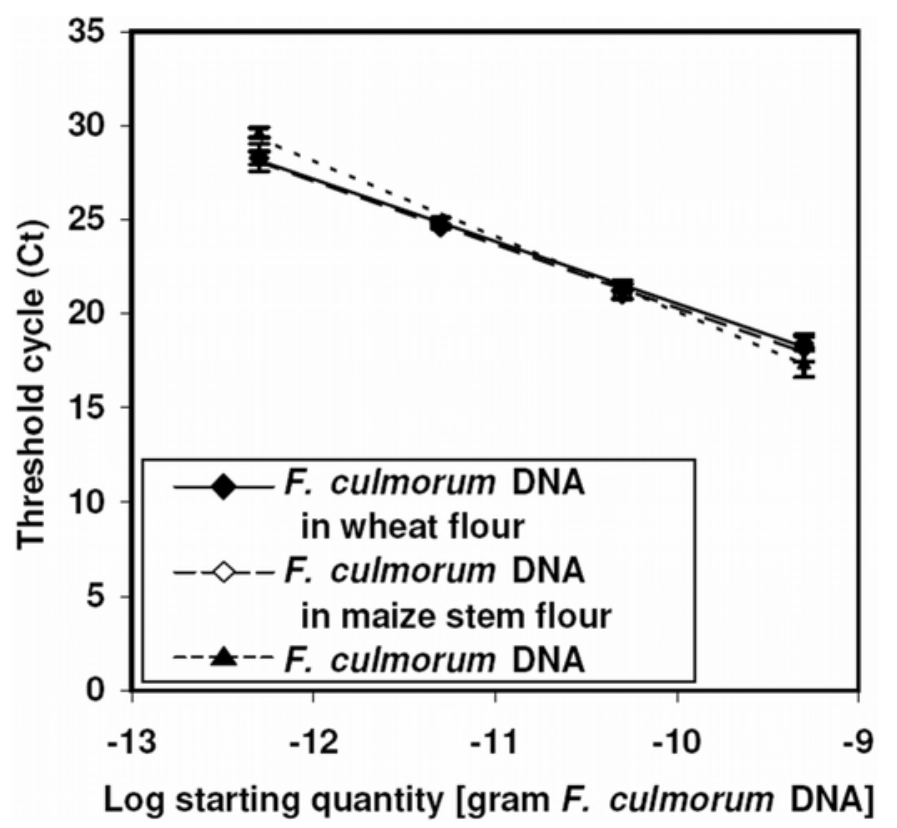

Figure 2: Standard curves used for the quantification of F. culmorum by real-time PCR. PCR was performed in a real-time thermocycler with primer pairs specific for F. culmorum and SYBR Green I fluorescence detection as described in Materials and Methods. Standard curves consisted of 10 -fold serial dilutions from $0.5 \mathrm{pg}$ to $0.5 \mathrm{ng}$ F. culmorum DNA in different matrices as specified in the inlet. Threshold cycles $(\mathrm{Ct})$ means and standard deviations of three replicas were plotted against amount of F. culmorum DNA (logarithmic scale) and linear regression equations were calculated. $\mathrm{R}^{2}$ (square of the correlation coefficient) and PCR efficiency for the three matrices were: $0.998 / 100 \%$ for maize stem debris, $0,997 / 97 \%$ for wheat flour and $0.996 / 77 \%$ for water. 
In case of wheat flour, the calibration curve represents a range of $16.7 \mathrm{ng}$ to $16.7 \mu \mathrm{g}$ Fusarium spp. DNA per g wheat flour, while the standard curve for maize stem flour ranged from $33.3 \mathrm{ng}$ to $33.3 \mu \mathrm{g}$ Fusarium spp. DNA per g material. The upper limits of the detection lies outside the standard curve, but the amplification of field samples never resulted in $\mathrm{Ct}$ values lower than the highest DNA concentration used in the standard curve. For comparison, maize cobs fully colonized by F. graminearum after an artificial inoculation contained up to $143 \mu \mathrm{g} F$. graminearum DNA per gram maize material.

\section{Comparison with other PCR-based methods}

Qualitative PCR assays to detect a Fusarium species (Demeke et al., 2005; Jurado et al., 2005; Nicolaisen et al., 2005) are suitable for some purposes, but epidemiological questions require the quantification of the infecting agents. Real-time PCR assays available so far for the quantification of toxigenic Fusarium spp. in infected plants are costly because they utilize doubly-labeled probes in combination with kit-based DNA extraction (Waalwijk et al., 2004). A recently published competitive microsatellite amplification-based F. graminearum detection uses a kit-based DNA extraction, labeled primers and capillary electrophoresis of PCR products of co-amplified microsatellite alleles originating from a target strain and another strain used as a standard (Naef et al., 2006). The method is basically unsuitable for naturally infected material because it requires prior knowledge of microsatellite alleles present in the target strain. Further serious drawbacks are the need to weigh a separate mycelium standard for each sample and the restriction of the quantification range to just two orders of magnitude.

Our method allows the quantification of F. culmorum and F. graminearum at low costs in a high-throughput environment suitable for epidemiological studies. Concerning costs, the price of a DNA extraction kit for 50-100 mg plant material varies between 2.0 to $2.5 €$ per sample while the value of chemicals used in our protocol to extract DNA from $1 \mathrm{~g}$ material is $0.40 €$, the working time is similar for our assay and the DNeasy Plant Kit. The replacement of doubly-labeled hybridization probes by SYBR Green I-based detection further lowers the costs of the assay: a TaqMan probe used up in one reaction costs about $0.1 €$, the costs of the SYBR Green dye is about 0.1 cent. The costs of other reaction components and disposables except DNA polymerase are the same for all PCRbased methods. The demand for high-quality DNA polymerases (e.g., hot-start modification) tends to increase with the complexity of the method. For example, both Waalwijk et al. (2004) and Reischer et al. (2004a) use hot start polymerase in their 
TaqMan-based assays for Fusarium spp. Our assay for F. graminearum uses hot-start polymerase as a component of the SYBR Premix Ex Taq, while our F. culmorum assay uses a regular native Taq polymerase.

Compared with other published PCR assays for Fusarium spp., our method uses larger amounts of material, which reduces the sampling error by improving the representation of inhomogeneous material in the sample (Mulfinger, 2000).

\section{Analysis of field samples}

The method has been routinely used in our laboratory in projects on the epidemiology of FHB. Five hundred and seventy wheat flour samples and 310 maize debris samples collected throughout Germany from 2002 to 2005 were analyzed recently, while 2000 samples of wheat stem DNA extracted with a similar protocol were analyzed for the presence of each species in another project.

In accordance with Brandfass and Karlovsky (2006) and Waalwijk et al. (2003), F. graminearum, and to a lesser extent F. culmorum, play a dominant role in the infection of wheat kernels leading to FHB symptoms. The proportion of F. graminearum and F. culmorum depends on the growing season and other parameters.

In maize debris samples, F. culmorum is found more often than in wheat kernels, probably due to a higher saprophytic fitness of this fungus, but F. graminearum is still the dominant species. Detailed data are being prepared for publication.

\section{Conclusions}

The method developed in this study is suitable for cost-effective, high throughput quantification of F. graminearum and F. culmorum in plant material by real-time PCR. Extraction of DNA from $1 \mathrm{~g}$ of plant material, rather than from 50-100 $\mathrm{mg}$ usually used with commercial kits, substantially reduces sampling error caused by the inhomogeneous distribution of fungal mycelium in the matrix. The quantification limit for each species is $0.5 \mathrm{pg}$ of genomic DNA. The assay is suitable for the analysis of a large number of samples for F. culmorum and F. graminearum, which is particularly useful in epidemiological studies as exemplified by our investigation of a large collection of wheat flour and maize debris samples. 


\section{Acknowledgements}

We thank Joachim Weinert for providing us with the plant material and for his continuing support and discussions. Claudia Nordmann, Patricia Bartoschek and Martin Brokop are gratefully acknowledged for their technical assistance. The work was funded by a grant from the German Federal Ministry of Consumer Protection, Food and Agriculture (Grant No. 02 HS 023).

\section{Literature Cited}

Anonymous. 1999. Verordnung über Höchstmengen an Mykotoxinen in Lebensmitteln (Mykotoxin-Höchstmengenverordnung - MHmV), p. 1248-1251 Bundesgesetzblatt, Vol. 1. Bundesanzeiger Verlagsges.m.b.H., Bonn.

Anonymous. 2004. Verordnung zur Änderung der Mykotoxin-Höchstmengenverordnung und der Diätverordnung, p. 151-152 Bundesgesetzblatt, Vol. 1. Bundesanzeiger Verlagsges.m.b.H., Bonn.

Bai, G.H., and G. Shaner. 2004. Management and resistance in wheat and barley to Fusarium head blight. Annual Review of Phytopathology 42: 135-161.

Bottalico, A., and G. Perrone. 2002. Toxigenic Fusarium species and mycotoxins associated with head blight in small-grain cereals in Europe. European Journal of Plant Pathology 108: 611-624.

Brandfass, C., and P. Karlovsky. 2006. Simultaneous detection of Fusarium culmorum and F. graminearum in plant material by duplex PCR with melting curve analysis. BMC Microbiology 6: 4.

Demeke, T., R.M. Clear, S.K. Patrick, and D. Gaba. 2005. Species-specific PCR-based assays for the detection of Fusarium species and a comparison with the whole seed agar plate method and trichothecene analysis. International Journal of Food Microbiology 103: 271-284.

D'Mello, J.P.F., C.M. Placinta, and A.M.C. Macdonald. 1999. Fusarium mycotoxins: a review of global implications for animal health, welfare and productivity. Animal Feed Science \& Technology 80: 183-205.

Ecker, D.J., R. Sampath, P. Willett, J.R. Wyatt, V. Samant, C. Massire, T.A. Hall, K. Hari, J.A. McNeil, C. Buchen-Osmond, and B. Budowle. 2005. The Microbial Rosetta Stone Database: A compilation of global and emerging infectious microorganisms and bioterrorist threat agents. BMC Microbiology 5: 19. 
Edwards, S.G., J. O'Callaghan, and A.D.W. Dobson. 2002. PCR-based detection and quantification of mycotoxigenic fungi. Mycological Research 106: 1005-1025.

Jurado, M., C. Vazquez, B. Patino, and M.T. Gonzalez-Jaen. 2005. PCR detection assays for the trichothecene-producing species Fusarium graminearum, Fusarium culmorum, Fusarium poae, Fusarium equiseti and Fusarium sporotrichioides. Systematic and Applied Microbiology 28: 562-568.

Leonard, K.J., and W.R. Bushnell, (eds.) 2003. Fusarium Head Blight of Wheat and Barley, pp. 1-512. The American Phytopathological Society, St. Paul, Minnesota, USA.

Manen, J.-F., O. Sinitsyna, L. Aeschbach, A. Markov, and A. Sinitsyn. 2005. A fully automatable enzymatic method for DNA extraction from plant tissues. BMC Plant Biology 5: 23.

Martin, K.J., and P.T. Rygiewicz. 2005. Fungal-specific PCR primers developed for analysis of the ITS region of environmental DNA extracts. BMC Microbiology 5: 28.

McCartney, H.A., S.J. Foster, B.A. Fraaije, and E. Ward. 2003. Molecular diagnostics for fungal plant pathogens. Pest Management Science 59: 129-142.

Mulfinger, S., Niessen, L. and Vogel, R.F. 2000. PCR based quality control of toxigenic Fusarium spp. in brewing malt using ultrasonication for rapid sample preparation. Advances in Food Science 22: 38-46.

Murray, M.G., and W.F. Thompson. 1980. Rapid Isolation of High Molecular-Weight Plant DNA. Nucleic Acids Research 8: 4321-4325.

Naef, A., M. Senatore, and G. Defago. 2006. A microsatellite based method for quantification of fungi in decomposing plant material elucidates the role of Fusarium graminearum DON production in the saprophytic competition with Trichoderma atroviride in maize tissue microcosms. FEMS Microbiology Ecology 55: 211-220.

Nicholson, P., D.R. Simpson, G. Weston, H.N. Rezanoor, A.K. Lees, D.W. Parry, and D. Joyce. 1998. Detection and quantification of Fusarium culmorum and Fusarium graminearum in cereals using PCR assays. Physiological and Molecular Plant Pathology 53: 17-37.

Nicholson, P., E. Chandler, R.C. Draeger, N.E. Gosman, D.R. Simpson, M. Thomsett, and A.H. Wilson. 2003. Molecular tools to study epidemiology and toxicology of 
Fusarium head blight of cereals. European Journal of Plant Pathology 109: 691703.

Nicolaisen, M., A.F. Justesen, U. Thrane, P. Skouboe, and K. Holmstrom. 2005. An oligonucleotide microarray for the identification and differentiation of trichothecene producing and non-producing Fusarium species occurring on cereal grain. Journal of Microbiological Methods 62: 57-69.

O'Donnell, K., H.C. Kistler, B.K. Tacke, and H.H. Casper. 2000. Gene genealogies reveal global phylogeographic structure and reproductive isolation among lineages of Fusarium graminearum, the fungus causing wheat scab. Proceedings of the National Academy of Sciences of the United States of America 97: 79057910.

O'Donnell, K., T.J. Ward, D.M. Geiser, H.C. Kistler, and T. Aoki. 2004. Genealogical concordance between the mating type locus and seven other nuclear genes supports formal recognition of nine phylogenetically distinct species within the Fusarium graminearum clade. Fungal Genetics and Biology 41: 600-623.

Parry, D.W., P. Jenkinson, and L. McLeod. 1995. Fusarium ear blight (scab) in small grain cereals -- A review. Plant Pathology 44: 207-238.

Peraica, M., B. Radic, A. Lucic, and M. Pavlovic. 1999. Toxic effects of mycotoxins in humans. Bulletin of the World Health Organization 77: 754-766.

Pestka, J.J., and A.T. Smolinski. 2005. Deoxynivalenol: Toxicology and potential effects on humans. Journal of Toxicology and Environmental Health-Part B-Critical Reviews 8: 39-69.

Pieters, M.N., J. Freijer, B.J. Baars, D.C.M. Fiolet, J. van Klaveren, and W. Slob. 2002. Risk assessment of deoxynivalenol in food: Concentration limits, exposure and effects, p. 235-248 Mycotoxins and Food Safety, Vol. 504. KLUWER ACADEMIC/PLENUM PUBL, New York.

Pirgozliev, S.R., S.G. Edwards, M.C. Hare, and P. Jenkinson. 2003. Strategies for the control of Fusarium head blight in cereals. European Journal of Plant Pathology 109: 731-742.

Reischer, G.H., M. Lemmens, A. Farnleitner, A. Adler, and R.L. Mach. 2004a. Quantification of Fusarium graminearum in infected wheat by species specific real-time PCR applying a TaqMan Probe. Journal of Microbiological Methods 59: $141-146$. 
Reischer, G.H., M. Lemmens, A. Farnleitner, A. Adler, and R.L. Mach. 2004b. Erratum to "Quantification of Fusarium graminearum in infected wheat by species specific real-time PCR applying a TaqMan probe" [J. Microbiol. Methods 59 (2004) 141-146]. Journal of Microbiological Methods 59: 437-437.

Schena, L., F. Nigro, A. Ippolito, and D. Gallitelli. 2004. Real-time quantitative PCR: a new technology to detect and study phytopathogenic and antagonistic fungi. European Journal of Plant Pathology 110: 893-908.

Schilling, A.G., E.M. Moller, and H.H. Geiger. 1996. Polymerase chain reaction-based assays for species-specific detection of Fusarium culmorum, F. graminearum, and F. avenaceum. Phytopathology 86: 515-522.

Schnerr, H., R.F. Vogel, and L. Niessen. 2002. Correlation between DNA of trichothecene-producing Fusarium species and deoxynivalenol concentrations in wheat-samples. Letters in Applied Microbiology 35: 121-125.

Snijders, C.H.A. 1990. Systemic fungal growth of Fusarium culmorum in stems of winter wheat. Journal of Phytopathology-Phytopathologische Zeitschrift 129: 133-140.

Snijders, C.H.A. 2004. Resistance in wheat to Fusarium infection and trichothecene formation. Toxicology Letters 153: 37-46.

Stewart, C.N., and L.E. Via. 1993. A rapid CTAB DNA isolation technique useful for rapid fingerprinting and other PCR applications. Biotechniques 14: 748-751.

Waalwijk, C., P. Kastelein, I. de Vries, Z. Kerenyi, T. van der Lee, T. Hesselink, J. Kohl, and G. Kema. 2003. Major changes in Fusarium spp. in wheat in the Netherlands. European Journal of Plant Pathology 109: 743-754.

Waalwijk, C., R. van der Heide, I. de Vries, T. van der Lee, C. Schoen, G. Costrel-de Corainville, I. Hauser-Hahn, P. Kastelein, J. Kohl, P. Lonnet, T. Demarquet, and G.H.J. Kema. 2004. Quantitative detection of Fusarium species in wheat using TaqMan. European Journal of Plant Pathology 110: 481-494.

Ward, T.J., J.P. Bielawski, H.C. Kistler, E. Sullivan, and K. O'Donnell. 2002. Ancestral polymorphism and adaptive evolution in the trichothecene mycotoxin gene cluster of phytopathogenic Fusarium. Proceedings of the National Academy of Sciences of the United States of America 99: 9278-9283.

Wilson, I.G. 1997. Inhibition and facilitation of nucleic acid amplification. Applied and Environmental Microbiology 63: 3741-3751. 
Winton, L.M., J.K. Stone, L.S. Watrud, and E.M. Hansen. 2002. Simultaneous one-tube quantification of host and pathogen DNA with real-time polymerase chain reaction. Phytopathology 92: 112-116.

Xu, X.M. 2003. Effects of environmental conditions on the development of Fusarium ear blight. European Journal of Plant Pathology 109: 683-689. 


\title{
Chapter 4: Detection of Fusarium graminearum and
} F. culmorum in rachides from wheat ears afflicted with Fusarium head blight and in grain identifies F. graminearum as the major cause of FHB and DON contamination

Christoph Brandfass, Joachim Weinert, Petr Karlovsky

\begin{abstract}
Brandfass, C., Weinert, J., Karlovsky, P. 2006. Detection of Fusarium graminearum and F. culmorum in rachides from wheat ears afflicted with Fusarium head blight and in grain identifies F. graminearum as the major cause of FHB and DON contamination.
\end{abstract}

Fusarium head blight (FHB) is a disease of cereal crops, which has a severe impact on wheat production worldwide. Apart from reducing the yield and impairing grain quality, FHB leads to contamination of grain with mycotoxins. Numerous Fusarium species have been isolated from ears or kernels of cereal plants exhibiting scab symptoms. While the involvement of F. graminearum and F. culmorum is well established, the extent to which different Fusarium species might contribute to FHB and grain contamination with mycotoxins remains unclear. In order to distinguish between systemic colonization of the ear leading to FHB and infections confined to single-spikelets, we investigated 540 rachides prepared from wheat ears afflicted with FHB, which were collected throughout Germany in 2003. Essentially all rachides contained F. graminearum, F. culmorum or both, indicating that these two species were the causal agents of FHB in our samples. Rachides from fields with DON contamination higher than $500 \mu \mathrm{g}$ DON per $\mathrm{kg}$ grain were colonized with F. graminearum to a higher extent (94\%) as compared to rachides from fields yielding less contaminated grain (71\%). To assess the relative importance of $F$. graminearum and F. culmorum for the contamination of grain with deoxynivalenol (DON), fungal DNA and DON concentration were determined in 54 samples of grain harvested from the same fields and in additional 334 grain samples collected throughout 
Germany in 2003-2005. F. graminearum turned out to be the major cause of DON accumulation in wheat grain.

Additional keywords: Gibberella zeae, ear blight, wheat scab.

\section{Introduction}

Fusarium head blight (FHB) is a disease of cereal crops with a severe impact on wheat and barley production worldwide. The infection of heads of small grain cereals and maize plants with Fusarium spp. impairs both grain yield and quality (Leonard and Bushnell, 2003; Parry et al., 1995). The most serious consequence of FHB is the contamination of grain and cereal products with Fusarium mycotoxins (Pieters et al., 2002; Peraica et al., 1999), causing health risk in farm animals (Rocha et al., 2005; D'Mello et al., 1999) and humans (Pestka and Smolinski, 2005). Therefore, many countries have established maximum limits for Fusarium mycotoxins in grains, food and feeds (Anonymous, 2004; Anonymous, 1999; D'Mello et al., 1999). In spite of breeding efforts aiming at FHB-resistant cultivars (Bai and Shaner, 2004; Snijders, 2004) and the development of fungicides against FHB, the disease continues to pose a major challenge to grain growers all over the world (Aldred and Magan, 2004; Pirgozliev et al., 2003).

A key prerequisite for FHB reduction through crop management is to understand the epidemiology of the disease. In spite of extensive research into FHB worldwide, there are still significant gaps in our understanding of the etiology of the disease. Surprisingly, even the identity of the Fusarium species causally involved is not clarified definitely. While most authors maintain that five to seventeen fungal species participate on FHB development (Edwards, 2004; Doohan et al., 2003; Pirgozliev et al., 2003; Xu, 2003; Birzele et al., 2002; Parry et al., 1995), other argue that only F. graminearum and F. culmorum are causally involved in the disease (Champeil et al., 2004; Waalwijk et al., 2003, Weinert, pers. commun.). F. graminearum is supposed to dominate hotter central Europe, whereas F. culmorum shall occur mainly in cooler maritime regions of northwest Europe (Parry et al., 1995). The controversy about the number of Fusarium species involved in FHB arose from the fact that a number of species have been isolated from infected or even healthy-looking ears collected in the field (Nicholson et al., 2003; Bottalico and Perrone, 2002; Parry et al., 1995), but it is not known which actively contribute to FHB. Many species might just grow saprophytically on the spike surface or within the dead tissue, which is normally removed during grain cleaning and processing. 
Some species might infect a single spikelet without spreading along the ear, which is not expected to cause typical FHB symptoms. Therefore, the first goal of our work was to find out to which extent rachides of wheat ears afflicted with FHB are colonized by the DON producers F. graminearum or F. culmorum. A species-specific duplex PCR assay based on melting curve analysis (without electrophoresis) was used to facilitate processing the large number of samples.

Both F. graminearum and F. culmorum produce two toxicologically relevant groups of mycotoxins, trichothecenes (nivalenol, deoxynivalenol (DON) and their acetylated derivatives) and zearalenone and its derivatives. DON is known to be a virulence factor of F graminearum in wheat (Langevin et al., 2004; Bai et al., 2002; Proctor et al., 1995), thus having a direct role in the disease. The correlation coefficient for DON and DNA content were reported to be 0.68 (Nicholson et al., 2003) and 0.82 (Waalwijk et al., 2004) for the sum of F. culmorum and F. graminearum DNA, and 0.96 in artificially inoculated wheat samples for Fusarium species containing biosynthetic genes for DON (Schnerr et al., 2002). Therefore, the presence of the trichothecene in grain can be explained to a large extent by the activity of these Fusarium species. Furthermore, a strong correlation between the severity of FHB and the DON level after artificial inoculation with Fusarium spp. was found (Haidukowski et al., 2005; Mesterhazy et al., 2005). In contrast, the relative contribution of F. graminearum and F. culmorum to the contamination of grain with trichothecenes is not known. Therefore, the second goal of our work was to determine the association between the amount of DON accumulated in grain and the biomass of each fungus, determined by quantitative real-time PCR.

\section{Materials and Methods}

\section{Qualitative detection of $F$. graminearum and $F$. culmorum in wheat rachides}

The qualitative determination of F. graminearum and F. culmorum in wheat rachides was done following the protocol of Brandfass and Karlovsky (2006a).

\section{Preparation of wheat grain}

Wheat grain samples (88-92\% dry matter) were separated from the chaff by airflow and sieve cleaning with a stationary threshing machine, while particular attention was paid to the complete removal of rachides and the glumes. 500 g-portions of cleaned grain were 
ground in a cross hammer mill (Cross Beater Mill SK 1, bottom sieve $2 \mathrm{~mm}$, Retsch, Haan, Germany), the flour was mixed and $40 \mathrm{~g}$ sub-samples were stored at $-20^{\circ} \mathrm{C}$.

\section{Quantitative DNA extraction from plant material}

To extract DNA from ground wheat flour, $1 \mathrm{~g}$ of flour was blended in a $50 \mathrm{ml}$-tube (Sarstedt, Nümbrecht, Germany) with $10 \mathrm{ml}$ CTAB-buffer (10 mM Tris, $20 \mathrm{mM}$ EDTA, $0.02 \mathrm{M}$ cetyltrimethylammonium bromide (CTAB, Merck, Darmstadt, Germany), $0.8 \mathrm{M}$ $\mathrm{NaCl}, 0.03 \mathrm{M}$ N-laurylsarcosine (Fluka, Buchs, Switzerland), 0.13 M sorbitol, 1\% (w/v) polyvinylpolypyrolidone, $\mathrm{pH}$ set to 8.0 with $\mathrm{NaOH}$ (Merck, Darmstadt, Germany). $20 \mu 1$ mercaptoethanol (Fluka, Buchs, Switzerland) and $0.2 \mathrm{mg}$ proteinase K (from a stock solution $20 \mathrm{mg} \mathrm{ml}^{-1}$, Merck, Darmstadt, Germany) were added shortly before use. The mixture was treated for $5 \mathrm{sec}$ in an ultrasonic bath (Sonorex RK 100, Bandelin, Berlin, Germany). After an incubation at $42^{\circ} \mathrm{C}$ for $10 \mathrm{~min}$, followed by $10 \mathrm{~min}$ at $65^{\circ} \mathrm{C}$ (the content of the tubes was mixed every $3 \mathrm{~min}$ ), $8 \mathrm{ml}$ of chloroform-isoamyl alcohol (24:1, Roth, Karlsruhe, Germany) were added. The samples were thoroughly emulsified, incubated for $10 \mathrm{~min}$ on ice and centrifuged for $10 \mathrm{~min}$ at 5,000 $\mathrm{g}$ at room temperature. 600 $\mu 1$ of the upper phase were transferred to a $1.5-\mathrm{ml}$ tube containing $194 \mu 1$ of a $30 \%(\mathrm{w} / \mathrm{v})$ polyethylene glycol 6000 (Serva, Heidelberg, Germany) solution and $100 \mu 15 \mathrm{M} \mathrm{NaCl}$, mixed, and centrifuged for $15 \mathrm{~min}$ at $15,000 \mathrm{~g}$ at room temperature. The pellet was washed with 70\% (v/v) ethanol (Roth, Karlsruhe, Germany), dried and dissolved in 200 $\mu 1$ TE (10 mM Tris, $1 \mathrm{mM}$ EDTA, $\mathrm{pH}$ set to 8.0 with $\mathrm{HCl}$ ). To ensure that the DNA was dissolved completely, the pellet covered by TE buffer was incubated over night at $4^{\circ} \mathrm{C}$. The quality and quantity of DNA were assessed by electrophoresis in $0.8 \%(\mathrm{w} / \mathrm{v})$ agarose gels (Cambrex, Rockland, ME, USA) prepared in TAE buffer (40 mM Tris, $1 \mathrm{mM}$ EDTA, $\mathrm{pH}$ set to 8.5 with acetic acid). The electrophoresis was carried out at $4 \mathrm{~V} \mathrm{~cm}^{-1}$ for $60 \mathrm{~min}$. Double-stranded DNA was stained with ethidium (ethidium bromide, $2 \mathrm{mg} \mathrm{l}^{-}$ $\left.{ }^{1}\right)$, (Applichem, Darmstadt, Germany). The gels were documented with the help of a digital imaging system (Vilber Lourmat, Marne la Vallee, France). Densitometry values were compared with those of Lambda Phage DNA (methylated, from Escherichia coli host strain W3110, Sigma, Taufkirchen, Germany). The densitometry was performed using Multi Analyst-Software (BioRad, Hercules, CA, USA). A 1:10-dilution of the DNA solution was used in the PCR. 


\section{Preparation of standards for quantitative real-time PCR}

The fungal cultures were maintained and their DNA was extracted as described in (Brandfass and Karlovsky, 2006a). DNA standards and DNA from unknown samples have to be amplified under identical conditions. Therefore, quantified standard-DNA of Fusarium spp. was mixed with DNA extracted from uncontaminated wheat flour to imitate matrix effects. A dilution series from $0.5 \mathrm{pg}$ to $0.5 \mathrm{ng}$ of Fusarium spp. DNA with a dilution factor of 10 was produced separately for $F$. culmorum and F. graminearum DNA in the matrix of plant DNA. For each pathogen a standard curve for wheat flour was set up. In addition to the standard curve, two negative controls were processed in each PCR set, one containing no template (water) and one containing $50 \mathrm{pg}$ of the other Fusarium species (e.g. F. graminearum for F. culmorum analysis) mixed with DNA of a healthy plant.

\section{PCR amplifikation}

The iCycler System (BioRad, Hercules, CA, USA) was used for the amplification and quantification of Fusarium spp. DNA in plant samples. Primers Fg16N F (ACAGAT GACAAGATTCAGGCACA) and Fg16N R (TTCTTTGACATCTGTTCAACCCA) were used to amplify a $280 \mathrm{bp}$ fragment specific for F. graminearum (Nicholson et al., 1998). Primers OPT18 F (GATGCCAGACCAAGACGAAG) and OPT18 R (GATGCC AGACGCACTAAGAT) served to multiply a $472 \mathrm{bp}$ fragment specific for F. culmorum (Schilling et al., 1996). All primers were synthesized by Operon Biotechnologies (Cologne, Germany). Both primer pairs were derived from randomly amplified genomic fragments, the function of the target sequences is unknown.

The amplification mix for F. culmorum-specific PCR consisted of $\mathrm{NH}_{4}$-reaction buffer (16 mM $\left(\mathrm{NH}_{4}\right)_{2} \mathrm{SO}_{4}, 67 \mathrm{mM}$ Tris- $\mathrm{HCl}, 0.01 \%$ (v/v) Tween-20, $\mathrm{pH} 8.8$ at $25^{\circ} \mathrm{C}$; Bioline, Luckenwalde, Germany), $4 \mathrm{mM} \mathrm{MgCl} 2,0.2 \mathrm{mM}$ of each dATP, dTTP, dCTP and dGTP (Bioline, Luckenwalde, Germany), $0.3 \mu \mathrm{M}$ of primer OPT18 F and OPT18 R, $0.25 \mathrm{u}$ BIOTaq DNA polymerase (Bioline, Luckenwalde, Germany), $10 \mathrm{nM}$ Fluorescein (BioRad, Hercules, CA, USA, diluted from $1 \mu \mathrm{M}$ in $1 \mathrm{x} \mathrm{NH}_{4}$-reaction buffer, to collect well factors, which is specific for the iCycler), 0.1x SYBR Green I solution (Invitrogen, Karlsruhe, Germany), $1 \mu$ of template DNA and doubly distilled water $\left(\mathrm{ddH}_{2} \mathrm{O}\right)$ filled to a total volume of $25 \mu$. The amplification mix for the F. graminearum-specific PCR consisted of 1x SYBR Premix Ex Taq (contains TaKaRa Ex Taq HS, dNTP Mixture, $\mathrm{Mg}^{2+}$, and SYBR Green I, Takara Bio, Otsu, Japan), $0.3 \mu \mathrm{M}$ of primer Fg16N F and 
Fg16N R, $10 \mathrm{nM}$ Fluorescein, $1 \mu \mathrm{l}$ of template DNA and $\mathrm{ddH}_{2} \mathrm{O}$ filled to $25 \mu 1$. The detection of amplification products, based on the fluorescence of SYBR Green I, was performed with filters set at $490 \pm 10 \mathrm{~nm}$ for excitation and $530 \pm 15 \mathrm{~nm}$ for emission. The PCR was performed with the following cycling protocol. Initial denaturation for $1.5 \mathrm{~min}$ at $95^{\circ} \mathrm{C}$ (the denaturation time is used by the thermocycler to collect data for the calculation of the well correction factors, which is needed to compensate for differences among wells of the microtiter plate) was followed by 35 cycles with $30 \mathrm{~s}$ at $94^{\circ} \mathrm{C}, 45 \mathrm{~s}$ at $64^{\circ} \mathrm{C}$, and $45 \mathrm{~s}$ at $72^{\circ} \mathrm{C}$. The final elongation was performed for $5 \mathrm{~min}$ at $72^{\circ} \mathrm{C}$. During the PCR, the detection of fluorescence was carried out in the annealing step of each cycle. Following amplification, the melting curves were acquired by heating the samples to $95^{\circ} \mathrm{C}$ for $1 \mathrm{~min}$, cooling to $55^{\circ} \mathrm{C}$ for one min and then slowly increasing the tempera-

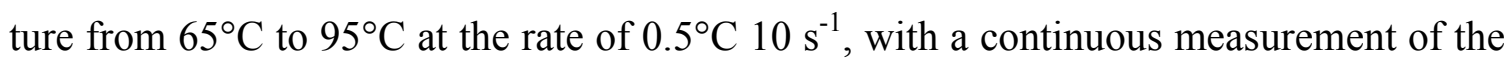
fluorescence.

\section{PCR product and Fusarium spp. quantification}

The quantitative data were exported from the iCycler software using the "Reports" function within the "PCR Standard Curve" sheet of the iCycler program. To relate the DNA quantity per PCR tube (in pg) to DNA content in plant sample (in $\mu \mathrm{g} \mathrm{kg}^{-1}$ ), the result of PCR analysis was multiplied with a factor 33.3, which reflects dilutions performed during DNA extraction.

\section{Quantitative analysis of deoxynivalenol (DON)}

The quantification of deoxynivalenol was performed with the Ridascreen DON enzyme immunoassay (R-Biopharm, Darmstadt, Germany) following the manufacturers instructtions with the following modification. Five grams of ground wheat grain were added to $25 \mathrm{ml}$ of distilled water and mixed for $60 \mathrm{~min}$ on a horizontal shaker $(100 \mathrm{rpm})$ at $4{ }^{\circ} \mathrm{C}$. An aliquot of $1 \mathrm{ml}$ was transferred to a $1.5-\mathrm{ml}$ tube and centrifuged for $10 \mathrm{~min}$ at 15,000 g. Fifty microliters of the resulting supernatant were used in the test. The standard curve was supplemented with an additional standard of $66.0 \mu \mathrm{g} \mathrm{kg}^{-1} \mathrm{DON}$ and the absorbance of the wells was read at $405 \mathrm{~nm}$ (reference $595 \mathrm{~nm}$ ).

\section{Field samples}

Field samples were taken throughout Germany in cooperation with the Federal Plant Protection Extension Services. To identify the infectious agent causing FHB, wheat heads with FHB symptoms were sampled in 2003 at the milk development stage from 54 fields distributed throughout Germany. The rachides were isolated from 10 spikes 
selected from each field, dissected into pieces spanning 2-3 segments of the spike axis and surface-sterilized. These segments were used to isolate the colonizing fungi on agar plates containing potato dextrose medium (PDA; Merck, Darmstadt, Germany). Then the segments were used for DNA extraction and determination of the presence of F. graminearum and F. culmorum as described in Brandfass and Karlovsky (2006a). The DON-content of grain from the same fields was determined after the harvest.

In 388 wheat flour samples collected throughout Germany from 2003 to 2005, DON content was determined by ELISA (see above). Samples with DON levels exceeding 300, 200 and $100 \mu \mathrm{g} \mathrm{kg}^{-1}$ in years 2003, 2004 and 2005, respectively, were selected for the quantification of F. graminearum and F. culmorum DNA by real-time PCR. These yearspecific thresholds were set with consideration of the general level of DON contamination, the available sample number and the PCR detection limit (Brandfass and Karlovsky, 2006b). Further 30, 25 and 14 samples from year 2003, 2004 and 2005, respectively, were analyzed to represent samples with a low DON content. An overview of all samples is given in Table 1. DNA yield was checked by agarose electrophoresis for each sample prior PCR.

Table 1: Number and distribution of wheat rachides and grain samples $2003-2005$.

\begin{tabular}{|l|c|c|c|c|}
\hline & $\begin{array}{c}\text { Number of fields for } \\
\text { rachides analysis } \\
\text { (10 rachides each) }\end{array}$ & \multicolumn{2}{|c|}{ Number of wheat grain samples } \\
\hline Federal States & $\mathbf{2 0 0 3}$ & $\mathbf{2 0 0 3}$ & $\mathbf{2 0 0 4}$ & $\mathbf{2 0 0 5}$ \\
\hline Bavaria & 4 & 4 & 6 & 7 \\
\hline Brandenburg & 3 & 4 & 6 & 10 \\
\hline Lower Saxony & 21 & 51 & 90 & 31 \\
\hline $\begin{array}{l}\text { Mecklenburg Western } \\
\text { Pomerania }\end{array}$ & 6 & 6 & 1 & \\
\hline Northrhine-Westphalia & 13 & 2 & & 11 \\
\hline Rhineland Palatinate & & 29 & 44 & 17 \\
\hline Saarland & & & 1 & 11 \\
\hline Saxony & $\mathbf{5 4}$ & $\mathbf{1 2 0}$ & $\mathbf{1 7 4}$ & $\mathbf{9 4}$ \\
\hline Schleswig Holstein & & & & \\
\hline Thuringia & & 2 & 1 & \\
\hline total & & & & \\
\hline
\end{tabular}




\section{Weather data}

Weather data recorded at the meteorological station in Göttingen, Germany were obtained online from the DWD (German Meteorological Service) in Offenbach via the Central Institution for Decision Support Systems in Crop Protection (ZEPP). The data set included daily readings of temperature $\left[{ }^{\circ} \mathrm{C}\right]$, relative humidity [\%], both recorded $2 \mathrm{~m}$ above ground, and precipitation [mm] from 2003 to 2005 .

\section{Results}

\section{Analysis of wheat rachides for Fusarium colonization}

Our first goal was to identify the causal agent of FHB and DON contamination in Germany. To differentiate systemic infection spreading along the ear from the infection confined to a single-spikelet and from mycelium and spores transferred to the ears by the wind, we analyzed fungal DNA within the rachides of wheat heads with FHB symptoms rather than extracting DNA from the entire heads. Qualitative duplex PCR with melting curve analysis was used for the detection of F. graminearum and F. culmorum in DNA extracted from each of the 540 rachides collected from 54 fields in the 2003 season. F. graminearum and/or F. culmorum DNA was found in 516 samples (96\%), indicating that these two species were responsible for the brown coloration of the rachides. The surface-sterilized rachides sections were placed on PDA plates as described in Brandfass and Karlovsky (2006a). With a few exceptions, only one morphologically distinct fungal species grew out of each rachis. The morphology of the colonies was assessed visually and cultures deviating from a typical phenotype of F. graminearum and F. culmorum were transferred to SNA and identified microscopically. The only Fusarium species found apart from F. graminearum and F. culmorum was $F$. poae, occurring just in 3 instances in rachides, which also contained F. graminearum or F. culmorum, and in 4 instances in rachides where none of the other two Fusarium spp. was detected. Other fungal species occasionally recovered from the rachides were Alternaria spp., Rhizoctonia cerealis and Epicoccum spp.

A North-South gradient in the ratio of F. graminearum to F. culmorum frequently reported in the literature was not detectable (Fig. 1), because no significant correlation between the latitude of the field, from which the rachides originated, and the proportion of the occurrence of F. graminearum or F. culmorum was found (Pearson's test of correlation, $\alpha=5 \%)$. 


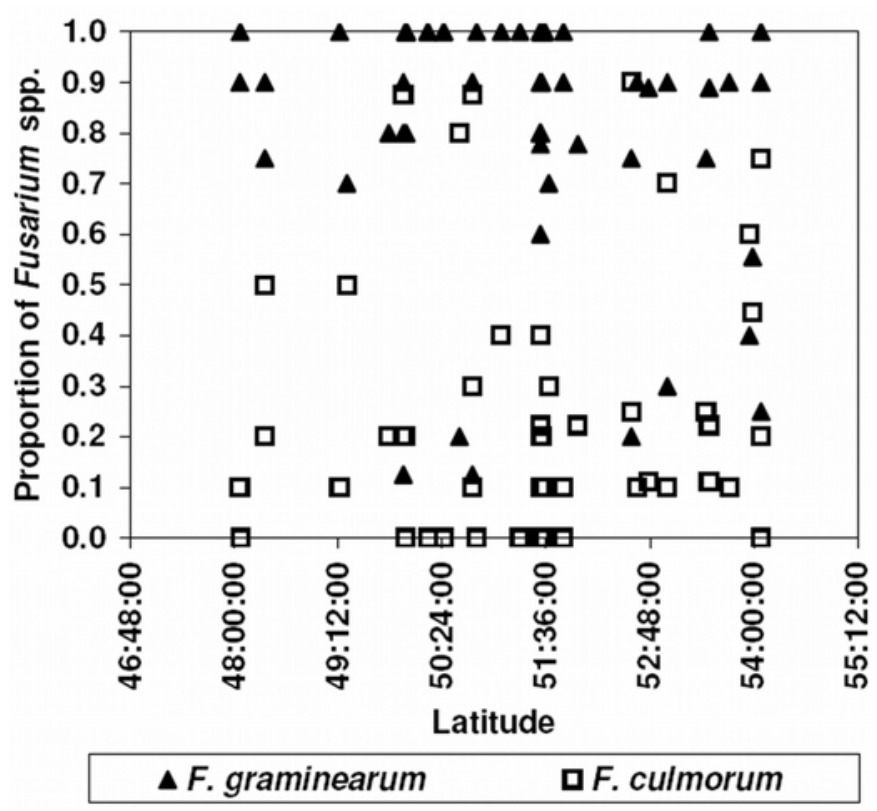

Figure 1: South-North distribution of Fusarium spp. The proportion of the occurrence of F. graminearum and F. culmorum in wheat rachides is drawn against the latitude of the origin of the samples. The rachides were prepared from wheat ears with symptoms of FHB collected throughout Germany in 2003 at the milk development stage (10 rachides per site).

\section{Relationship between rachis colonization and the contamination of grain with DON}

The results of DNA analysis were sorted according to the DON content of grain harvested from the corresponding fields in the fall of the same year. Fig. 2 summarizes the results. At 23 sites with wheat grain samples containing more than $500 \mu \mathrm{g}$ per $\mathrm{kg}$ DON, $91.2 \%$ of the rachides contained F. graminearum and $4.4 \%$ contained F. culmorum, while both pathogens were detectable in remaining $4.4 \%$ of the samples. Grain from 31 sites contained less of DON than $500 \mu \mathrm{g}$ per $\mathrm{kg}$. A portion of $74.4 \% \mathrm{of}$ rachides collected in these fields contained $F$. graminearum alone, 23.9\% rachides contained F. culmorum and mixed infection by both pathogens was detected in $1.7 \%$ of the samples.

In addition to the determination of DON content, DNA of F. graminearum and F. culmorum was quantified in these grains by real-time PCR as described in Materials and Methods. The samples were grouped according to their DON content using a threshold of $500 \mu \mathrm{g} \mathrm{kg}^{-1}$ DON. Grain samples contaminated with more than $500 \mu \mathrm{g} \mathrm{kg}^{-1}$ DON (23 fields) contained $83 \mu \mathrm{g} \mathrm{kg}^{-1}$ F. graminearum DNA and $3 \mu \mathrm{g} \mathrm{kg}^{-1}$ F. culmorum DNA on the average, whereas grain contaminated with less DON than $500 \mu \mathrm{g} \mathrm{kg}^{-1}$ 
contained $15 \mu \mathrm{g} \mathrm{kg}^{-1}$ F. graminearum DNA and $3 \mu \mathrm{g} \mathrm{kg}^{-1}$ F. culmorum DNA (Fig. 3).

The difference in F. graminearum DNA content was significant (Mann test, $\mathrm{p}<0.0001$ ).

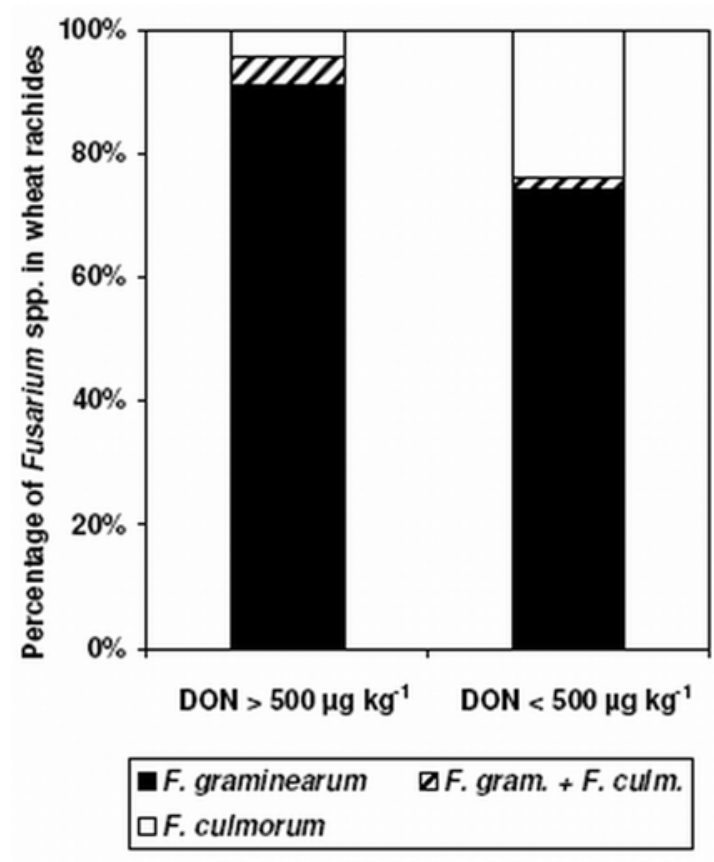

Figure 2: $F$. graminearum and $F$. culmorum DNA in wheat rachides in 2003. Wheat ears with symptoms of FHB were collected throughout Germany in 2003 at the milk development stage (10 ears per site). Fusarium DNA was analyzed by PCR and the results were sorted according to the DON content of grain harvested from the same field.

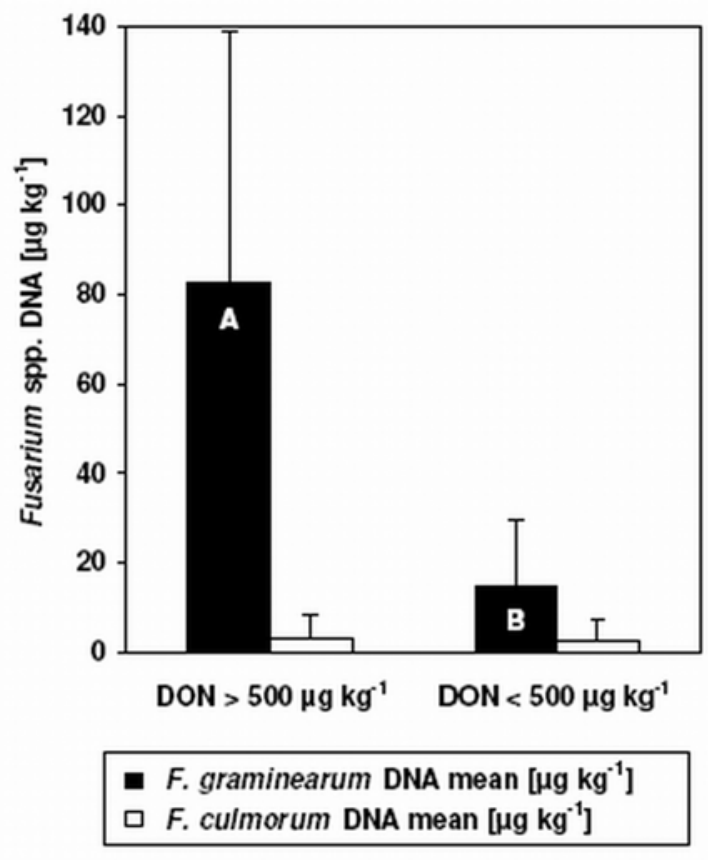

Figure 3: Fusarium DNA content of wheat grain with respect to the DON content (2003). Grain was harvested from the same fields used for collecting rachides. The Fusarium spp. DNA content was determined by real-time PCR and DON content was measured by ELISA as described in Materials and Methods section. The samples were grouped according to their DON content as indicated in the figure and the means and standard deviations of F. graminearum and F. culmorum DNA amounts were calculated for each group. The F. graminearum DNA contents differed significantly (Mann-Test, p < 0.0001). 


\section{Relationship between DON contamination and DNA content of grain}

The analysis of rachides indicated that the major cause of DON contamination of grain was F. graminearum. However, the DON producer F. culmorum was found in a considerable number of rachides and also in grain samples. Therefore, we analyzed 388 wheat grain samples collected from 2003 to 2005 (Table 1) for their DON and Fusarium spp. DNA content. The 54 grain samples of 2003 evaluated in the context of the rachides analysis described above were a subset of 120 samples analyzed here from the 2003 harvest.

Looking at the whole time span from 2003 to 2005, the DON concentration correlated well with the F. graminearum DNA content (squared correlation coefficient $\mathrm{R}^{2}=0.73, \mathrm{p}$ $<0.001$ for Pearson's test of correlation). The F. culmorum DNA content did not correlate with DON content. In line with the results of the rachides analysis, this finding indicates that the contamination of wheat grain with DON was caused mainly by F. graminearum. The contribution of F. culmorum to DON accumulation appears insignificant.

A comparison of the results for each year revealed clear differences. The slope of the regression line (Fig. 4) was highest in 2003 (24.0) and lowest in 2005 (5.3). The $\mathrm{R}^{2}$ value as a measure of the quality of the correlation varied too, showing a large increase from 2003 to 2004 and 2005. The means of the DNA and DON contents in wheat of the analyzed years are given in Fig. 5.
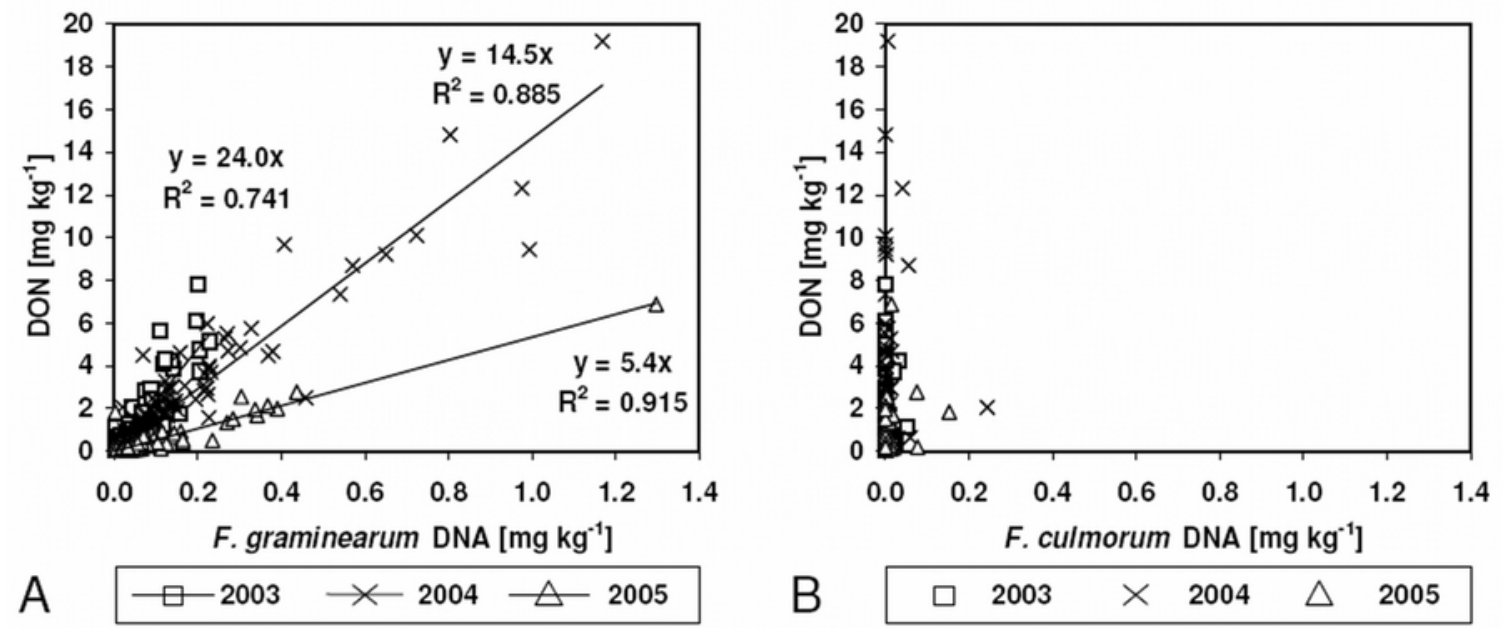

Figure 4: Correlation of DON amount in wheat grain with Fusarium spp. DNA content (2003-2005). The DON content of the grain is plotted against A) F. graminearum DNA and B) F. culmorum DNA for each year separately. Linear regression was calculated for each pair of variables. The regression equation and $\mathrm{R}^{2}$ (square of the correlation coefficient) are shown in the graph. 

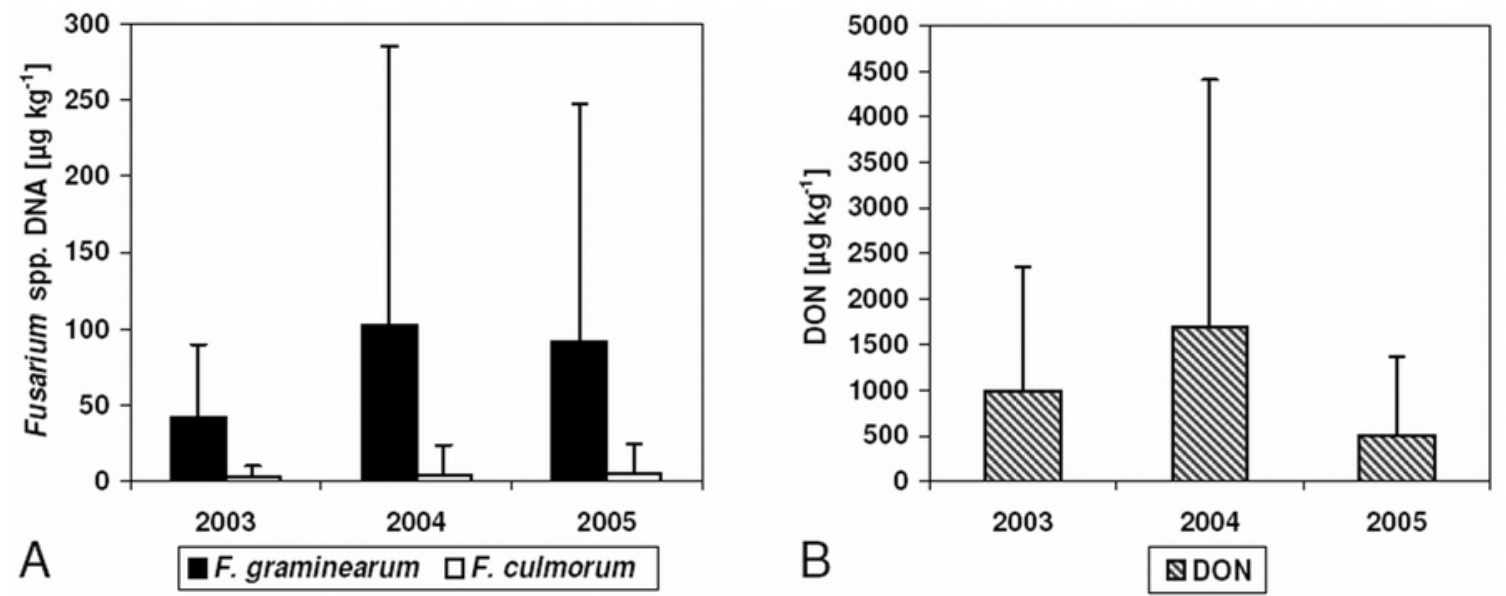

Figure 5: Fusarium spp. DNA and DON content in wheat grain collected throughout Germany 2003-2005. Means and standard deviations of all analyzed grain samples are shown.

\section{Weather data}

Weather data of the meteorological station of the DWD (German Meteorological Service) in Göttingen were used, because it is settled approximately in the centre of Germany and many samples came from the area around Göttingen each year. Averages of two time spans were calculated for each year (Table 2). The first time span includes the period of wheat flowering, extended by seven days prior the bloom according to Hooker et al. (2002) and De Wolf et al. (2003). This period represents the time when the infection with Fusarium spp. occurs. A second set of weather data was collected from the end of bloom up to the harvesting season. This phase represents the fungal development during grain ripening.

The infection phase of the year 2003 is characterized by the most precipitation and highest temperature in comparison to the other years. Concerning the fungal development phase, the most humid growing season was the year 2004, followed by 2005 and finally the comparable dry fungal development phase 2003. 
Table 2: Weather condition in central Germany 2003-2005. Weather data of the meteorological station of the DWD in Göttingen were used. Averaged daily readings of temperature $\left[{ }^{\circ} \mathrm{C}\right]$ and relative humidity (Humidity in \%), the sum of precipitation [mm] and the number of days with more than $3 \mathrm{~mm}$ precipitation are shown. The data are summarized for the periods "Head emergence and flowering" and "Ripening", which represent year-specific averaged growth stages of wheat in Göttingen. The ripening phase of 2004 is longer because a long rainy period delayed the harvest until September.

\begin{tabular}{|c|c|c|c|c|}
\hline & Year & 2003 & 2004 & 2005 \\
\hline \multirow{6}{*}{ 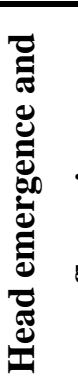 } & Time span & $30.05-15.06$ & $04.06-20.06$ & $08.06-26.06$ \\
\hline & Temperature $\left[{ }^{\circ} \mathrm{C}\right]$ & 19.1 & 15.1 & 15.8 \\
\hline & Humidity [\%] & 76.3 & 78.8 & 75.0 \\
\hline & Precipitation [mm] & 55.2 & 35.0 & 13.7 \\
\hline & \# Precip $>3$ mm & 4 & 4 & 2 \\
\hline & Ranking infection & 1 & 2 & 3 \\
\hline \multirow{6}{*}{ 足 } & Time span & 16.06.-15.08. & 21.06.-31.08 & $27.06-15.08$ \\
\hline & Temperature $\left[{ }^{\circ} \mathrm{C}\right]$ & 19.5 & 16.9 & 16.8 \\
\hline & Humidity [\%] & 67.8 & 76.9 & 76.9 \\
\hline & Precipitation [mm] & 61.3 & 206.1 & 123.2 \\
\hline & \# Precip $>3 \mathrm{~mm}$ & 8 & 19 & 14 \\
\hline & Ranking fungal growth & 3 & 1 & 2 \\
\hline
\end{tabular}

\section{Discussion}

The aim of the study was firstly to find out whether F. graminearum and F. culmorum infection alone can explain FHB incidence in our sample set. Secondly, we investigated the relationship between DON contamination and the biomass of F. graminearum and F. culmorum with the goal of assessing the relative contribution of these species to DON accumulation in grain.

\section{Causal agent of FHB}

It is often stated in the literature that FHB is caused by a complex consisting of up to 17 fungal species, including mycotoxin producers F. graminearum, F. culmorum, F. poae, F. avenaceum and F. sporotrichioides (e.g., Edwards, 2004). An apparent support for this view is provided by publications reporting the isolation of numerous fungal species from surface-sterilized heads of small grain cereal plants (e.g., Birzele et al., 2002; Parry et al., 1995). However, these surveys do not distinguish between (i) fungi growing 
saprophytically within dead surface tissues, which protect them from sodium hypochlorite used for the sterilization, (ii) fungal species, which can infect living tissue but remain confined to a single spikelet, and (iii) pathogens, which are able to penetrate the base of the spikelet, enter the rachis, grow within the rachis downwards and systemically colonize the ear. Only fungi of the last kind cause typical FHB symptoms, which are bleaching of the ear upwards the infection site, browning of the rachis downward the infection site carrying green spikelets at milk development stage, and colonization of the lower part of the ear in the later stages of the infection, which leads to the accumulation of high amounts of DON. We prepared rachides from wheat heads exhibiting FHB symptoms, collected from fields representing all climatic zones and major wheat growing areas in Germany. The rachides were investigated for Fusarium colonization by PCR and by the isolation of fungi from inside the surface sterilized rachides.

Our PCR analysis targeted F. graminearum and F. culmorum, which are the only producers of DON (Bottalico and Perrone, 2002), with the intention to subject fungi isolated from rachides not colonized by F. graminearum or F. culmorum to a detailed mycological analysis. However, it turned out that essentially all (96\%) rachides from heads afflicted with FHB contained either F. graminearum or F. culmorum. The PCR result was confirmed by the analysis of fungal isolates originating from surface-sterilized rachides: apart from $F$. graminearum and F. culmorum, only $F$. poae has been recovered a couple of times from a total of over 500 rachides analyzed. We concluded that F. graminearum and F. culmorum are the only Fusarium species responsible for the systemic colonization of wheat heads afflicted with FHB. Other Fusarium species frequently isolated from wheat ears and kernels, notably F. avenaceum, F. poae and F. sporotrichioides, do not seem to be relevant for FHB.

Recently, a predominant presence of F. graminearum and F. poae has been reported from four European countries (Xu et al., 2005). In this work wheat heads were sampled randomly without taking into account the severity of FHB. The ability of the species to colonize ears systemically was not addressed. The result of Xu et al. therefore does not contradict to our conclusion. The abundance of $\mathrm{F}$. poae in the collection by $\mathrm{Xu}$ et al. indicates that European populations of $F$. poae colonize dead tissues in the heads of cereal plants and infect single spikelets. F. poae has not been reported to colonize the axis and therefore does not cause typical FHB symptoms. 
Authors claiming that FHB is caused by a complex of fungal species also regularly state that F. culmorum predominates at the cooler, maritime regions, whereas F. graminearum tend to predominate at the hotter central Europe (Parry et al., 1995). Germany extends from the northern coast up to the southern area settled in continental central Europe. Thus, a gradient of the proportion of F. graminearum and F. culmorum is to be expected. However, no such gradient was detectable in our sample set. This might be due to an extensive replacement of $F$. culmorum by F. graminearum in the whole area in recent years, as also discussed for the Netherlands (Waalwijk et al., 2003).

\section{Relative contribution of $F$. graminearum and F. culmorum to DON accumulation}

Three lines of evidence support the view that F. graminearum alone is responsible for the economically relevant contamination of wheat grain with DON. Firstly, the relative occurrence of $F$. graminearum as compared to F. culmorum in wheat rachides is higher in samples from fields yielding grain with a high DON content (Fig. 2). Secondly, the amount of F. graminearum DNA in wheat grain contaminated with DON is an order of magnitude higher than the amount of F. culmorum DNA (Fig. 3 and 4). The final and most important argument for an exclusive role of $F$. graminearum in DON contamination is a tight correlation between fungal DNA and DON content for F. graminearum and the lack of such correlation for F. culmorum (Fig. 4). The predominance of F. graminearum was also reported for wheat kernels from ears with FHB symptoms in the Netherlands (Waalwijk et al., 2003). It has repeatedly been reported that DON amounts in grain and the total content of F. graminearum and F. culmorum DNA in naturally infected material correlate well (Waalwijk et al., 2004; Nicholson et al., 2003). These results can be explained by the fact that the amount of F. culmorum DNA in our samples was one to two orders of magnitude lower than the amount of F. graminearum DNA. Providing that the relative amounts of F. culmorum and F. graminearum biomass in field material investigated in the work cited above were similar, the correlation between total Fusarium DNA and the DON content was largely determined by F. graminearum.

\section{DON accumulation, FHB rating and virulence: a common lapse in the inter- pretation of their relationship}

A tight correlation between DON content and FHB severity has been found in numerous field studies and construed to support the hypothesis that DON acts as virulence factor. Although the role of DON in virulence of F. graminearum has been unequivocally proven with the help of genetically engineered strains defective in the DON production 
(Bai et al., 2002; Proctor et al., 2002; Desjardins et al., 2000; Proctor et al., 1997; Desjardins et al., 1996; Proctor et al., 1995), most of the reasoning to this end, based on the correlation of FHB rating with DON content, is principally flawed. For example, Wanyoike et al. (2002) found a significant correlation between the rating of head blight caused by F. graminearum isolates and the DON contents in infected grain (correlation coefficient $0.68-0.75$ ) and concluded that the DON-producing capacity could, therefore, be a decisive factor of virulence of $F$. graminearum. The catch is that even if DON production had no affect on plant colonization and FHB rating, a close correlation between DON content and FHB rating would very likely occur, because both phenomena are controlled by the amount of fungal biomass in the ear. Rather than representing a cause-effect relationship, DON accumulation and FHB rating are two effects of a common cause. The logical lapse in the interpretation of DON accumulation in FHBafflicted ears became so common that it has been perpetuated in numerous reviews (for example - Mesterhazy et al., 2005; Snijders, 2004; Wong et al., 1995).

\section{DON productivity}

Because the amount of F. graminearum DNA and DON content correlate well, it is generally assumed that the amount of DON produced by a unit of fungal biomass in a unit of time (DON productivity) is constant. A few studies, which addressed this question directly, support this view. For example, Cumagun et al. (2004) investigated the ability to colonize a susceptible wheat cultivar and DON accumulation for a segregating population of 50 progenies of a G. zeae cross in three environments. They found that the ratio of DON amount and fungal biomass did not change significantly among progenies and environments. DON production by F. graminearum in vitro increased with relative humidity (Beyer et al., 2005) and with temperature (Hope et al., 2005; Martins and Martins, 2002).

The capacity of F. graminearum to synthesize DON in grain (DON productivity) is represented by the slope of the regression line in the graph of DON concentration versus fungal DNA content. Surprisingly, we found large differences in DON productivity among the years 2003, 2004 and 2005 (Fig. 4). We can exclude the influence of agronomical factors because the data were derived from a large set comprising different planting areas, pre-crops and other agronomical conditions. A significant effect of DON production by F. culmorum is unlikely because the biomass of F. culmorum was much smaller than F. graminearum and it has not been correlated with DON content. 
Field populations of F. graminearum consist of strains with different DON productivity (Gilbert et al., 2002; Mesterhazy, 2002). The differences in DON productivity among the years can therefore be explained by a shifting composition of F. graminearum populations in time, leading to the enrichment of strains with a lower capacity to produce DON in years 2004 and 2005 as compared to 2003. An alternative explanation is the effect of weather conditions, which varied largely from 2003 to 2005.

\section{The effect of weather on FHB and DON production}

Weather data collected in Göttingen are summarized in Table 2. The so called infection phase was established according to published prediction models (De Wolf et al., 2003; Hooker et al., 2002), the fungal development phase was defined as the time span from the end of the infection phase till the harvest.

Most Fusarium species produce inoculum, grow best, and are most pathogenic to cereal heads at warm temperatures and under humid conditions. Conditions favorable for in vitro growth are also generally the most favorable for mycotoxin production on cereal grains (Doohan et al., 2003). For example, Brennan et al. (2005) found that eight wheat cultivars inoculated with single isolates of F. graminearum contained higher amounts of fungal DNA at $20^{\circ} \mathrm{C}$ compared to $16^{\circ} \mathrm{C}$.

The warm and humid weather in the infection phase of the year 2003 was most favorable for the infection, but during the following ripening phase the weather became hot and dry, hardly allowing fungal growth. This was the growing season least favorable for fungal growth, resulting in the lowest averaged DNA content (Fig. 5). In contrast, the DON production per fungal biomass was highest in 2003. Hope et al. investigated the effect of water activity $\left(\mathrm{a}_{(\mathrm{w})} 0.99-0.85\right)$ and temperature $\left(15\right.$ and $\left.25^{\circ} \mathrm{C}\right)$ on the growth and DON production by F. graminearum on wheat grains. They found that the production of DON occurred over a much narrower range than the growth. The maximum DON production by $F$. graminearum occurred at high water activities at both temperature levels (Hope et al., 2005). The year 2003 allowed for fungal growth mainly in the short infection period, which was favorable for both DON production and F. graminearum development. We speculate that fungal growth and DON production was interrupted by the hot and dry period which followed. This may explain the highest DON production efficiency in combination with the lowest biomass in 2003 (Fig. 4).

The years 2004 and 2005 were both moderately warm and wet (Tab. 2), with 2004 having more precipitation in both infection and ripening phase implicating better 
conditions for fungal development in both phases. As a result, the F. graminearum contamination as well as the total DON production was higher in 2004 than in 2005.

In both years, the biomass of F. graminearum could develop continuously, including periods of low DON production. The higher DON productivity in 2004 as compared to 2005 might be explained by a longer period of conditions favorable for DON production in 2004, as 2004 had more rain at comparable temperatures.

As a result, as successful infection in Germany does not need necessarily lead to a FHB epidemic, as might be interpreted from the risk assessment model of De Wolf et al. (2003). Another approach to identify important weather variables and their timing for predicting concentrations of DON in mature grain at wheat heading (Hooker et al., 2002) is in better accordance with our results.

\section{Conclusion}

Applying a rachides analysis of wheat ears afflicted with Fusarium head blight and grain analysis for DON and Fusarium spp. DNA, we showed that F. graminearum is the main causing agent of FHB and DON contamination of wheat in Germany. This is in accordance with Waalwijk et al. (2003), who experienced an increased prevalence of F. graminearum in the Netherlands.

\section{Acknowledgements}

The Central Institution for Decision Support Systems in Crop Protection (Bad Kreuznach, Germany) and the plant protection services of the Federal States are gratefully acknowledged for providing us with the plant material. We thank Claudia Nordmann, Patricia Bartoschek and Petra Romanczuk-Schultz for their technical assistance. The work was funded by a grant from the German Federal Ministry of Consumer Protection, Food and Agriculture (Grant No. 02 HS 023).

\section{Literature Cited}

Aldred, D., and N. Magan. 2004. Prevention strategies for trichothecenes. Toxicology Letters 153: 165-171.

Anonymous. 1999. Verordnung über Höchstmengen an Mykotoxinen in Lebensmitteln (Mykotoxin-Höchstmengenverordnung - MHmV), p. 1248-1251 Bundesgesetzblatt, Vol. 1. Bundesanzeiger Verlagsges.m.b.H., Bonn. 
Anonymous. 2004. Verordnung zur Änderung der Mykotoxin-Höchstmengenverordnung und der Diätverordnung, p. 151-152 Bundesgesetzblatt, Vol. 1. Bundesanzeiger Verlagsges.m.b.H., Bonn.

Bai, G.H., and G. Shaner. 2004. Management and resistance in wheat and barley to Fusarium head blight. Annual Review of Phytopathology 42: 135-161.

Bai, G.H., A.E. Desjardins, and R.D. Plattner. 2002. Deoxynivalenol-nonproducing Fusarium graminearum causes initial infection, but does not cause disease spread in wheat spikes. Mycopathologia 153: 91-98.

Beyer, M., J.A. Verreet, and W.S.M. Ragab. 2005. Effect of relative humidity on germination of ascospores and macroconidia of Gibberella zeae and deoxynivalenol production. International Journal of Food Microbiology 98: 233240.

Birzele, B., A. Meier, H. Hindorf, J. Kramer, and H.W. Dehne. 2002. Epidemiology of Fusarium infection and deoxynivalenol content in winter wheat in the Rhineland, Germany. European Journal of Plant Pathology 108: 667-673.

Bottalico, A., and G. Perrone. 2002. Toxigenic Fusarium species and mycotoxins associated with head blight in small-grain cereals in Europe. European Journal of Plant Pathology 108: 611-624.

Brandfass, C., and P. Karlovsky. 2006a. Simultaneous detection of Fusarium culmorum and F. graminearum in plant material by duplex PCR with melting curve analysis. BMC Microbiology 6: 4.

Brandfass, C., and P. Karlovsky. 2006b. Cost-effective quantification of Fusarium culmorum and F. graminearum in plant material by real-time PCR. submitted.

Brennan, J.M., D. Egan, B.M. Cooke, and F.M. Doohan. 2005. Effect of temperature on head blight of wheat caused by Fusarium culmorum and F. graminearum. Plant Pathology 54: 156-160.

Champeil, A., T. Dore, and J.F. Fourbet. 2004. Fusarium head blight: epidemiological origin of the effects of cultural practices on head blight attacks and the production of mycotoxins by Fusarium in wheat grains. Plant Science 166: 1389-1415.

Cumagun, C.J.R., F. Rabenstein, and T. Miedaner. 2004. Genetic variation and covariation for aggressiveness, deoxynivalenol production and fungal colonization among progeny of Gibberella zeae in wheat. Plant Pathology 53: 446-453. 
De Wolf, E.D., L.V. Madden, and P.E. Lipps. 2003. Risk assessment models for wheat Fusarium head blight epidemics based on within-season weather data. Phytopathology 93: 428-435.

Desjardins, A.E., G.H. Bai, R.D. Plattner, and R.H. Proctor. 2000. Analysis of aberrant virulence of Gibberella zeae following transformation-mediated complementation of a trichothecene-deficient (Tri5) mutant. Microbiology-Uk 146: 2059-2068.

Desjardins, A.E., R.H. Proctor, G.H. Bai, S.P. McCormick, G. Shaner, G. Buechley, and T.M. Hohn. 1996. Reduced virulence of trichothecene-nonproducing mutants of Gibberella zeae in wheat field tests. Molecular Plant-Microbe Interactions 9: 775781.

D'Mello, J.P.F., C.M. Placinta, and A.M.C. Macdonald. 1999. Fusarium mycotoxins: a review of global implications for animal health, welfare and productivity. Animal Feed Science \& Technology 80: 183-205.

Doohan, F.M., J. Brennan, and B.M. Cooke. 2003. Influence of climatic factors on Fusarium species pathogenic to cereals. European Journal of Plant Pathology 109: 755-768.

Edwards, S.G. 2004. Influence of agricultural practices on fusarium infection of cereals and subsequent contamination of grain by trichothecene mycotoxins. Toxicology Letters 153: 29-35.

Gilbert, J., D. Abramson, B. McCallum, and R. Clear. 2002. Comparison of Canadian Fusarium graminearum isolates for aggressiveness, vegetative compatibility, and production of ergosterol and mycotoxins. Mycopathologia 153: 209-215.

Haidukowski, M., M. Pascale, G. Perrone, D. Pancaldi, C. Campagna, and A. Visconti. 2005. Effect of fungicides on the development of Fusarium head blight, yield and deoxynivalenol accumulation in wheat inoculated under field conditions with Fusarium graminearum and Fusarium culmorum. Journal of the Science of Food and Agriculture 85: 191-198.

Hooker, D.C., A.W. Schaafsma, and L. Tamburic-Ilincic. 2002. Using weather variables pre- and post-heading to predict deoxynivalenol content in winter wheat. Plant Disease 86: 611-619.

Hope, R., D. Aldred, and N. Magan. 2005. Comparison of environmental profiles for growth and deoxynivalenol production by Fusarium culmorum and F. graminearum on wheat grain. Letters in Applied Microbiology 40: 295-300. 
Langevin, F., F. Eudes, and A. Comeau. 2004. Effect of trichothecenes produced by Fusarium graminearum during Fusarium head blight development in six cereal species. European Journal of Plant Pathology 110: 735-746.

Leonard, K.J., and W.R. Bushnell, (eds.) 2003. Fusarium Head Blight of Wheat and Barley, pp. 1-512. The American Phytopathological Society, St. Paul, Minnesota, USA.

Martins, M.L., and H.M. Martins. 2002. Influence of water activity, temperature and incubation time on the simultaneous production of deoxynivalenol and zearalenone in corn (Zea mays) by Fusarium graminearum. Food Chemistry 79: 315-318.

Mesterhazy, A. 2002. Role of deoxynivalenol in aggressiveness of Fusarium graminearum and F. culmorum and in resistance to Fusarium head blight. European Journal of Plant Pathology 108: 675-684.

Mesterhazy, A., T. Bartok, G. Kaszonyi, M. Varga, B. Toth, and J. Varga. 2005. Common resistance to different Fusarium spp. causing Fusarium head blight in wheat. European Journal of Plant Pathology 112: 267-281.

Nicholson, P., D.R. Simpson, G. Weston, H.N. Rezanoor, A.K. Lees, D.W. Parry, and D. Joyce. 1998. Detection and quantification of Fusarium culmorum and Fusarium graminearum in cereals using PCR assays. Physiological and Molecular Plant Pathology 53: 17-37.

Nicholson, P., E. Chandler, R.C. Draeger, N.E. Gosman, D.R. Simpson, M. Thomsett, and A.H. Wilson. 2003. Molecular tools to study epidemiology and toxicology of Fusarium head blight of cereals. European Journal of Plant Pathology 109: 691703.

Parry, D.W., P. Jenkinson, and L. McLeod. 1995. Fusarium ear blight (scab) in small grain cereals -- A review. Plant Pathology 44: 207-238.

Peraica, M., B. Radic, A. Lucic, and M. Pavlovic. 1999. Toxic effects of mycotoxins in humans. Bulletin of the World Health Organization 77: 754-766.

Pestka, J.J., and A.T. Smolinski. 2005. Deoxynivalenol: Toxicology and potential effects on humans. Journal of Toxicology and Environmental Health-Part B-Critical Reviews 8: 39-69.

Pieters, M.N., J. Freijer, B.J. Baars, D.C.M. Fiolet, J. van Klaveren, and W. Slob. 2002. Risk assessment of deoxynivalenol in food: Concentration limits, exposure and 
effects, p. 235-248 Mycotoxins and Food Safety, Vol. 504. KLUWER ACADEMIC/PLENUM PUBL, New York.

Pirgozliev, S.R., S.G. Edwards, M.C. Hare, and P. Jenkinson. 2003. Strategies for the control of Fusarium head blight in cereals. European Journal of Plant Pathology 109: 731-742.

Proctor, R.H., T.M. Hohn, and S.P. McCormick. 1995. Reduced Virulence of Gibberella zeae Caused by Disruption of a Trichothecene Toxin Biosynthetic Gene. Molecular Plant-Microbe Interactions 8: 593-601.

Proctor, R.H., T.M. Hohn, and S.P. McCormick. 1997. Restoration of wild-type virulence to Tri5 disruption mutants of Gibberella zeae via gene reversion and mutant complementation. Microbiology-Uk 143: 2583-2591.

Proctor, R.H., A.E. Desjardins, S.P. McCormick, R.D. Plattner, N.J. Alexander, and D.W. Brown. 2002. Genetic analysis of the role of trichothecene and fumonisin mycotoxins in the virulence of Fusarium. European Journal of Plant Pathology 108: 691-698.

Rocha, O., K. Ansari, and F.M. Doohan. 2005. Effects of trichothecene mycotoxins on eukaryotic cells: A review. Food Additives and Contaminants 22: 369-378.

Schilling, A.G., E.M. Moller, and H.H. Geiger. 1996. Polymerase chain reaction-based assays for species-specific detection of Fusarium culmorum, F. graminearum, and F. avenaceum. Phytopathology 86: 515-522.

Schnerr, H., R.F. Vogel, and L. Niessen. 2002. Correlation between DNA of trichothecene-producing Fusarium species and deoxynivalenol concentrations in wheat-samples. Letters in Applied Microbiology 35: 121-125.

Snijders, C.H.A. 2004. Resistance in wheat to Fusarium infection and trichothecene formation. Toxicology Letters 153: 37-46.

Waalwijk, C., P. Kastelein, I. de Vries, Z. Kerenyi, T. van der Lee, T. Hesselink, J. Kohl, and G. Kema. 2003. Major changes in Fusarium spp. in wheat in the Netherlands. European Journal of Plant Pathology 109: 743-754.

Waalwijk, C., R. van der Heide, I. de Vries, T. van der Lee, C. Schoen, G. Costrel-de Corainville, I. Hauser-Hahn, P. Kastelein, J. Kohl, P. Lonnet, T. Demarquet, and G.H.J. Kema. 2004. Quantitative detection of Fusarium species in wheat using TaqMan. European Journal of Plant Pathology 110: 481-494.

Wanyoike, M.W., F. Walker, and H. Buchenauer. 2002. Relationship between virulence, fungal biomass and mycotoxin production by Fusarium graminearum in winter 
wheat head blight. Zeitschrift Fur Pflanzenkrankheiten Und PflanzenschutzJournal of Plant Diseases and Protection 109: 589-600.

Wong, L.S.L., D. Abramson, A. Tekauz, D. Leisle, and R.I.H. Mckenzie. 1995. Pathogenicity and Mycotoxin Production of Fusarium Species Causing Head Blight in Wheat Cultivars Varying in Resistance. Canadian Journal of Plant Science 75: 261-267.

Xu, X.M. 2003. Effects of environmental conditions on the development of Fusarium ear blight. European Journal of Plant Pathology 109: 683-689.

Xu, X.M., D.W. Parry, P. Nicholson, M.A. Thomsett, D. Simpson, S.G. Edwards, B.M. Cooke, F.M. Doohan, J.M. Brennan, A. Moretti, G. Tocco, G. Mule, L. Hornok, G. Giczey, and J. Tatnell. 2005. Predominance and association of pathogenic fungi causing Fusarium ear blight in wheat in four European countries. European Journal of Plant Pathology 112: 143-154. 


\section{Chapter 5: General discussion}

\section{Methods developed}

The relative contribution of F. graminearum and F. culmorum to FHB depends upon a range of variables, which might also affect the amount of mycotoxins produced. Realtime PCR was the method of choice to determine the identity and the amount of these fungi within host tissues in a particular situation.

As we dealt with complex plant material like wheat flour, plant debris and wheat rachides, suitable DNA extraction methods had to be developed first. The starting point was a CTAB-based protocol invented by Murray and Thompson (1980) and developed and simplified by others (e.g., Stewart and Via, 1993). Looking at the wheat rachides, the small sample size and firm texture of the material put high demands on the homogenization of the samples. After unsuccessful attempts to disintegrate rachides in standard 2-ml tubes in a reciprocal mill, a large stainless steel ball (32 g) in a stainless steel container eventually enabled us to pulverize of rachides reproducibly. The DNA extraction for quantitative PCR faced another problem, because the colonization of plant material by Fusarium spp. is inhomogeneous, causing a large variation in DNA content among replicas when standard-size samples $(100 \mathrm{mg})$ are analyzed. We aimed at constant extraction efficiencies and a possibly large sample volume at low costs to improve the representation of inhomogeneous material in the sample. This should result in a reduction of the sampling errors (Mulfinger, 2000). Sonification (Knoll et al., 2002) and some modifications in the upscaled extraction protocol enabled us to achieve this goal. Beside the difficulties mentioned so far, the inhibition of the PCR by DNA extracts, particularly in case of wheat flour and plant residues, had to be circumvented (Wilson, 1997). This was achieved primarily by diluting the DNA extract before analysis. Other cleaning procedures like a second precipitation of DNA or a column-based purification were also investigated, but the extra workload and costs of these procedures eventually led us to use a simple dilution instead, in spite of the potential loss of sensitivity it may cause.

To establish PCR specific for F. graminearum, we looked for published primers suitable for our real-time PCR conditions. The most promising primers were those published by Schilling et al. (1996) due to their thoroughly tested specificity. However, we failed to 
adapt the F. graminearum specific primers to real-time PCR conditions. The gaoA targeted primers published by Niessen and Vogel (1997) were not preferred due to the size of the amplified product and published problems with the specificity (Kingsley, 2001). Therefore, we focused on the optimization of primers Fg16N (Nicholson et al., 1998), as these primers produce a product of constant size in contrast to primers Fg16 described in the same publication. The constant product size was important because melting temperature as well as signal intensity, which is crucial for both duplex and quantitative PCR, changes with the product size.

O'Donnell et al. (2004) proposed the existence of nine phylogenetically distinct species within the F. graminearum clade. Only lineage 7 has so far been reported in Europe and America (Ward et al., 2002; O'Donnell et al., 2000). According to Waalwijk et al., F. graminearum lineages 1, 2, 6 and 7 were amplified using the Fg16 primer set, whereas no PCR products were detected for lineages 3, 4 and 5 (Waalwijk et al., 2003). As the primers Fg16N used in our study amplify a section of the sequence amplified with the Fg16 primer set (Nicholson et al., 1998), it is not sure that all the lineages amplified using the Fg16 primer set can be detected with the help of Fg16N primers. However, all F. graminearum isolates used to test the specificity of Fg16N tested positive suggesting that these primers ensure a reliable detection of $F$. graminearum isolates originated from Germany.

With respect to F. culmorum-specific primers, we succeeded to adapt conditions for Opt18 primers (Schilling et al., 1996). The specificity for $F$. graminearum and F. culmorum could be confirmed for the particular assays both in duplex and in quantitative PCR.

The first real-time PCR assay to be developed was the qualitative detection of F. culmorum and F. graminearum to enable the identification of the two pathogens within rachides to determine the causing agent of FHB symptoms. A duplex assay was targeted in order to reduce the workload and costs occurring in the analysis of a high number of samples. As the fluorescent dye SYBR Green I intercalates unspecifically to all double-stranded DNA products, the main problem was the adjustment of the PCR signal intensity of the two products during the melting curve analysis. This problem was increased by the fact that the longer F. culmorum product binds the dye more efficiently than the F. graminearum product, leading to a suppression of the F. graminearum signal. This effect was partially compensated for by increasing the dye concentration. The same 
phenomenon was reported by Giglio et al. (2003) for different PCR products. These problems were eliminated by reducing the total Fusarium spp. DNA amount used in the assay, as the competition for dye binding does not play a significant role as long as the amount of F. culmorum DNA is low. Although the quantity of F. culmorum DNA in a particular sample is not known before the analysis, limitation of the total rachis DNA amount used in the assay secured reliable detection of both fungi.

The second obstacle to be overcome was the analysis of iCycler data, as the form in which the results of the melting curve analysis are provided has not been designed for evaluation in a high-throughput environment. This may be a reason why none of the published duplex PCR assays with SYBR Green uses the iCycler (Fukushima et al., 2003; Hernandez et al., 2003; Jothikumar et al., 2003). Therefore, we designed a spreadsheet, which transformed the output from the thermocycler into a user-friendly, color-enhanced tabular report. It is interesting to remark that the areas under the peaks in the first derivative of the melting curves, which can be used to estimate the quantity of a PCR product, are not available within the iCycler interface, but appear during the transfer of melting curve data when copied to a spreadsheet. These data are used to evaluate different signals in the melting curve to exclude false positives by setting thresholds in relation to the positive standards representing the detection limit. This was necessary as the peak analysis of the first derivative of the melting curves is very sensitive, responding to small changes in the slopes of the melting curve. These extremely small peaks are by far not visible in an electrophoretic gel, but rather originate from system-specific processing of optical data.

One reason for the difficulties we met might be the relatively large size of PCR products used in the duplex reaction (280 and $472 \mathrm{bp}$ ). Other published duplex or multiplex assays used shorter PCR products, which might be more easy to separate by melting curve analysis and also less prone to competition in SYBR Green binding. The product sizes used in other multiplex assays with SYBR Green were 85 and 98 bp for a duplex assay (Jothikumar et al., 2003), and 75 to 280 bp (Hernandez et al., 2003) or 95 to 383 bp (Fukushima et al., 2003) for multiplex assays using SYBR Green.

To compare our method with a classical approach, morphological taxonomy requires cultivation for at least 12 days, followed by time-consuming microscopic examination. The method developed in this study allows the simultaneous identification of F. graminearum and F. culmorum in one PCR without the use of doubly labeled hybridization probes or electrophoresis. Species-specific PCR products are differentiated 
by melting curve analysis, allowing a fast and cost-effective analysis of a large number of samples.

The second main task of this study was the quantitative detection of F. graminearum and F. culmorum in complex plant material like wheat flour and plant debris via real-time PCR. When we started the optimization of the primer Fg16N using a native Taq polymerase, the sensitivity of detection was insufficient to detect $F$. graminearum in many wheat flour samples of 2003 contaminated with DON. As we found out later, the cause was in part a high DON productivity in 2003 in combination with a low disease severity of FHB, leading to relatively low Fusarium spp. DNA contents accompanied by detectable DON amounts. After comparing different commercial kits and polymerases, we found that a particular PCR premix containing a hot-start polymerase (SYBR Premix Ex Taq, produced by Takara Bio, Otsu, Japan) secured the best performance for the F. graminearum assay, lowering the detection limit tenfold. No other premix or hot-start polymerase tested that time performed as well with this assay. We suppose that the higher specificity of amplification achieved with the help of hot-start polymerase might partly explain the superiority of this premix, as the primers tend to generate unspecific PCR products at low DNA concentrations.

For quantification purpose, a suitable standard curve had to be established to relate the PCR results to the amount of fungal DNA in the sample. As in any indirect analytical method, the quality of the standard curve is crucial for quantitative real-time PCR. Coamplification of specific plant DNA sequences (Winton et al., 2002) could not serve as an internal standard because plant DNA in plant debris is degraded by saprophytes to a variable degree. Mixing defined amounts of fungal mycelium with uncontaminated plant material to prepare standard curves was also hardly possible as fungal biomass in our plant samples was very low, making the preparation of defined mycelium/plant mixtures difficult. Therefore, the calibration curve was constructed with pure Fusarium spp. DNA mixed with DNA extracted from healthy maize or wheat flour. This procedure ensured that DNA standards and DNA from unknown samples were amplified under identical conditions. However, we found that standard curves analyzed with or without the addition of plant DNA did not differ significantly. 
We are aware of the fact that our quantitative real-time PCR detection system is not the only one available. Nevertheless it has several advantages, which we believe to make this system preferable in comparison with other PCR-based methods. As we wanted to quantify Fusarium spp., qualitative PCR assays to detect a Fusarium species (Demeke et al., 2005; Jurado et al., 2005; Nicolaisen et al., 2005) were per se not suitable for our purposes. In addition, the assay of Nicolaisen et al. does not allow the differentiation of F. graminearum and F. culmorum. Real-time PCR assays available so far for the quantification of toxigenic Fusarium spp. in infected plants are costly because they utilize doubly-labeled probes (Reischer et al., 2004a; Reischer et al., 2004b; Waalwijk et al., 2004). Thereby the assay of Reischer et al. detects only F. graminearum, whereas the TaqMan based detection system of Waalwijk et al. quantifies five species in separate reactions. Here the costs will play a dominant role, as for some primer and probe combinations further modifications (Minor Groove Binder) were necessary to ensure specificity. A recently published competitive microsatellite-based F. graminearum detection (Naef et al., 2006) is basically unsuitable for naturally infected material because it requires prior knowledge of microsatellite alleles present in the target strain. Therefore, this assay can only be used in experiments with artificial inoculation. Finally, the real-time PCR systems discussed were not available when we started our work.

The method developed in this study is suitable for cost-effective, high- throughput quantification of F. graminearum and F. culmorum in plant material by real-time PCR to be applied in epidemiological studies.

\section{Causal agent of FHB}

The collected data should serve for a further elucidation of the epidemiology of FHB by identifying the causing agent of this disease in Germany. This was accomplished by the qualitative detection of F. graminearum and F. culmorum in 10 symptomatic wheat rachides per field on 54 fields in 2003 and the determination of the relative importance of these Fusarium spp. in relation to the DON content of the corresponding harvested grain. We only analyzed the DON-producing Fusarium spp. F. graminearum and F. culmorum, as deoxynivalenol is the most frequently encountered Fusarium mycotoxins in FHB (Bottalico and Perrone, 2002), and DON is a virulence factor responsible for the fungal spread via the rachis causing the typical head blight symptoms (Jansen et al., 2005; Langevin et al., 2004). In addition, we wanted to know to which extent the often stated fact that F. graminearum is the dominant species in hotter central Europe and that $F$. 
culmorum tends to predominate in cooler maritime regions of northwest Europe (Bottalico and Perrone, 2002; Parry et al., 1995), is true for Germany. This statement cannot be supported by our data, as F. graminearum was found to be the dominant species all over Germany including the northern area near the coast. F. culmorum played only a minor role in rachides of 2003 derived from fields with a DON content of the corresponding harvested grain less than the legal limit for processed products $\left(500 \mu \mathrm{g} \mathrm{kg}^{-}\right.$ $\left.{ }^{1}\right)$. This may be due to a higher aggressiveness of this fungus when only few infections occur or due to lacking ascospore inoculum of $G$. zeae on the corresponding field. The major prevalence of F. graminearum was also reported from the Netherlands in wheat kernel samples of symptomatic ears (Waalwijk et al., 2003). The same holds true for the United States, where FHB is exclusively accredited to F.graminearum (Leonard and Bushnell, 2003).

Recently, a predominance presence of F. graminearum and F. poae has been reported in four European countries (Xu et al., 2005). Thereby, it has to be considered that the sampling was done randomly, neither associated with the severity of FHB nor with the toxin contamination of harvested grain. Hence, their results cannot be directly compared with our results, as F. graminearum is discussed being more aggressive and pathogenic than $F$. poae. The frequently occurring $F$. poae might therefore have a high potential of dispersal, with limited or varying effects on toxin content of the harvested grain. For example, Bottalico and Perrone report that the occurrence of T-2 toxin derivatives produced by $F$. poae have only been recorded in conjunction with sporadic epidemics of F. sporotrichioides and F. poae (Bottalico and Perrone, 2002).

The data attained in 2003 by the in-depth analysis of the rachides were confirmed by the results of the wheat flour samples of 2003 to 2005. In all three years F. graminearum was the by far dominating contaminating agent of wheat grain. F. culmorum was the only other noteworthy species, but it was still found only rarely in samples of 2003.

Plant residues on the soil surface are reported to be a primarily inoculum source for FHB (Xu, 2003; Parry et al., 1995). Spores produced on plant debris are ascospores of G. zeae as well as conidia of F. graminearum and F. culmorum. As both types of spores have been shown to be important for causing FHB (Xu, 2003), and both have mainly fieldspecific effects (Dill-Macky and Jones, 2000; Fernando et al., 1997), the content of F. graminearum and F. culmorum in plant debris was quantified from 2002 to 2005 to gain knowledge about the composition of the potential inoculum on a field. In 310 maize 
debris samples collected throughout Germany in autumn and spring, F. culmorum was found more frequently than in wheat kernel samples, probably due to a higher saprophytic fitness of this fungus. However, F. graminearum was still the dominant species, especially in samples collected in autumn after maize harvest. In spring of the following year, samples were collected from the same locations cropped with wheat in this year. Despite the comparable amounts of F. culmorum and F. graminearum at a lower total level in the spring samples serving as sources of inoculum for FHB, only F. graminearum was detectable in the corresponding wheat samples. This emphasizes the role of the formation of ascospores on maize residues for the risk of a FHB epidemic. In plant residues of other crops collected, namely wheat and rapeseed straw, no Fusarium spp. DNA was detectable.

\section{Relationship of toxin contamination and Fusarium spp. DNA}

It is known that DON and DNA content of the sum of F. graminearum and F. culmorum correlate well (Waalwijk et al., 2004; Nicholson et al., 2003). The same is valid for artificially inoculated trichothecene producing Fusarium spp. (Schnerr et al., 2002). This might indicate that these two species, which are the only known DON producing Fusarium spp., produce quite constant amounts of DON in relation to their biomass. However, these data do not answer the question, which of these two fungi is the causing agent of DON contamination.

Our results show that the DON production relevant for grain contamination is caused nearly exclusively by F. graminearum. Looking at the whole time span 2003 to 2005, a significant correlation of the DON concentration and the F. graminearum DNA content could be detected. ( $\mathrm{R}^{2}=0.73$ (square of the correlation coefficient), $\mathrm{p}<0.001$, Pearson's test of correlation). No correlation could be found between F. culmorum DNA and the DON concentration. Even the analysis of the sum of F. graminearum and F. culmorum DNA did not change the square of the correlation coefficient. This might explain the good correlations found for the sum of F. graminearum and F. culmorum in the literature, as these correlations are at least mainly caused by F. graminearum. In experiments with artificial inoculation, the use of visual FHB ratings may be also suitable, as the main source of inoculum is known (Haidukowski et al., 2005; Mesterhazy et al., 2005).

Despite these facts, the coherency of the DON contamination with FHB ratings is still in discussion. Thereby the term DON production or DON content needs to be separated from DON productivity, which is the DON production per unit of fungal biomass or 
DNA. Wanyoike et al. found significant correlation between head blight rating (AUDPC) of different $F$. graminearum isolates and the DON contents in infected grain $(r=0.68$ 0.75, Wanyoike et al., 2002) indicating that the visual FHB rating may give information about the DON content of samples infected with different isolates, at least under the same environmental conditions. Contrasting results were found by Brennan et al., who investigated the effect of small temperature differentials $\left(16\right.$ vs. $\left.20^{\circ} \mathrm{C}\right)$ on the pathogenicity of single isolates of $F$. graminearum and on the FHB severity determined on eight wheat cultivars. In their studies $F$. graminearum caused greater overall visual disease symptoms at $16^{\circ} \mathrm{C}$ than at $20^{\circ} \mathrm{C}$. Contrary results were obtained for the fungal DNA content. Plants contained higher amounts of $F$. graminearum DNA at $20^{\circ} \mathrm{C}$ than at $16^{\circ} \mathrm{C}$ (Brennan et al., 2005). This makes the use of visual disease assessment unsuitable as a measure of fungal colonization. Cumagun et al. investigated the relationship of F. graminearum biomass to DON production. They found a good correlation between DON production and Fusarium exoantigen content among a progeny population of $G$. zeae in wheat, even across 3 environments (Cumagun et al., 2004). In summary, the relation of FHB ratings to fungal biomass of F. graminearum might be questionable, whereas constant amounts of DON seem to be produced per unit of fungal biomass.

Our results show that the DON production relevant for grain contamination in relation to the fungal biomass changes among years. The factor of the regression equation to convert the F. graminearum DNA content to DON content (both in $\mu \mathrm{g} \mathrm{kg}^{-1}$ ), representing the DON productivity, decreases from 24.6 in 2003 to 5.3 in 2005 with an intermediate position of 14.9 in 2004. This might be due to a general shift within the F. graminearum population of Germany to strains with a lower DON productivity in the last two years, or due to an effect of different weather constellations.

The DON productivity is not correlated with the total DON or F. graminearum DNA contents of the three years. Similar results were obtained under constant environmental conditions by Wanyoike et al., who found only a low to moderate association between DON productivity of different isolates of $F$. graminearum and head blight ratings or DON content produced by these isolates (Wanyoike et al., 2002).

To describe weather parameters relevant for the development of FHB in Germany, a set of weather data recorded in Göttingen was chosen because it is settled in the centre of Germany and in all years many samples were collected in the area around Göttingen. Weather data for each year were summarized in two time spans, designated infection phase and fungal development phase to represent the meteorological differences of the 
three analyzed years. The infection phase includes the period of flowering plus seven days prior the bloom according to Hooker et al. (2002) and De Wolf et al. (2003). A second set of weather data is summarized from the end of bloom up to the harvesting season. This phase represents the fungal development during the ripening.

The year 2003 was the year with most precipitation at highest temperature in the infection phase. If the model of De Wolf et al. held true for our situation, a FHB epidemic could be expected. As this was not the case, either the fungal development phase had a decisive impact on the FHB development or the time span set for perithecia formation and infection was not sufficient for our conditions.

Looking at the time span in which the fungal development takes place, the most humid growing season is the year 2004, followed by 2005 and finally the comparable hot and dry fungal development phase of 2003. The same order was found looking at the total amount of F. graminearum DNA present in the samples. This suggests an important role of this phase in relation to the fungal colonization. This assumption is supported by the fact that most Fusarium species grow best and are most pathogenic to cereal heads at warm temperatures and under humid conditions (Doohan et al., 2003).

The year 2003 displays a special constellation of weather conditions. The warm and humid weather in the infection phase was most favorable for infection with Fusarium spp., but in the following ripening phase the weather became comparatively hot and dry, hardly allowing fungal growth within spikes. As a result, the averaged DNA content of the grain was the lowest of all years. In contrast, the DON production per fungal biomass was the highest in 2003. Hope et al. found that the production of DON occurred over a much narrower range of temperature and water availability than that for growth of F. graminearum (Hope et al., 2005). The year 2003 may have allowed the fungal growth and DON production mainly in the short infection period. As the fungal development was interrupted by the hot and dry weather afterwards, comparatively large amounts of DON were produced in relation to the total fungal biomass. This may explain the highest DON production efficiency in combination with the least biomass in 2003.

Due to the comparatively cold and wet summer in 2004 and 2005, the biomass of F. graminearum could develop continuously including periods of low DON production. The DON productivity might have been higher in 2004 than in 2005 due to longer periods of conditions favorable for DON production, as in 2004 more precipitation occurred at comparable temperatures. However, we found an interesting phenomenon, which has to be further elucidated. 
In a conclusion, a successful infection in Germany does not necessarily cause a FHB epidemic, as might be interpreted from the risk assessment model of De Wolf et al. (2003). Another approach to identify important weather variables and their timing for predicting concentrations of DON in mature grain (Hooker et al., 2002) is in better accordance with our results. However, this model becomes more inaccurate at high DON concentration and is only based on data from parts of Ontario limiting the applicability of the results. Therefore, Xu called for future research focusing on the development of more generally applicable forecasting models and on understanding the relationships between disease severity, fungal biomass and the production of associated mycotoxins ( $\mathrm{Xu}, 2003)$. FHB is a disease, which appear in epidemics highly dependent of the weather constellation of a specific year. This becomes even clearer after this study, as not only the total DON and DNA contents, but also the averaged DON productivity of the F. graminearum population in Germany are subject to change between the years. In addition, the extent of an FHB epidemic depends on a given inoculum source, for example maize residues available due to a reduced tillage system.

Therefore, the obtained data will help to adapt the model FUSOPT to predict FHB and DON contamination in Germany. The model shows the effect of agronomical risk constellations and demonstrates possibilities to reduce FHB by adapting agronomical practices. Fields and regions with high risk of a FHB infection are identified and fieldspecific threshold for plant protection are calculated. Thus, the model shall become an essential part of good agricultural practice to reduce FHB and toxin contamination in wheat.

\section{References}

Bottalico, A., and G. Perrone. 2002. Toxigenic Fusarium species and mycotoxins associated with head blight in small-grain cereals in Europe. European Journal of Plant Pathology 108: 611-624.

Brennan, J.M., D. Egan, B.M. Cooke, and F.M. Doohan. 2005. Effect of temperature on head blight of wheat caused by Fusarium culmorum and F. graminearum. Plant Pathology 54: 156-160.

Cumagun, C.J.R., F. Rabenstein, and T. Miedaner. 2004. Genetic variation and covariation for aggressiveness, deoxynivalenol production and fungal colonization among progeny of Gibberella zeae in wheat. Plant Pathology 53: 446-453. 
De Wolf, E.D., L.V. Madden, and P.E. Lipps. 2003. Risk assessment models for wheat Fusarium head blight epidemics based on within-season weather data. Phytopathology 93: 428-435.

Demeke, T., R.M. Clear, S.K. Patrick, and D. Gaba. 2005. Species-specific PCR-based assays for the detection of Fusarium species and a comparison with the whole seed agar plate method and trichothecene analysis. International Journal of Food Microbiology 103: 271-284.

Dill-Macky, R., and R.K. Jones. 2000. The effect of previous crop residues and tillage on Fusarium head blight of wheat. Plant Disease 84: 71-76.

Doohan, F.M., J. Brennan, and B.M. Cooke. 2003. Influence of climatic factors on Fusarium species pathogenic to cereals. European Journal of Plant Pathology 109: 755-768.

Fernando, W.G.D., T.C. Paulitz, W.L. Seaman, P. Dutilleul, and J.D. Miller. 1997. Head blight gradients caused by Gibberella zeae from area sources of inoculum in wheat field plots. Phytopathology 87: 414-421.

Fukushima, H., Y. Tsunomori, and R. Seki. 2003. Duplex real-time SYBR green PCR assays for detection of 17 species of food- or waterborne pathogens in stools. Journal of Clinical Microbiology 41: 5134-5146.

Giglio, S., P.T. Monis, and C.P. Saint. 2003. Demonstration of preferential binding of SYBR Green I to specific DNA fragments in real-time multiplex PCR. Nucleic Acids Research 31.

Haidukowski, M., M. Pascale, G. Perrone, D. Pancaldi, C. Campagna, and A. Visconti. 2005. Effect of fungicides on the development of Fusarium head blight, yield and deoxynivalenol accumulation in wheat inoculated under field conditions with Fusarium graminearum and Fusarium culmorum. Journal of the Science of Food and Agriculture 85: 191-198.

Hernandez, M., D. Rodriguez-Lazaro, T. Esteve, S. Prat, and M. Pla. 2003. Development of melting temperature-based SYBR Green I polymerase chain reaction methods for multiplex genetically modified organism detection. Analytical Biochemistry 323: $164-170$.

Hooker, D.C., A.W. Schaafsma, and L. Tamburic-Ilincic. 2002. Using weather variables pre- and post-heading to predict deoxynivalenol content in winter wheat. Plant Disease 86: 611-619. 
Hope, R., D. Aldred, and N. Magan. 2005. Comparison of environmental profiles for growth and deoxynivalenol production by Fusarium culmorum and $F$. graminearum on wheat grain. Letters in Applied Microbiology 40: 295-300.

Jansen, C., D. von Wettstein, W. Schafer, K.H. Kogel, A. Felk, and F.J. Maier. 2005. Infection patterns in barley and wheat spikes inoculated with wild-type and trichodiene synthase gene disrupted Fusarium graminearum. Proceedings of the National Academy of Sciences of the United States of America 102: 16892-16897.

Jothikumar, N., X.W. Wang, and M.W. Griffiths. 2003. Real-time multiplex SYBR green I-based PCR assay for simultaneous detection of Salmonella serovars and Listeria monocytogenes. Journal of Food Protection 66: 2141-2145.

Jurado, M., C. Vazquez, B. Patino, and M.T. Gonzalez-Jaen. 2005. PCR detection assays for the trichothecene-producing species Fusarium graminearum, Fusarium culmorum, Fusarium poae, Fusarium equiseti and Fusarium sporotrichioides. Systematic and Applied Microbiology 28: 562-568.

Kingsley, M.T. 2001. Nucleic Acid-Based Detection and Identification of Bacterial and Fungal Plant Pathogens PNNL-13457. Pacific Northwest National Laboratory, Richland, Washington.

Knoll, S., S. Mulfinger, L. Niessen, and R.F. Vogel. 2002. Rapid preparation of Fusarium DNA from cereals for diagnostic PCR using sonification and an extraction kit. Plant Pathology 51: 728-734.

Langevin, F., F. Eudes, and A. Comeau. 2004. Effect of trichothecenes produced by Fusarium graminearum during Fusarium head blight development in six cereal species. European Journal of Plant Pathology 110: 735-746.

Leonard, K.J., and W.R. Bushnell, (eds.) 2003. Fusarium Head Blight of Wheat and Barley, pp. 1-512. The American Phytopathological Society, St. Paul, Minnesota, USA.

Mesterhazy, A., T. Bartok, G. Kaszonyi, M. Varga, B. Toth, and J. Varga. 2005. Common resistance to different Fusarium spp. causing Fusarium head blight in wheat. European Journal of Plant Pathology 112: 267-281.

Mulfinger, S., Niessen, L. and Vogel, R.F. 2000. PCR based quality control of toxigenic Fusarium spp. in brewing malt using ultrasonication for rapid sample preparation. Advances in Food Science 22: 38-46.

Murray, M.G., and W.F. Thompson. 1980. Rapid Isolation of High Molecular-Weight Plant DNA. Nucleic Acids Research 8: 4321-4325. 
Naef, A., M. Senatore, and G. Defago. 2006. A microsatellite based method for quantification of fungi in decomposing plant material elucidates the role of Fusarium graminearum DON production in the saprophytic competition with Trichoderma atroviride in maize tissue microcosms. FEMS Microbiology Ecology 55: 211-220.

Nicholson, P., D.R. Simpson, G. Weston, H.N. Rezanoor, A.K. Lees, D.W. Parry, and D. Joyce. 1998. Detection and quantification of Fusarium culmorum and Fusarium graminearum in cereals using PCR assays. Physiological and Molecular Plant Pathology 53: 17-37.

Nicholson, P., E. Chandler, R.C. Draeger, N.E. Gosman, D.R. Simpson, M. Thomsett, and A.H. Wilson. 2003. Molecular tools to study epidemiology and toxicology of Fusarium head blight of cereals. European Journal of Plant Pathology 109: 691703.

Nicolaisen, M., A.F. Justesen, U. Thrane, P. Skouboe, and K. Holmstrom. 2005. An oligonucleotide microarray for the identification and differentiation of trichothecene producing and non-producing Fusarium species occurring on cereal grain. Journal of Microbiological Methods 62: 57-69.

Niessen, M.L., and R.F. Vogel. 1997. Specific identification of Fusarium graminearum by PCR with gaoA targeted primers. Systematic and Applied Microbiology 20: 111-123.

O'Donnell, K., H.C. Kistler, B.K. Tacke, and H.H. Casper. 2000. Gene genealogies reveal global phylogeographic structure and reproductive isolation among lineages of Fusarium graminearum, the fungus causing wheat scab. Proceedings of the National Academy of Sciences of the United States of America 97: 7905-7910.

O'Donnell, K., T.J. Ward, D.M. Geiser, H.C. Kistler, and T. Aoki. 2004. Genealogical concordance between the mating type locus and seven other nuclear genes supports formal recognition of nine phylogenetically distinct species within the Fusarium graminearum clade. Fungal Genetics and Biology 41: 600-623.

Parry, D.W., P. Jenkinson, and L. McLeod. 1995. Fusarium ear blight (scab) in small grain cereals -- A review. Plant Pathology 44: 207-238.

Reischer, G.H., M. Lemmens, A. Farnleitner, A. Adler, and R.L. Mach. 2004a. Quantification of Fusarium graminearum in infected wheat by species specific real-time PCR applying a TaqMan Probe. Journal of Microbiological Methods 59: 141-146. 
Reischer, G.H., M. Lemmens, A. Farnleitner, A. Adler, and R.L. Mach. 2004b. Erratum to "Quantification of Fusarium graminearum in infected wheat by species specific real-time PCR applying a TaqMan probe" [J. Microbiol. Methods 59 (2004) 141146]. Journal of Microbiological Methods 59: 437-437.

Schilling, A.G., E.M. Moller, and H.H. Geiger. 1996. Polymerase chain reaction-based assays for species-specific detection of Fusarium culmorum, F. graminearum, and F. avenaceum. Phytopathology 86: 515-522.

Schnerr, H., R.F. Vogel, and L. Niessen. 2002. Correlation between DNA of trichothecene-producing Fusarium species and deoxynivalenol concentrations in wheat-samples. Letters in Applied Microbiology 35: 121-125.

Stewart, C.N., and L.E. Via. 1993. A rapid CTAB DNA isolation technique useful for rapid fingerprinting and other PCR applications. Biotechniques 14: 748-751.

Waalwijk, C., P. Kastelein, I. de Vries, Z. Kerenyi, T. van der Lee, T. Hesselink, J. Kohl, and G. Kema. 2003. Major changes in Fusarium spp. in wheat in the Netherlands. European Journal of Plant Pathology 109: 743-754.

Waalwijk, C., R. van der Heide, I. de Vries, T. van der Lee, C. Schoen, G. Costrel-de Corainville, I. Hauser-Hahn, P. Kastelein, J. Kohl, P. Lonnet, T. Demarquet, and G.H.J. Kema. 2004. Quantitative detection of Fusarium species in wheat using TaqMan. European Journal of Plant Pathology 110: 481-494.

Wanyoike, M.W., F. Walker, and H. Buchenauer. 2002. Relationship between virulence, fungal biomass and mycotoxin production by Fusarium graminearum in winter wheat head blight. Zeitschrift Fur Pflanzenkrankheiten Und Pflanzenschutz-Journal of Plant Diseases and Protection 109: 589-600.

Ward, T.J., J.P. Bielawski, H.C. Kistler, E. Sullivan, and K. O'Donnell. 2002. Ancestral polymorphism and adaptive evolution in the trichothecene mycotoxin gene cluster of phytopathogenic Fusarium. Proceedings of the National Academy of Sciences of the United States of America 99: 9278-9283.

Wilson, I.G. 1997. Inhibition and facilitation of nucleic acid amplification. Applied and Environmental Microbiology 63: 3741-3751.

Winton, L.M., J.K. Stone, L.S. Watrud, and E.M. Hansen. 2002. Simultaneous one-tube quantification of host and pathogen DNA with real-time polymerase chain reaction. Phytopathology 92: 112-116.

Xu, X.M. 2003. Effects of environmental conditions on the development of Fusarium ear blight. European Journal of Plant Pathology 109: 683-689. 
Xu, X.M., D.W. Parry, P. Nicholson, M.A. Thomsett, D. Simpson, S.G. Edwards, B.M. Cooke, F.M. Doohan, J.M. Brennan, A. Moretti, G. Tocco, G. Mule, L. Hornok, G. Giczey, and J. Tatnell. 2005. Predominance and association of pathogenic fungi causing Fusarium ear blight in wheat in four European countries. European Journal of Plant Pathology 112: 143-154. 


\section{Summary}

Fusarium head blight (FHB) is a disease of cereal crops, which has a severe impact on wheat production worldwide. Apart from reducing the yield and impairing grain quality, FHB leads to contamination of grain with mycotoxins. The Fusarium species primarily involved in FHB are F. graminearum and F. culmorum, both producing deoxynivalenol (DON), the most important mycotoxin in wheat grain. Although the relative importance of F. graminearum and F. culmorum and their infection pathways has great impact on epidemiological questions, it has not be clarified in all details so far. For the differentiation of these pathogens, two real-time PCR methods were developed and applied, which allow a qualitative and quantitative detection of fungal biomass within host tissue. Samples for this study have been collected throughout Germany from 2003 to 2005.

F. graminearum and F. culmorum were determined qualitatively in symptomatic wheat rachides with a duplex PCR assay enabling the identification of the causal agent of FHB in a single PCR reaction. The method is based on the analysis of melting curves of amplification products generated in a real-time PCR thermocycler. The quantitative detection of both fungi in complex plant material like wheat flour and plant debris was realized in separated real-time PCR reactions, applying SYBR Green I fluorescence detection. The specificity of both assays for F. graminearum and F. culmorum was confirmed. Suitable high-throughput DNA extraction methods were developed for all types of samples analyzed in this study, including wheat rachides, grain samples and plant debris. For quantitative PCR, an upscaled DNA extraction protocol with increased extraction efficiency was used to reduce the sampling error. In addition to the analysis with the quantitative PCR, the DON content of the grain samples was measured.

The scope of the study was both the identification of the infecting agent in the wheat rachides and the determination of the relative importance of $F$. graminearum and F. culmorum in relation to the DON content of wheat samples to establish a risk assessment model for FHB. The results show that F. graminearum is the main causing agent of FHB and DON contamination in Germany. F. culmorum was sometimes detected in wheat rachides of 2003, but did not play a significant role in wheat grain samples 2003 to 2005. The collected data serve to adjust quantitative parameters of a computer-based 
decision support system aiming at the minimization of Fusarium infection and toxin contamination of grain in Germany, which is being developed by our collaborators. 


\section{Zusammenfassung}

Die Getreidekrankheit „Partielle Weißährigkeit“ (Ährenfusariose oder Fusarium head blight, FHB) beeinträchtigt den Weizenanbau weltweit. Neben Ertrags- und Qualitätsverlusten verursacht FHB die Kontamination des Weizens mit Mykotoxinen. Die hauptsächlich an FHB beteiligten Fusarium-Arten sind F. graminearum und F. culmorum, die beide das wichtigste Mycotoxin im Weizen, Deoxynivalenol (DON), bilden. Die relative Bedeutung von F. graminearum und F. culmorum und ihrer Infektionswege hat für epidemiologische Fragestellungen große Bedeutung und konnte für Deutschland bisher nicht abschließend geklärt werden. Für die Unterscheidung wurden zwei Real-time PCR-Methoden entwickelt und angewendet, die den qualitativen und quantitativen Nachweis dieser Pathogene in den verschiedenen Wirtsgeweben ermöglichen, die in Weizenanbaugebieten aus dem Bundesgebiet 2003 bis 2005 entnommen wurden.

F. graminearum und F. culmorum wurden qualitativ in symptomatischen Weizenspindeln mit einer Duplex PCR-Methode bestimmt, wodurch die Identifizierung des Verursachers der FHB-Symptome ermöglicht wurde. Die Methode basiert auf einer Schmelzkurvenanalyse des Amplifikates im Real-time PCR-Gerät. Der quantitative Nachweis beider Pilze im komplexen Pflanzenmaterial, wie Weizenmehl und Ernterückstände, wurde unter Verwendung der Detektion des Fluoreszenzfarbstoffes SYBR Green I in getrennten Real-time PCR-Reaktionen realisiert. Die Spezifität beider Methoden für F. graminearum und F. culmorum wurde bestätigt. Für den Hochdurchsatz geeignete DNA-Extraktionsmethoden wurden für alle Probenarten, wie Weizenspindeln, Getreideproben und Pflanzenrückstände, entwickelt. Für die quantitative PCR reduzierte eine DNA-Extraktionsmethode mit einer homogenen Extraktionseffizienz in größerem Maßstab den Fehler der Probenahme. Neben der Analyse mit der quantitativen PCR wurde auch der DON-Gehalt der Getreideproben gemessen.

Das Ziel der Arbeit war zum einen die Identifizierung des infizierenden Pathogens in Weizenspindeln und zum anderen die Bestimmung der relativen Bedeutung von F. graminearum und F. culmorum im Verhältnis zum DON-Gehalt des Weizens, um ein Modell zur Risikobewertung für FHB zu etablieren. Die Ergebnisse zeigen, dass F. graminearum der Hauptverursacher von FHB und DON-Kontamination in Deutschland ist. F. culmorum wurde in den Weizenspindeln aus 2003 vereinzelt 
gefunden, spielt aber keine bedeutende Rolle in den Weizenproben aus 2003 bis 2005. Mit den gesammelten Daten sollen außerhalb dieser Arbeit die quantitativen Parameter einer computergestützten Entscheidungshilfe eingestellt werden. Diese soll dazu dienen, das Risiko einer FHB-Infektion und einer Toxinbelastung in Deutschland zu minimieren. 


\section{Danksagung}

An dieser Stelle möchte ich mich ganz besonders bei Herrn Prof. Dr. Petr Karlovsky für die Bereitstellung des Themas, die Diskussionen und die Hilfsbereitschaft sowie für die gewährte Freiheit und die Unterstützung bei der Durchführung dieser Arbeit und schließlich für die Durchsicht der Manuskripte bedanken.

Bei Herrn Prof. Dr. Andreas von Tiedemann bedanke ich mich für die bereitwillige Übernahme des Korreferates.

Bei Dr. Joachim Weinert bedanke ich mich für 3 Jahre sehr gute Zusammenarbeit, für die umfassende Bereitstellung von Daten und Proben sowie für die ständige Diskussionsund Hilfsbereitschaft.

Mein Dank gilt auch Herrn Dr. Birger Koopmann für die immer gewährte Hilfsbereitschaft bei Problemen jeglicher Art.

Heike Rollwage und Petra Romanczuk-Schulz möchte ich für die gute Zusammenarbeit im Labor und die Unterstützung bei technischen Problemen danken.

Bei unseren Azubis Sarah Greco, Martin Brokop, Patricia Bartoschek und Claudia Nordmann bedanke ich mich ganz herzlich für die technische Unterstützung.

Mein herzlicher Dank gilt auch Frau Martina Bode für die Hilfe und Unterstützung bei allen administrativen Problemen.

Bei Ulrike Brandfaß, Christina Eynck, Nadine Riediger und Joachim Weinert möchte ich mich ganz herzlich für die kurzfristige Korrektur der Dissertation bedanken.

Allen Mitarbeitern des Fachgebietes Pflanzenpathologie und Pflanzenschutz danke ich für das gute Arbeitsklima und für die mir entgegengebrachte Unterstützung bei dieser Arbeit. 
Dank gilt auch dem Dienstleistungszentrum Ländlicher Raum, Rheinhessen-NaheHunsrück und der Zentralstelle der Länder für EDV-gestützte Entscheidungshilfen und Programme im Pflanzenschutz (ZEPP) in Bad Kreuznach, sowie der Bundesforschungsanstalt für Landwirtschaft (FAL) in Braunschweig und den Pflanzenschutzdiensten der Länder für die Bereitstellung der Proben und der Daten.

Dem Bundesministerium für Ernährung, Landwirtschaft und Verbraucherschutz danke ich für die Finanzierung dieser Arbeit.

Bei Helena bedanke ich mich für die liebevolle Unterstützung sowie die Geduld und Rücksichtnahme während der ganzen Promotion, insbesondere in der Schlussphase bei Vorbereitungen unserer Hochzeitsfeier.

Schließlich möchte ich mich auch bei meinen Eltern für die in jeder Hinsicht gewährte Unterstützung und Entlastung sowie für das große Verständnis ganz herzlich bedanken.

In dankbarem Gedenken an Ines Pöhler, die mich in die Geheimnisse der Real-time PCR eingeführt hat und uns viel zu früh verlassen musste. 


\section{Publications}

Brandfass, C., J. Weinert, and P. Karlovsky. 2006. Detection of Fusarium graminearum and F. culmorum in rachides from wheat ears afflicted with Fusarium head blight and in grain identifies F. graminearum as the major cause of FHB and DON contamination. submitted.

Brandfass, C., and P. Karlovsky. 2006. Cost-effective quantification of Fusarium culmorum and F. graminearum in plant material by real-time PCR. submitted.

Brandfaß, C., J. Weinert, B. Kleinhenz, and P. Karlovsky. 2006. Anwendung Real-time PCR basierter Nachweisverfahren für Fusarium graminearum und F. culmorum als Grundlage für die Etablierung eines Prognosemodells. Tagungsbericht des Arbeitskreises Mykologie, Biologische Bundesanstalt für Land- und Forstwirtschaft (BBA), Berlin Dahlem Deutsche Phytomedizinische Gesellschaft, in press.

Brandfass, C., and P. Karlovsky. 2006. Simultaneous detection of Fusarium culmorum and F. graminearum in plant material by duplex PCR with melting curve analysis. BMC Microbiology 6: 4.

Brandfaß, C., J. Weinert, B. Kleinhenz, A. von Tiedemann, and P. Karlovsky. 2005. Fusarium-Arten in Spindeln symptomatischer FHB-Ähren - Eine Bestimmung mit Hilfe der Real-time PCR als Grundlage für die Etablierung eines Prognosemodells. Phytomedizin 35 (2): 54-55.

Brandfaß, C., J. Weinert, B. Kleinhenz, A. von Tiedemann, and P. Karlovsky. 2005. Bestimmung der wichtigsten am Komplex der Ährenfusariose in der BRD beteiligten Fusariumarten mit Hilfe der Real-time PCR als Grundlage eines Prognosemodells. Tagungsband der 18. Tagung der DPG Projektgruppe "Krankheiten im Getreide", Biologische Bundesanstalt für Land- und Forstwirtschaft (BBA), Braunschweig Deutsche Phytomedizinische Gesellschaft, http://www.phytomedizin.org/70.html.

Weinert, J., B. Kleinhenz, C. Brandfaß, P. Karlovsky, and A. von Tiedemann. 2005. Untersuchungen zum unterschiedlichen Auftreten von FHB und DONBelastungen im Erntegut von Weizen als Grundlage eines Prognose- und Entscheidungsmodells. Tagungsband der 18. Tagung der DPG Projektgruppe "Krankheiten im Getreide", Biologische Bundesanstalt für Land- und 
Forstwirtschaft (BBA), Braunschweig Deutsche Phytomedizinische Gesellschaft, http://www.phytomedizin.org/70.html.

Brandfaß, C., I. Pöhler, J. Weinert, and P. Karlovsky. 2004. Etablierung von Real-time PCR basierten Nachweisverfahren für Fusarium graminearum und F. culmorum sowie deren Anwendung. 54. Deutsche Pflanzenschutztagung, Hamburg; Mitt. BBA 396: 221-222. 


\section{Lebenslauf}

Name: $\quad$ Christoph Brandfaß

Geburtstag: $\quad 06.08 .1974$

Geburtsort: Northeim

Familienstand: verheiratet

\section{Promotion:}

05.2003 - 07.2006 Promotion am Fachgebiet Pflanzenpathologie und Pflanzenschutz der Georg-August-Universität Göttingen im Rahmen des Promotionsstudienganges „International Ph.D.-Program for Agricultural Sciences in Göttingen (IPAG)“ ${ }^{“} \mathrm{zu}$ dem Thema: „Establishment and application of real-time PCR-based methods to study the epidemiology of Fusarium Head Blight"

\section{Studium:}

10.1997-09.2002 Diplomstudium der Agrarwissenschaften, Fachrichtung Pflanzenproduktion an der Justus-Liebig-Universität Gießen, zweiteilige Diplomarbeit:

„Zytologische Untersuchungen zur Infektion von Zuckerrüben (Beta vulgaris) durch Cercospora beticola und Isolierung von zwei Promotoren aus der Genfamilie Subtilisin-ähnlicher Proteasen“ am Instituts für Phytopathologie und Angewandte Zoologie (IPAZ) der Universität Gießen und bei der PLANTA - Angewandte Pflanzengenetik und Biotechnologie GmbH in Einbeck Abschluss: Dipl.-Ing. agr.

\section{Berufsausbildung:}

08.1995 - 07.1997 Ausbildung mit Abschluss zum Landwirt

\section{Wehrdienst:}

$08.1994-09.1995$ Zivildienst beim Arbeiter Samariter Bund in Nörten-Hardenberg

\section{Schulbildung:}

08.1987 - 06.1994 Gymnasium Corvinianum Northeim, Abschluss: Abitur

$08.1981-07.1987$ Grundschule und Orientierungsstufe in Katlenburg-Lindau 


\section{Eidesstattliche Erklärung}

Hiermit erkläre ich eidesstattlich, dass diese Dissertation selbständig und ohne unerlaubte Hilfe angefertigt wurde.

Göttingen, im Mai 2006 